\title{
Pullout Strength of Epoxy Anchors Installed Underwater
}

\author{
A Thesis \\ presented to \\ the Faculty of California Polytechnic State University, \\ San Luis Obispo
}

In Partial Fulfillment

of the Requirements for the Degree

Master of Science in Civil and Environmental Engineering

by

Jeffrey Lee Blanchette

December 2012 
(C) 2012

Jeffrey Lee Blanchette ALL RIGHTS RESERVED 
TITLE:

AUTHOR:

DATE SUBMITTED:

COMMITTEE CHAIR:

COMMITTEE MEMBER:

COMMITTEE MEMBER
Pullout Strength of Epoxy Anchors Installed Underwater

Jeffrey Lee Blanchette

December $7^{\text {th }} 2012$
Damian Kachlakev, Professor

Bing Qu, Assistant Professor 


\section{ABSTRACT \\ Pullout Strength of Epoxy Anchors Installed Underwater \\ Jeffrey Lee Blanchette}

This work presents the development of a test program and the results from the final round of testing to better understand the effect a submerged anchor installation has on the pullout strength of epoxy anchors. Two different epoxies were tested at embedment depths of two, four, and six bar diameters. These tests utilized three distinct installation procedures under dry and submerged conditions. The testing program occurred over five phases, with the final round used in analysis consisting of 24 anchor pullout tests. These tests showed that the presence of water did not have an effect on the epoxy bond when anchor holes were cleaned dry and installed underwater, but it did have a significant impact on the ability to consistently clean each anchor when it was submerged.

Keywords: epoxy anchors; pullout test; post installed anchors; underwater; concrete; 


\section{ACKNOWLEDGMENTS}

This project would not have been possible without generous donations from SM\&RC Structural Engineers, Simpson Strong Tie, and Cal Portland Construction; also the facilities, laboratories and equipment that were utilized for testing at the California Polytechnic State University in San Luis Obispo.

I also want thank my advisor, Dr. Jansen. His vast knowledge of engineering principles and his continued guidance were a valuable resource every step of the way. I appreciate his dedication to this project and the hours of time he put in. I want to thank Professor Qu and Professor Kachlakev for their time and effort editing my thesis and their dedication to the students at Cal Poly.

Lastly I want to thank my family and friends. My parents have been my biggest supporters throughout my life and have provided me with every opportunity to succeed. Also Stephanie Tam's continued support, understanding and dedication have meant more than she could ever know. 


\section{TABLE OF CONTENTS}

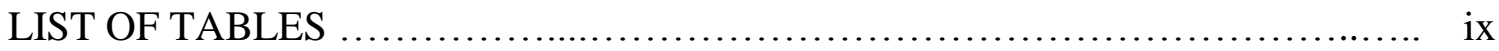

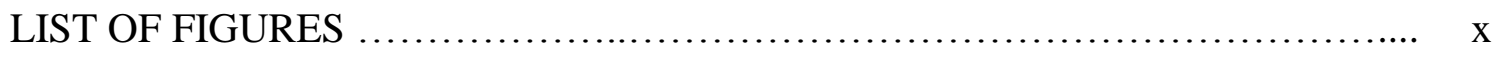

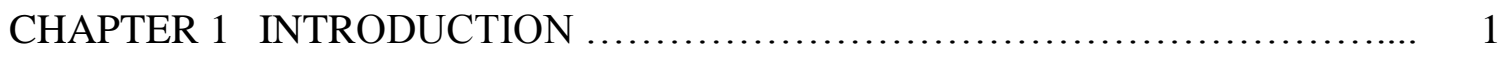

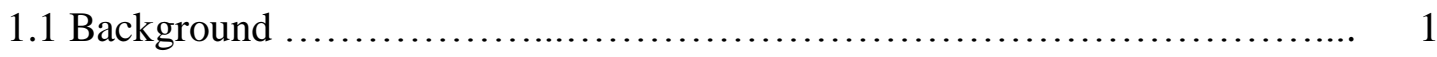

1.2 Scope and Objectives ............................................. 2

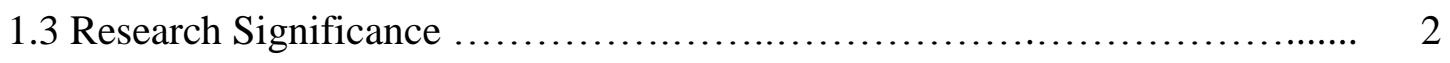

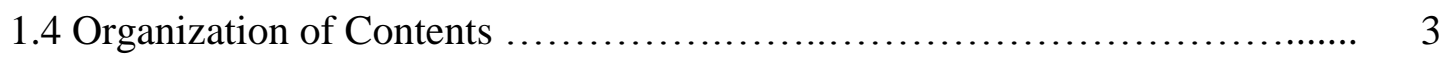

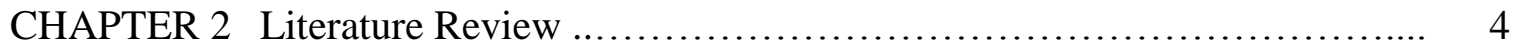

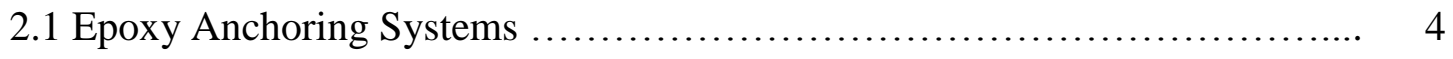

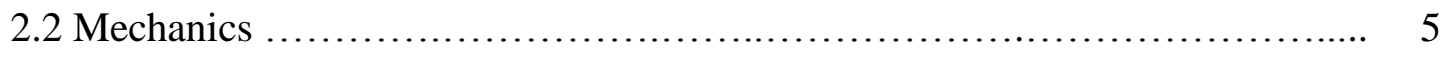

2.3 Factorings Influencing Pullout Load .................................. 7

2.3.1 Material Properties ............................................ 7

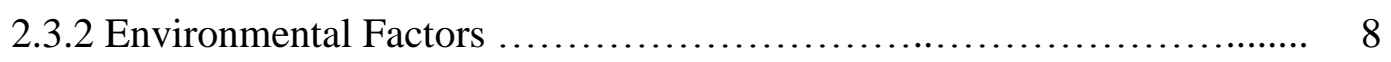

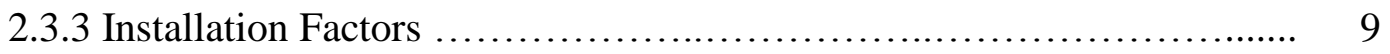

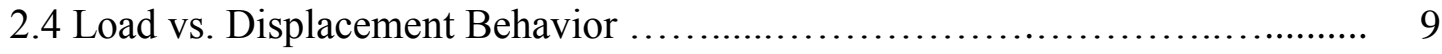

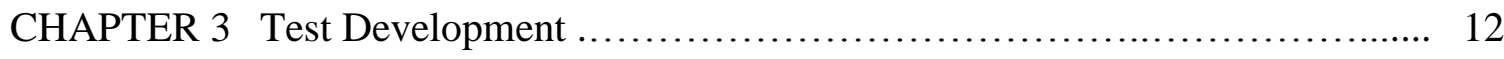

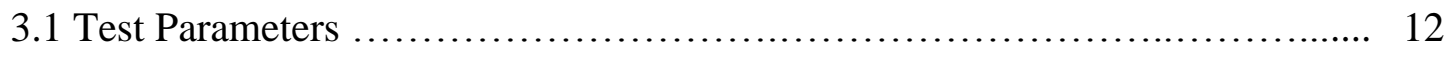

3.1.1 ASTM Parameters ............................................ 12

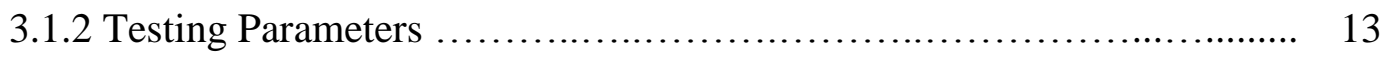

3.2 Preliminary Testing ................................................ 14

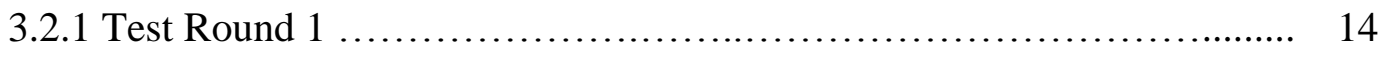

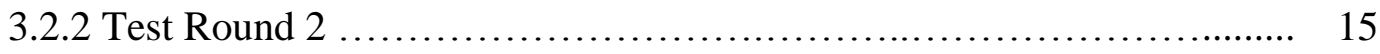


3.2.3 Test Round 3 ....................................................... 19

3.2.4 Test Round 4 ................................................... $\quad 20$

CHAPTER 4 Materials and Test Setup ............................................... 22

4.1 Materials ................................................................. 22

4.1.1 Concrete Mix ..................................................... 22

4.1.2 Thread Rod Properties ............................................. 23

4.2 Installation Methods ..................................................... 25

4.2.1 Installation Procedure .................................................... 25

4.2.2 Cleaning Methods .................................................. 26

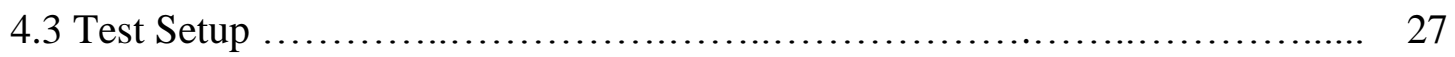

4.4 Loading and Failure Criteria ................................................ 29

4.5 Final Round Test Matrix …............................................ 30

CHAPTER 5 Results and Analysis ............................................... 31

5.1 Pullout Strengths ........................................................... 31

5.1.1 Predicted Pullout Strengths ........................................... 31

5.1.2 Epoxy A Pullout Strength Results ..................................... 32

5.1.3 Epoxy A and B Pullout Strength Comparison .......................... 34

5.1.4 Dry Cleaning with Wet and Dry Installations ............................ 35

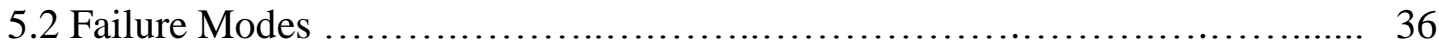

5.2.1 Dry Cleaning Failure Modes .......................................... 36

5.2.2 Underwater Cleaning Failure Modes ................................... 37

5.2.3 Load vs. Displacement Behavior .................................. 38

CHAPTER 6 Conclusions and Future Research ................................... 41

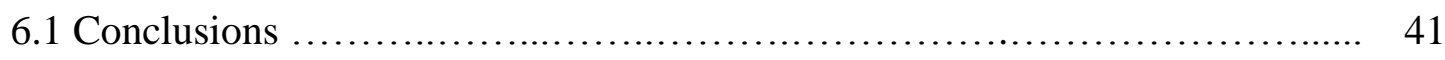

6.2 Future Research Recommendations ....................................... 42 
References .

APPENDICES

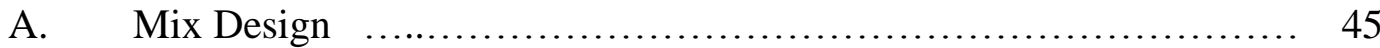

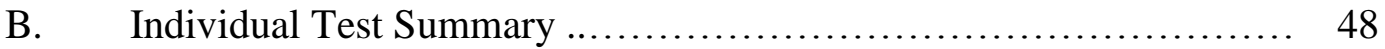

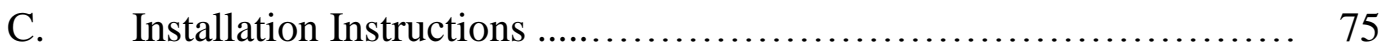




\section{List of Tables}

Table 4.1-Concrete Strengths at Pullout Testing .............................. 23

Table 4.2-Threaded Rod Tensile Test Results .................................. 24

Table 4.3-Final Round Test Matrix ....................................... 30

Table 5.1-Epoxy A Pullout Strengths (Kips) ............................... 33 


\section{List of Figures}

Figure 2.1-Interlock Between Adhesive and Threads ........................... 5

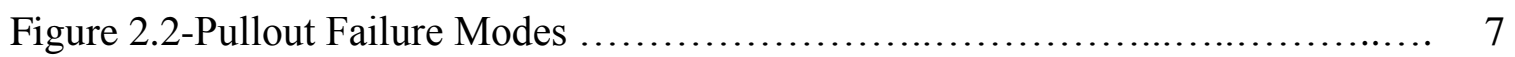

Figure 2.3-Typical Load vs. Displacement Trend Lines .......................... 7

Figure 3.1-Anchor to Test Frame Connection ................................ 13

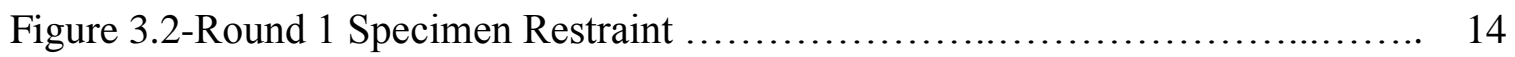

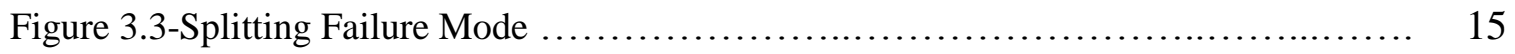

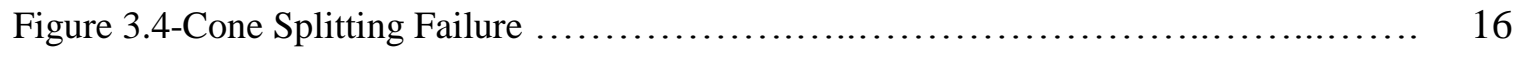

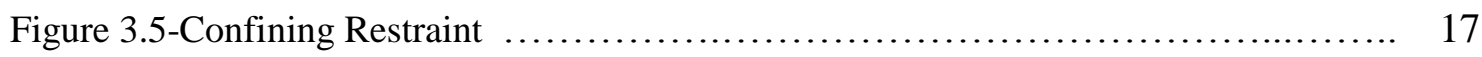

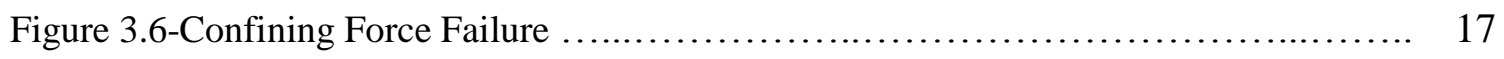

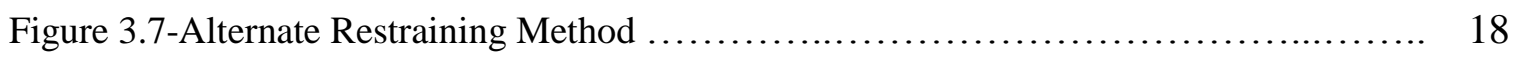

Figure 3.8-Alternate Restraint Failure ....................................... 19

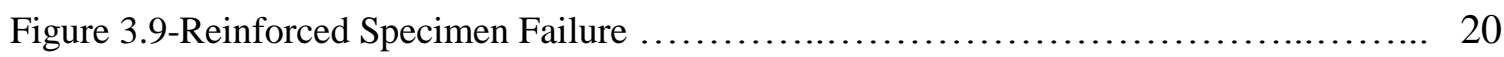

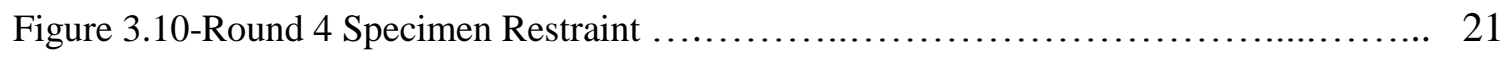

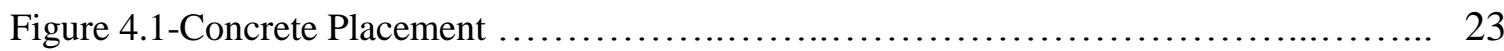

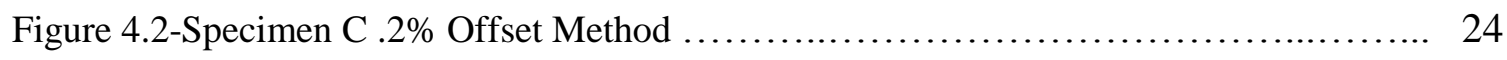

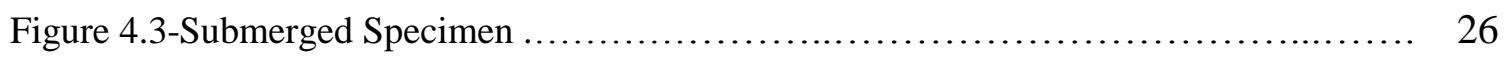

Figure 4.4-Specimen Hold Down Configuration ................................. 27

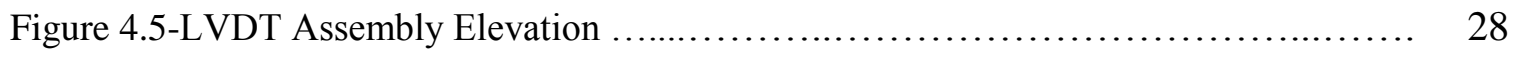

Figure 4.6-Test Table Specimen Setup ........................................ 29

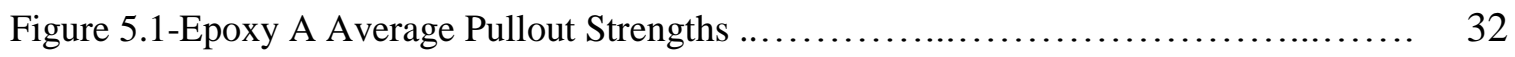

Figure 5.2-6 Bar Diameter Embedment Epoxy A and B Average Pullout Strength .......... 34

Figure 5.3-Epoxy A Dry Cleaning and Mixed Installation Pullout Strengths $\ldots \ldots \ldots \ldots \ldots \ldots . . . . . .35$

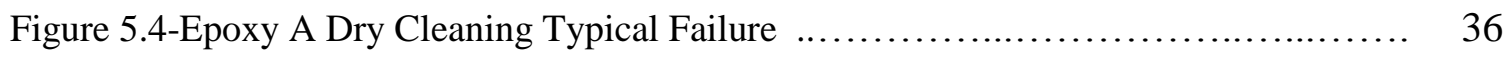


Figure 5.5-Wet Cleaning Mixed Cone Bond Failure

Figure 5.6- Wet Cleaning Complete Bond Failure .............................. 38

Figure 5.7-6 Bar Dia. Embedment Failure Comparison $\ldots \ldots \ldots \ldots \ldots \ldots \ldots \ldots \ldots \ldots \ldots \ldots \ldots \ldots$ 


\section{Chapter 1 Introduction}

\subsection{Background}

Although post installed adhesive anchors have been around for many years it wasn't until the 1990's that they began gaining widespread use. In 1995 the first adhesive anchor testing criteria, AC58, was adopted and later superseded by AC308 in 2005, with the goal of getting adhesive anchors adopted into the ACI 318 Building Code (Mattis and Wollmershauser, 2007). In 2011 this goal was met, but throughout the process, the majority of testing focused on dry installations under moderate conditions.

Because the pullout strength of adhesive anchors are often affected by adverse environmental conditions that do not impact traditional mechanical anchors, more testing is needed to expand their applications. One specific environmental installation condition is a submerged anchor installation. The majority of pullout tests for anchors installed under submerged conditions has been done on a case by case basis in the field and 
produced scattered results. More independent laboratory research is needed to provide a precise, cohesive picture of how anchors are impacted by these conditions.

\subsection{Scope and Objectives}

The primary goal of this project is to evaluate if the pullout strength of epoxy anchors is affected by being installed underwater. If the pullout strength is affected, tests will determine if it is the presence of water interfering with the bond or a difficulty cleaning the hole underwater. ASTM E488 uses $1 / 2$ " -13 UNC threaded as the standard rod size for comparison between different testing programs, so all tests will be limited to this diameter threaded rod and will be installed at shallow embedments to prevent a steel failure. Only a vertical anchor installation will be tested, all tests will be done at moderate temperatures and underwater installations will be done using fresh water. Because the pullout strength of anchors is highly dependent on the base material's concrete strength, all anchor tests used for the final analysis will be installed in concrete from the same batch.

\subsection{Research Significance}

A better understanding of the effects submerged installation conditions have on the pullout strength of epoxy anchors is needed to expand their applications. These applications include, but are not limited to, hydraulic structures, submerged foundations, and port and marine structures. Engineers need to be confident in the performance of epoxy anchor systems to use them in these applications and that confidence begins with understanding how the presence of water affects their performance. This paper will 
provide a preliminary perspective on these effects and will help pinpoint the specific aspects of epoxy anchor systems that submerged installations impact.

\subsection{Organization of Contents}

This report consists of a literature review that gives some background on different epoxy anchor systems, their failure modes, and the many factors that affect their pullout strength. It then discusses the stages undertaken to develop a suitable test setup. These two opening chapters will be followed up by the results obtained during the final round of testing and the conclusions that can be drawn from them. 


\section{Chapter 2 Literature Review}

\subsection{Epoxy Anchoring Systems}

Epoxy anchor systems consist of a steel threaded rod or rebar that is inserted into a drilled hole in a cured concrete member and securely bonded using epoxy. The epoxy itself consists of two parts, a bonding agent and curing compound. When mixed, the curing compound causes the epoxy to harden, forming the bond between the anchor and the concrete (Cook et al., 1998).

There are two widely used systems to mix the two agents, a glass capsule system, and a two part injection system. In glass capsule systems, a glass capsule is inserted into the drilled hole containing the two unmixed components. When the anchor is inserted, usually by attaching it to a rotary hammer drill, the glass capsule is broken and the two components are mixed together. With the injection system, the two parts of the epoxy are kept in separate tubes and mixed together in a mixing nozzle as it is injected into the hole. 
The anchor is then inserted by slowing rotating it as it is placed in the hole (Cook et al., 1998). This rotation ensures that the epoxy fills the threads on the rod. Once the epoxy cures, it allows for load transfer between the anchor rod and concrete base material.

\subsection{Mechanics}

Bonded anchors transfer load along the entire length of the anchor through a combination of chemical bond and frictional forces. Assuming the anchor is made of a steel threaded rod, the force travels down the thread rod, is distributed to the epoxy, and into the concrete (Cook et al., 1998). The force is transferred from the thread rod to the epoxy by the interlock formed between the adhesive and the individual threads on the rod as shown in Figure 2.1. The adhesive then carries the force to the concrete through a combination of chemical bond and friction.

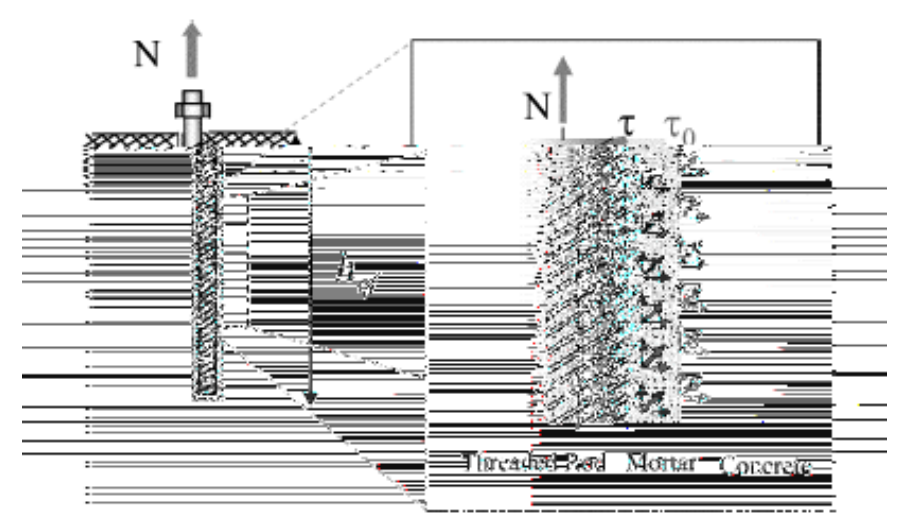

Figure 2.1 - Interlock Between Adhesive and Threads (Eligehausen et al., 2004) 
Pullout failure of epoxy anchor systems typically exhibit five distinct failure modes; these can be seen graphically in Figure 2.2 (Eligehausen et al., 2006). These failures will be designated Type I through Type $\mathrm{V}$ and will be referenced in later chapters.

Type I: Type I failures typically occur at shallow embedment's. The anchor fails with a concrete breakout cone beginning at the base of the anchor. This cone occurs at a slope of approximately $35^{\circ}$ in relation to the surface of the concrete and typically at embedment depths that are less than 5 bar diameters.

Type II: The second failure mode consists of a bond failure between the concrete and the epoxy. This bond failure can occur along the entire length of the anchor or be a combination of a concrete breakout cone with a depth of two to three bar diameters and a bond failure along the rest of the anchor.

Type III: Similar to a Type II failure a Type III failure occurs when the bond between the steel anchor and epoxy fails.

Type IV: The fourth failure mode is a mixture of failures Type II and III where part of the bond fails between the steel and epoxy and part fails between the concrete and epoxy.

Type V: In cases with a deep anchor embedment the bond strength and concrete breakout cone capacity can exceed the steel rod strength causing the rod to fracture. 


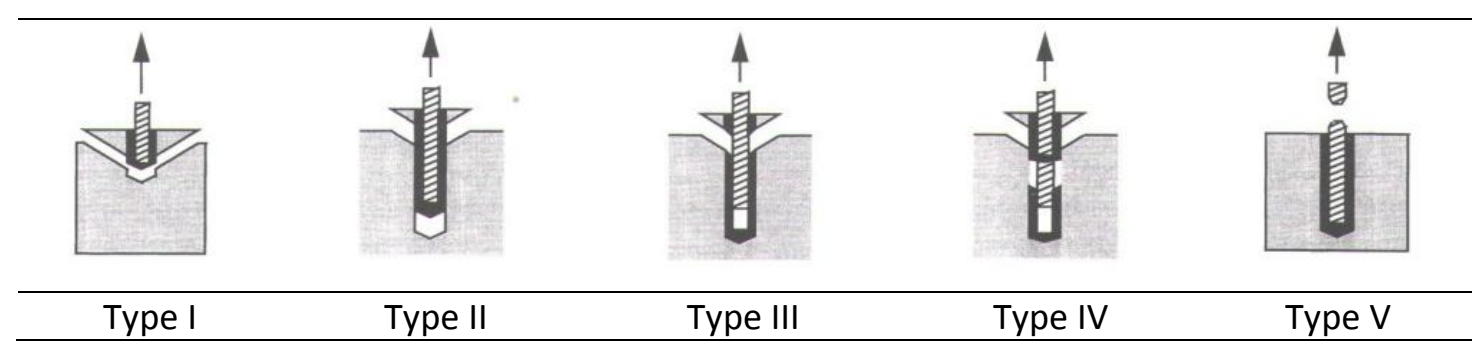

Figure 2.2 - Pullout Failure Modes

(Cook et al., 1998)

In addition to these failures it is also possible for base member to fail prior to anchor pullout. This can be in the form of a beam splitting or from a concrete failure around an anchor that is installed at the edge of a slab or other concrete member. These failure modes are influenced by a number of factors.

\subsection{Factors Influencing Pullout Load}

The factors influencing pullout strength can be divided into three categories material properties, environmental factors, and installation factors.

\subsubsection{Material Properties}

Concrete Strength- The concrete strength does not have a significant effect on the bond strength but it does affect the strength of the concrete breakout cone (Cook, et al., 2001). A higher compressive strength concrete will result in a higher capacity concrete breakout cone. In anchor systems where the steel rod strength is not exceeded, higher concrete strengths typically result in higher pullout capacities. 
Epoxy Type- The epoxy type directly affects the bond strength of the anchor. Each epoxy manufacturer specifies a bond strength and this value is verified through a third party evaluation service. Different epoxies are rated for different environmental conditions, usage applications, and cure times. Engineers must be aware of these factors when specifying a type of epoxy.

Anchor Rod Strength - When the embedment strength exceeds the rod strength, rod failure often occurs. In these cases the ultimate strength of the anchor system is the rod strength.

Aggregate Type- The effect of aggregate type is not widely known, however limited research has shown that the porosity of the aggregate may affect the bond strength (Cook et al., 2001).

\subsubsection{Environmental Factors}

Temperature- Temperature affects the anchor during installation and during the service life of the anchor. During installation the temperature of both the epoxy and base material must be within the manufacturer's specified range or the pullout strength of the anchor will be significantly reduced. Also extreme temperatures during the life of an anchor such as exposure to a fire can cause a premature failure.

Water Filled Holes Installation- The presence of water during installation may significantly reduce the pullout strength. 


\subsubsection{Installation Factors}

Hole Roughness- The hole roughness directly effects the friction force that develops between the epoxy and concrete. This roughness corresponds to the type of drill used. Rotary hammer drills tend to leave a rough hole, while diamond core drilling tends to have a smooth hole lowering the friction capacity (Unterweger et al., 1998).

Hole Cleaning- The degree to which a hole is cleaned is one of the most important factors when using epoxy anchors. An improper cleaning can result in anywhere between zero and a hundred percent loss in strength (Cook, 1994). This loss of strength is caused by excess drilling residue interfering with the bond formed between the epoxy and concrete.

Cure Time- Anchors must be allowed to cure the full amount of time specified by the manufacturer to ensure a proper bond has formed. This cure time is often dependent on the temperature during curing. Higher temperatures will cause the epoxy to cure faster, while lower temperatures will cause it to cure slower.

Because of these factors epoxy anchors have faced skepticism in the engineering community and they often require special inspection when being used. This has delayed their inclusion into ACI 318 and further testing of these factors will expand their use.

\subsection{Load vs. Displacement Behavior}

The load vs. displacement data can be analyzed by breaking it into three key points and looking at the behavior of the curve around these points. The variations of 
these sections show the important properties of the system including the ultimate strength, failure mode, and stiffness of the system.

Please refer to figure 2.3 for the following discussion. The slope of the section between points 1 and 2 is highly dependent on the test configuration and stiffness of the rod used. This is because epoxy bond between the concrete and the rod is relatively stiff compared to the rod itself. The difference in stiffness requires the test setup to measure displacement as close to the surface of the concrete as possible. Keeping this distance small eliminates the relatively large displacement in the exposed portion of the rod. The resulting displacement values are only for the embedded portion of the anchor. Point 3 represents the ultimate strength of the system. The height of this peak is affected by all the factors discussed in section 2.3. The resulting curve after point 3 shows the failure mode of the anchor. Complete cone or steel failures will drop sharply down to zero after the peak load is reached. A mixed cone bond failure typically drops sharply to a lower value and then has a period of extended displacement with a decreasing load capacity. 


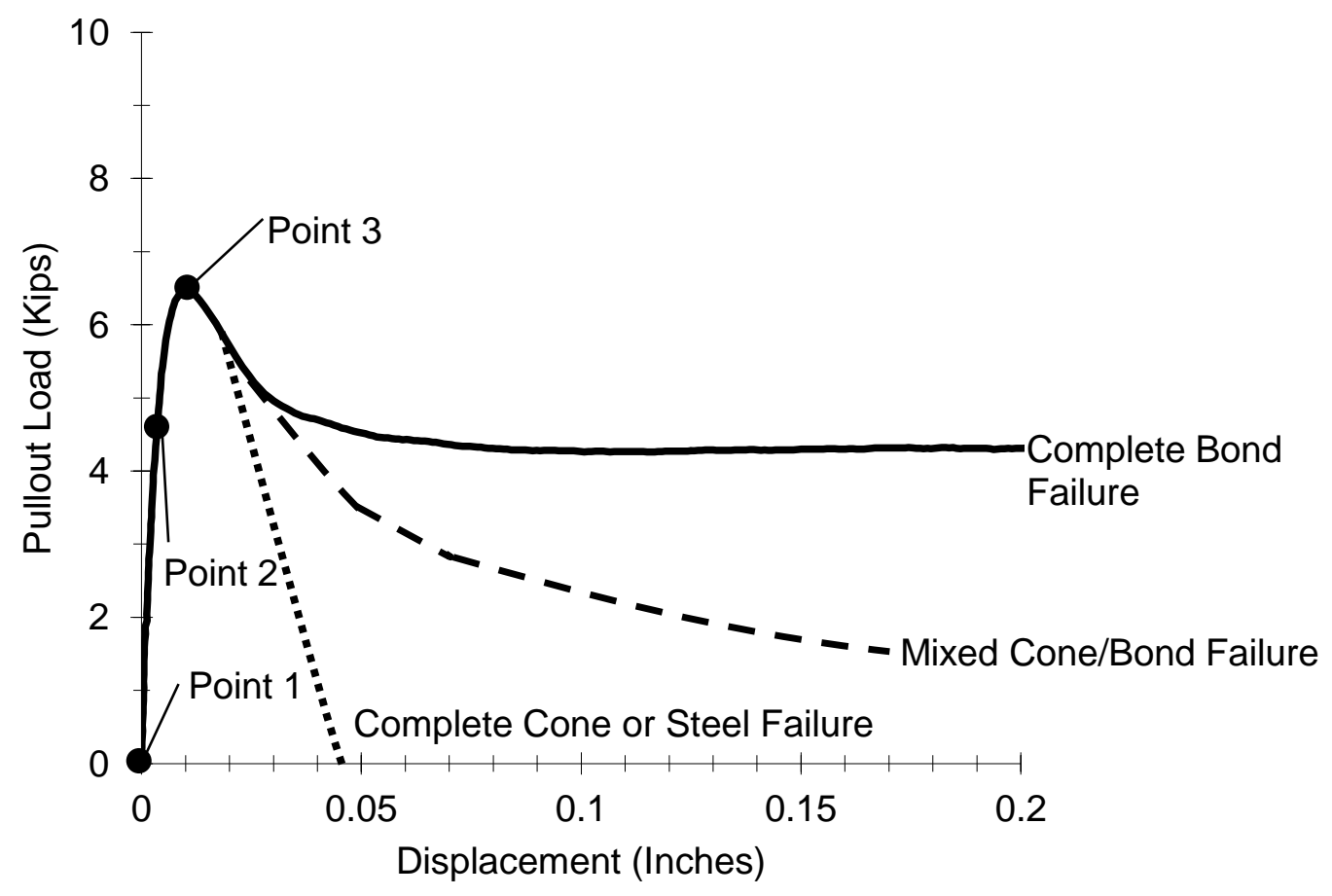

Figure 2.3 - Typical Load vs. Displacement Trend Lines

The sharp drop is a result of the strength loss from the concrete cone failure with the left over resisting force being provided by the friction force between the epoxy and the concrete or rod. Complete bond failures typically result in a small drop in load after the peak load is reached followed by a period extended displacement with little to no drop in load. 


\section{Chapter 3 Test Development}

\subsection{Test Parameters}

A large part of this project was developing a testing setup and procedure that would prevent a premature failure of the concrete member and allow a pullout failure to occur at the desired embedment depths $\left(\mathrm{h}_{\mathrm{ef}}\right)$. These tests needed to stay within the parameters of the ASTM standards and work effectively with the current laboratory equipment.

\subsubsection{ASTM Parameters}

To ensure the actual pullout load is found, anchor tests must follow parameters for edge distance, specimen depth, and a number of other factors. The edge distance must be a minimum of $1.0 * \mathrm{~h}_{\mathrm{ef}}$ from the centerline of the anchor to the edge of the test frame for a total of $2.0 * h_{\mathrm{ef}}$ between test member supports. In addition to these surface requirements the member must be at least $1.5 * \mathrm{~h}_{\mathrm{ef}}$ deep (ASTM E 488, 2003). 
The anchor itself must be installed according to the manufacturer's guidelines and of sufficient strength to prevent a steel failure when testing for bond strength (ASTM E 1512, 2007). Loading should be applied parallel to the tension axis of the anchor and any bending stresses must be minimized, as a result a connection that rotated on two axes was placed between the anchor and the test machine as depicted in Figure 3.1.

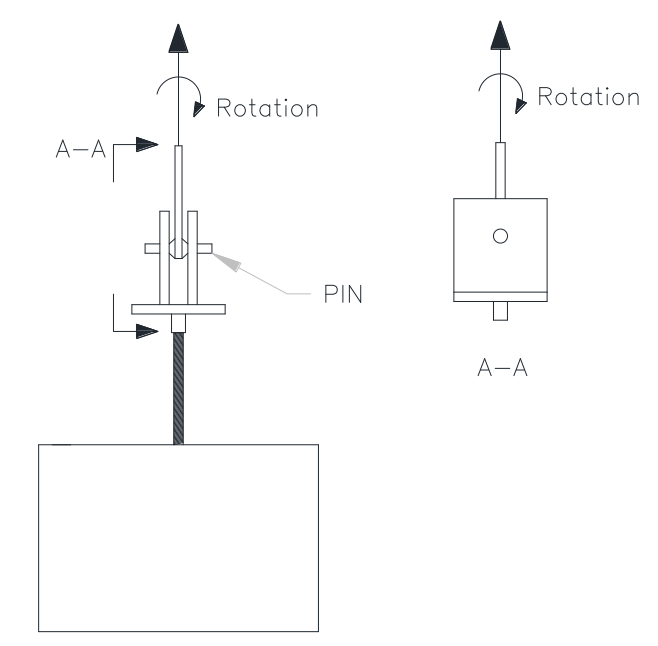

\section{Figure 3.1 - Anchor to Test Frame Connection}

\subsubsection{Testing Parameters}

In addition to the technical standards, testing was also greatly influenced by the laboratory setup and failure modes required. This had the biggest impact on specimen size. Each one needed to be small enough that it could be moved on and off the test table by a single individual. However making the specimen too small would result in the concrete member failing instead of the anchor itself. Also the embedment needed to be shallow to prevent a steel failure. As a result several preliminary test rounds were done to 
establish a specimen size. These tests also helped establish the data collection methods and how to anchor the specimen to the test table.

\subsection{Preliminary Testing}

\subsubsection{Test Round 1}

An initial round of tests utilized a concrete specimen that was as small as the ASTM standards would allow. The specimen was based on an embedment depth of nine bar diameters using a half inch thread rod. The specimen size was 10 "x10"x15", with the anchor being installed on the 10"x15" face. During these tests the specimen was constrained with two channels anchored to the test table by threaded rods on each end as shown in Figure 3.2.

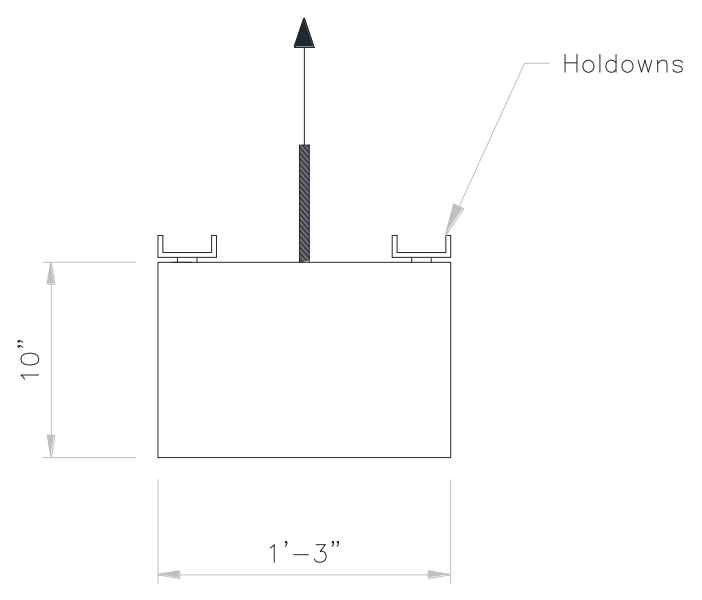

Figure 3.2 - Round 1 Specimen Restraint 
These tests resulted in the specimen failing by splitting down the middle at the point where the anchor was installed as seen in Figure 3.3. This was not the desired concrete cone failure that is typically observed when anchors at shallow embedments fail. A key difference noted with the splitting failures is that all of them resulted in the epoxy partially or fully debonding from the threaded rod. During the final round of testing this type of bond failure was not seen.

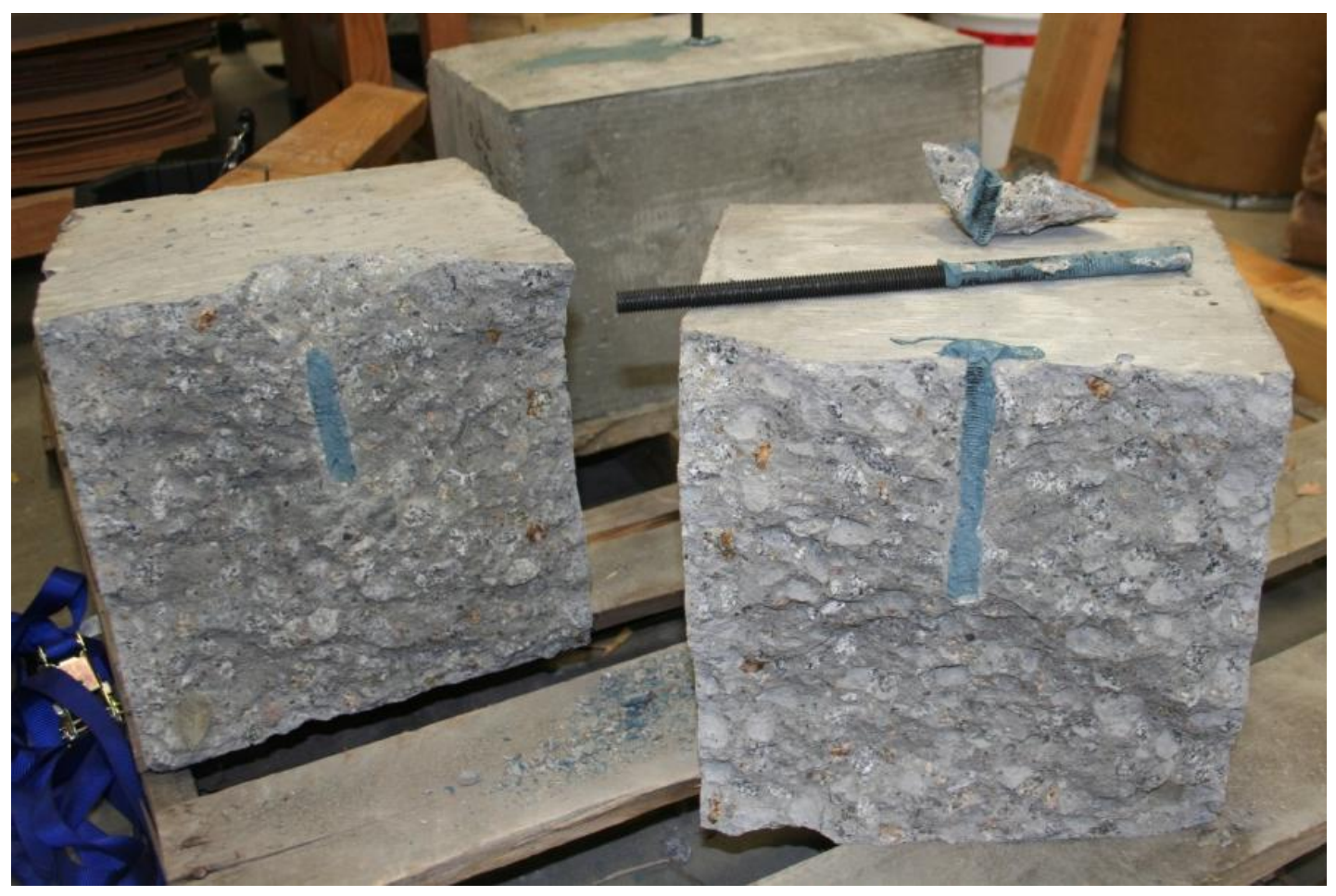

Figure 3.3 - Splitting Failure Mode

\subsubsection{Test Round 2}

Initially the failure modes seen in test round one seemed as though the bending stress in combination with the expansion stress from the anchor pullout in the specimen 
was too high and that was causing the splitting failure. As a result the second round of tests utilized a deeper specimen to reduce these stresses. During this round the specimen sizes were increased to 12 "x10"x15". These resulted in a similar failure with a small cone portion in the top of the specimen breaking off as shown in Figure 3.4.

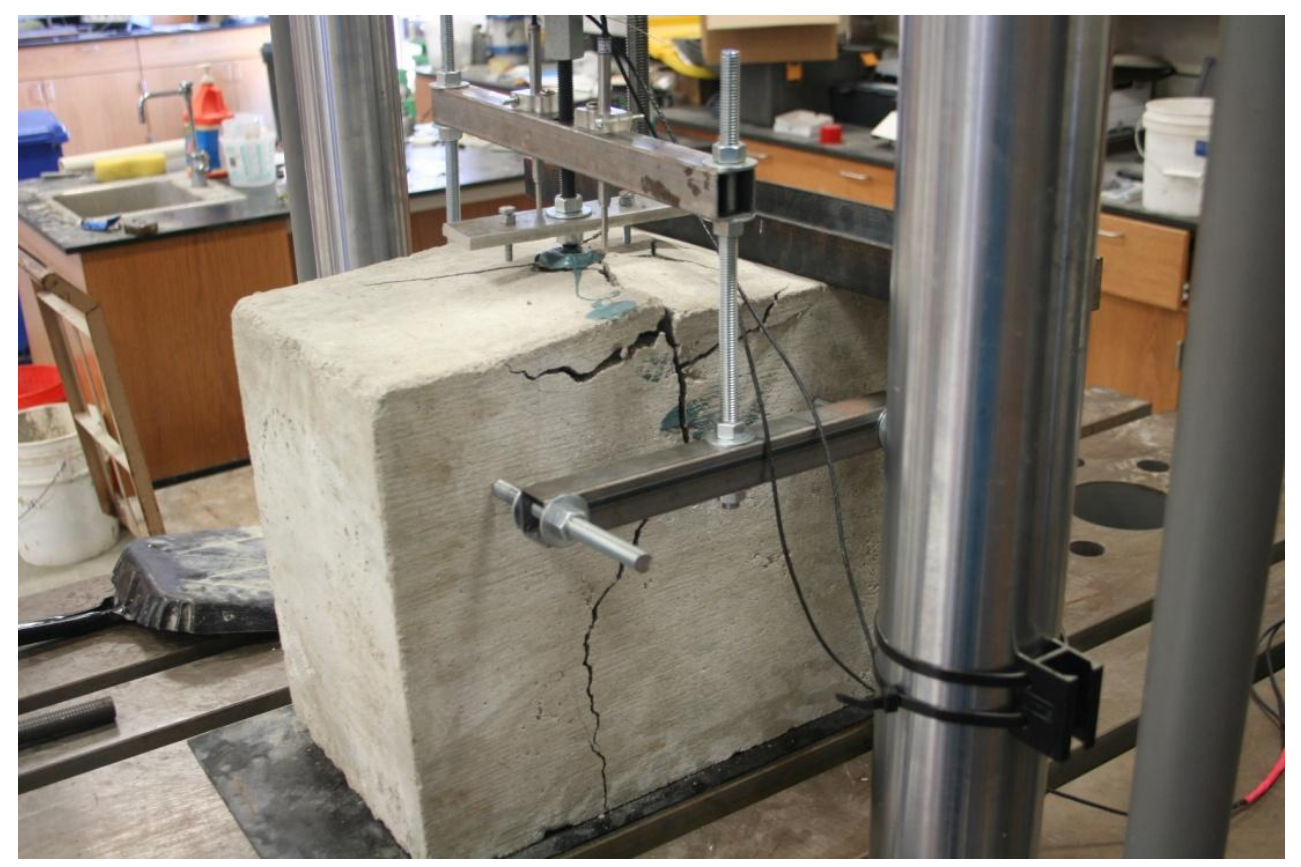

Figure 3.4 - Cone Splitting Failure

In an attempt to further prevent this splitting failure by reducing the tensile stress at the top of the specimen, a confining force was added (Figure 3.5). This added stress resulted in the entire top portion of the specimen breaking off at failure as seen in Figure 3.6. 


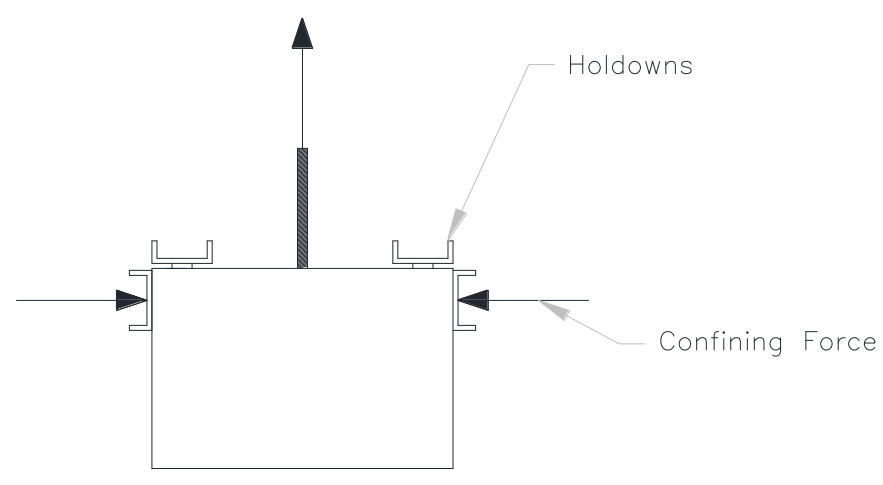

Figure 3.5 - Confining Restraint

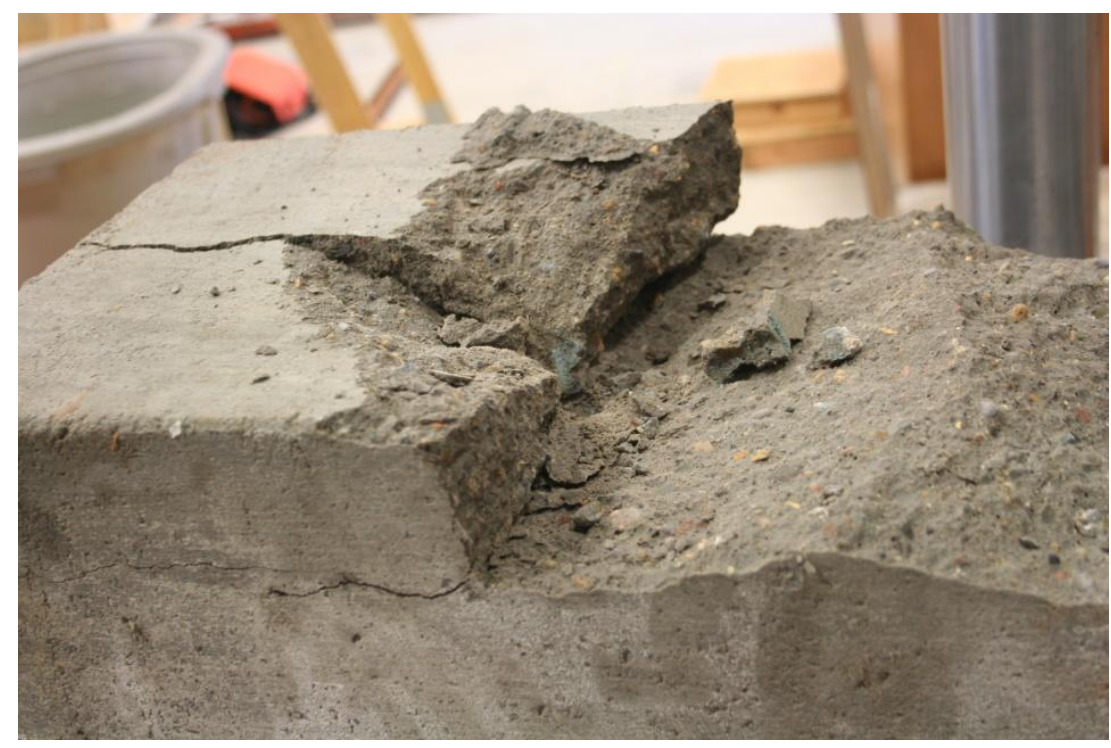

Figure 3.6 - Confining Force Failure

These tests showed that making the specimen deeper was not the solution, the specimen needed to be wider as well.

Additional tests were done utilizing the existing specimens; however, the anchors were installed in the 12 "x15" specimen face. Using the same restraining method (Figure 
3.2) at each end, the test again resulted in a splitting failure. An alternate restraining method was used where the specimen was anchored at the center of each edge, with a confining force added to the top portion as seen in Figure 3.7. This again resulted in the top portion of the specimen breaking off as shown in Figure 3.8. The same type of failure occurred at embedments of 6 bar diameters.

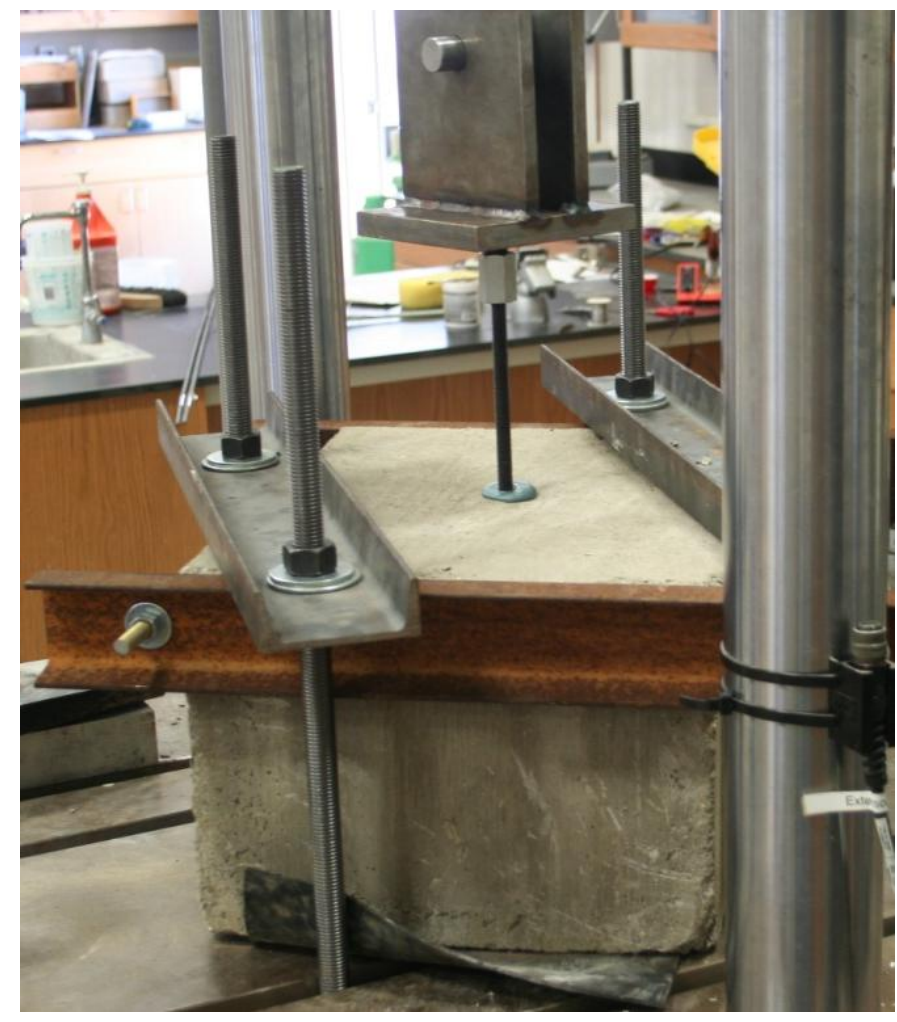

Figure 3.7 - Alternate Restraining Method 


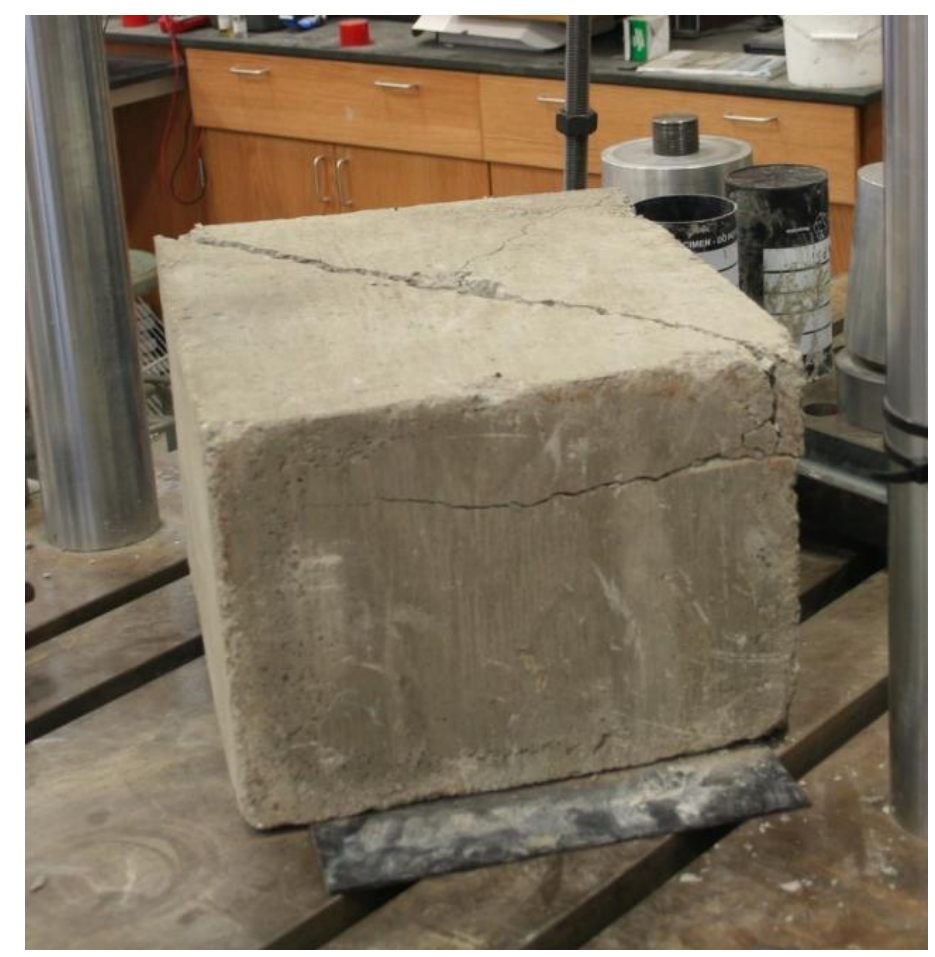

Figure 3.8 - Alternate Restraint Failure

\subsubsection{Test Round 3}

During test round three reinforcing steel was placed in the specimen to try and prevent a splitting failure. The specimens with reinforcement showed a similar failure mode to the specimens with the confining stress. They prevented the entire specimen from splitting but the entire top portion of the specimen above the reinforcement failed as seen in Figure 3.9. 


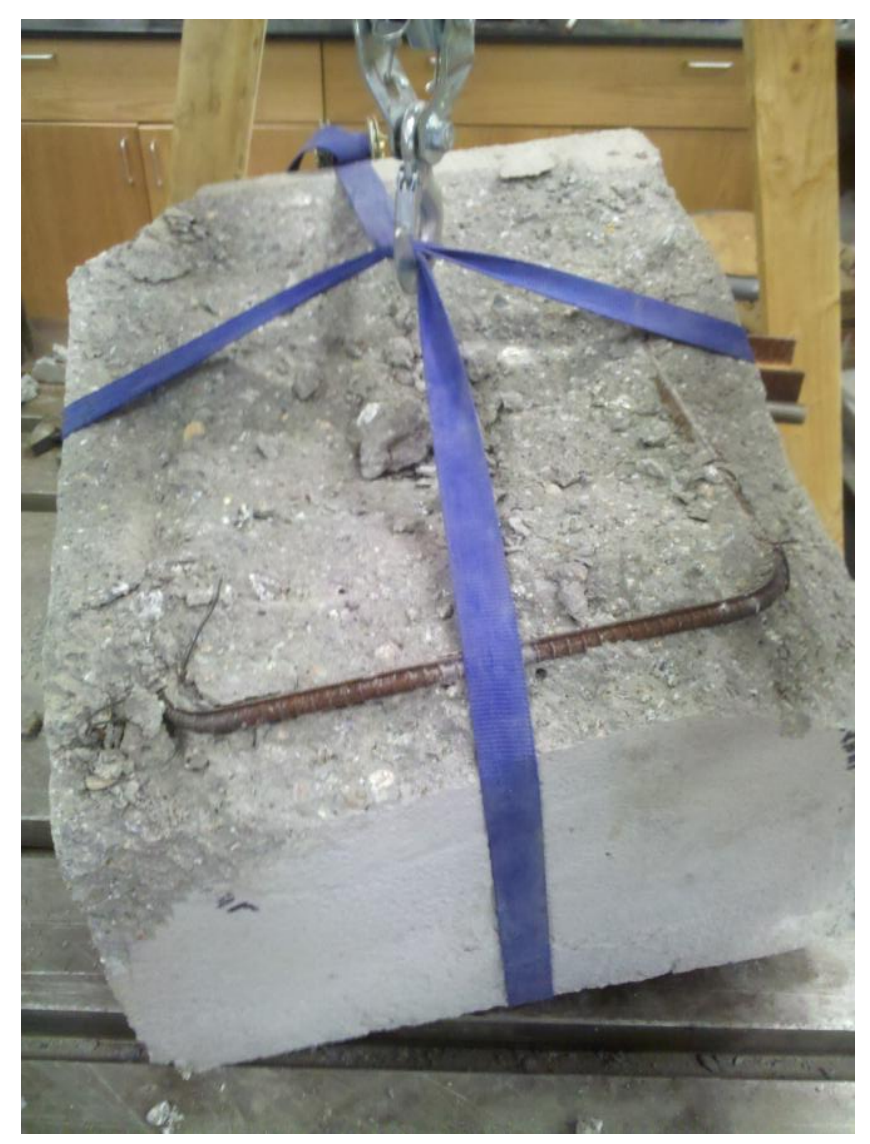

Figure 3.9 - Reinforced Specimen Failure Mode

After the third round of testing it was evident that the current specimen sizes were not going to work and a vastly different test configuration was needed.

\subsubsection{Test Round 4}

The fourth round of tests used a specimen configuration that more closely resembled a concrete slab. These specimens measured 22"x24"x10" with the anchor being installing on 22"x24" face. The thickness was kept as small as possible to reduce the weight of the specimen so they could still be moved on and off the test machine. Each specimen was cast with four holes to allow a thread rod to be inserted and anchored to the 
test machine as seen in Figure 3.10. This allowed for a smaller distance between supports and reduced the bending stress in the section.

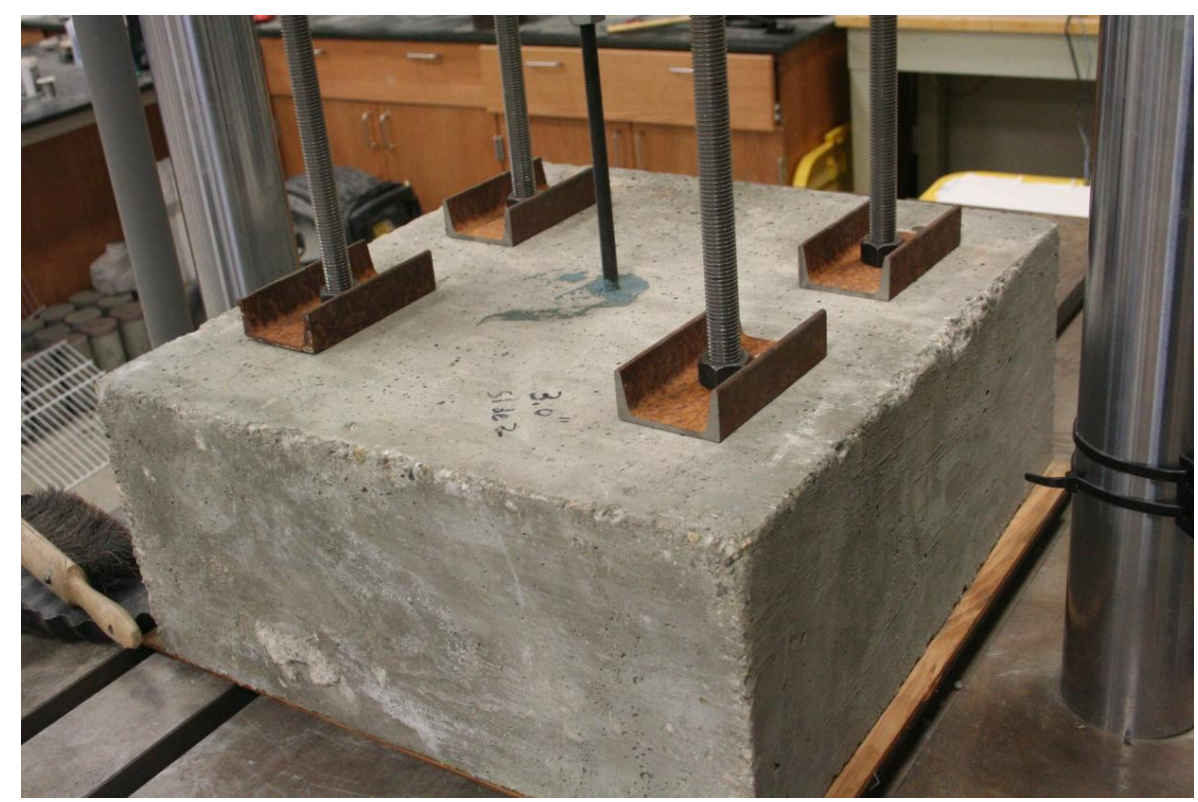

Figure 3.10 - Round 4 Specimen Restraint

This test setup showed desired Type I/II failure modes at embedment depths of two, four, and six bar diameters. At the nine bar diameter embedment a corner of the specimen broke off when using a high strength ASTM 193 grade B7 thread rod. Several tests were run with a standard strength thread rod and resulted in the rod breaking at an embedment of nine bar diameters. Ultimately this was the final setup used for testing, with the majority of testing focused on a 6 bar diameter embedment. 


\section{Chapter 4 Materials and Test Setup}

\subsection{Materials}

\subsubsection{Concrete Mix}

The concrete mix was targeted for a 28 day compressive strength of 4000 psi. The aggregate consisted of 3/8" maximum nominal size gravel and had a slump of 5 ". It was delivered by a ready mix truck, as shown in Figure 4.1. The mix design is provided in Appendix A. Compression tests $\left(\mathrm{f}^{\prime}{ }_{\mathrm{c}}\right)$ and splitting tension tests $\left(\mathrm{f}_{\mathrm{ct}}\right)$ were run at the time of testing to verify concrete strength as shown in Table 4.1. These results are for the final round of testing that was used for data analysis. The average compressive strength obtained was used to predict the pullout load of the dry installation anchors. 


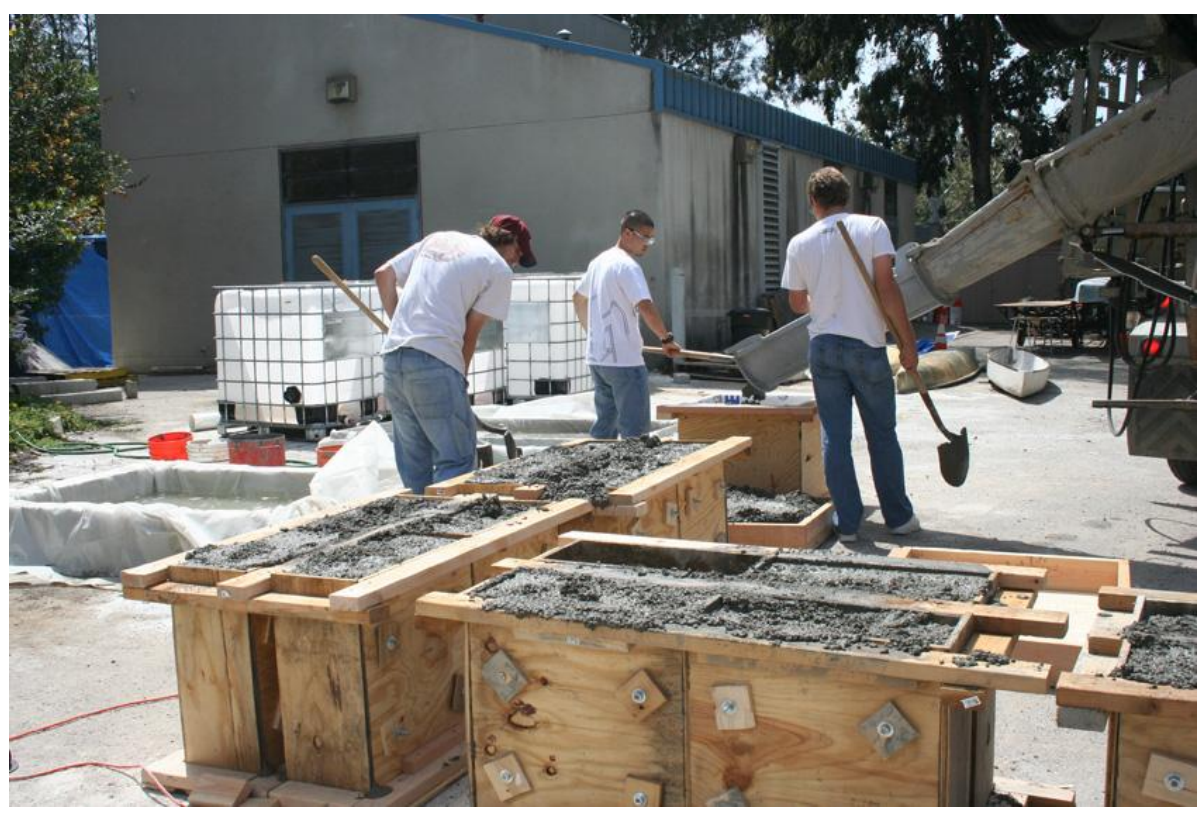

Figure 4.1 - Concrete Placement

\section{Table 4.1 - Concrete Strengths at Pullout Testing}

\begin{tabular}{ccc}
\hline \hline Test & $\mathbf{f}_{\mathbf{c}}(\mathbf{p s i})$ & $\mathbf{f}_{\mathbf{c t}}(\mathbf{p s i})$ \\
\hline 1 & 4316 & 579 \\
2 & 4192 & 535 \\
\hline Average & 4254 & 557 \\
\hline \hline
\end{tabular}

\subsubsection{Thread Rod Properties}

The anchor itself consisted of $1 \frac{12}{2}$-13 UNC ASTM A193 grade B7 threaded rod. All anchors had a plain finish and no special coatings. Tension tests were performed on 12 " sections of rod to obtain values for yield strength and ultimate strength as seen Table 4.2. Yield strengths were calculated according to the .2 percent offset method shown graphically in Figure 4.2. Per ASTM A193 for Grade B7, the minimum tensile strength 
is $125 \mathrm{ksi}$ and the minimum yield strength is $105 \mathrm{ksi}$. The minimum elongation in 10 inches is 16 percent.

Table 4.2 - Threaded Rod Tensile Test Results

\begin{tabular}{cccc}
\hline Specimen & Yield (k) & Ultimate $(\mathbf{k})$ & Elongation in 8\% $(\%)$ \\
\hline A & 15.5 & 16.9 & 9.4 \\
B & 16.4 & 17.3 & - \\
C & 15.1 & 17 & 8.6 \\
D & 18 & 19.4 & - \\
\hline \hline Avg. & $115 \mathrm{ksi}$ & $124 \mathrm{ksi}$ & \\
\hline \hline
\end{tabular}

Two test values for percent elongation were not calculated because the bar fractured close to the restraint.

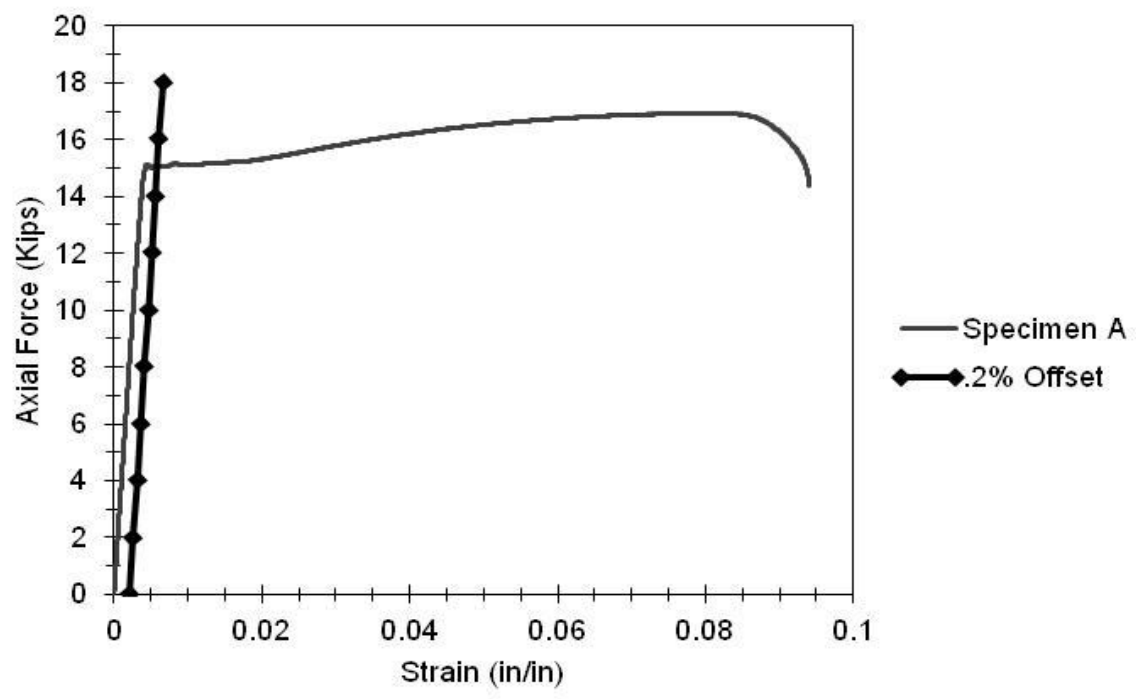

Figure 4.2 - Specimen C .2\% Offset Method 


\subsection{Installation Methods}

\subsubsection{Installation Procedure}

The installation method varied based on whether the installation was dry or conducted underwater. In each case, the holes were drilled using a rotary hammer drill and the epoxy was cured for 48 hours. The specific cleaning methods are outlined in section 4.2.2.

Dry installations were done according to the manufacturer's recommended installation guidelines, a typical installation guide can be found in Appendix C. The anchors themselves were wiped clean of any greasy substances to prevent issues with the epoxy bond. The holes were drilled in the center of the concrete specimen using the rotary hammer drill to the specified depth. Once the hole was properly cleaned the epoxy could be injected. Before injecting it, a small amount was squeezed out to the side to ensure the two epoxy components were properly mixed. This was verified by the teal color that the white resin and black hardener formed when mixed. The hole was then filled from the bottom up to prevent any air pockets from forming. Once the hole was filled about two thirds the threaded rod was inserted. As the threaded rod was inserted it was slowly turned to ensure the epoxy was in contact with the area between the threads. The rod was then checked to be sure it was placed vertically, not at an angle, and allowed to cure. This check was done by placing a square on the surface of the block and visually checking the anchor was perpendicular to the block's surface. Anchors cleaned underwater following the same process however; all specimens were submerged with 6 inches of water above the top of the specimen prior to drilling as depicted in Figure 4.3. 


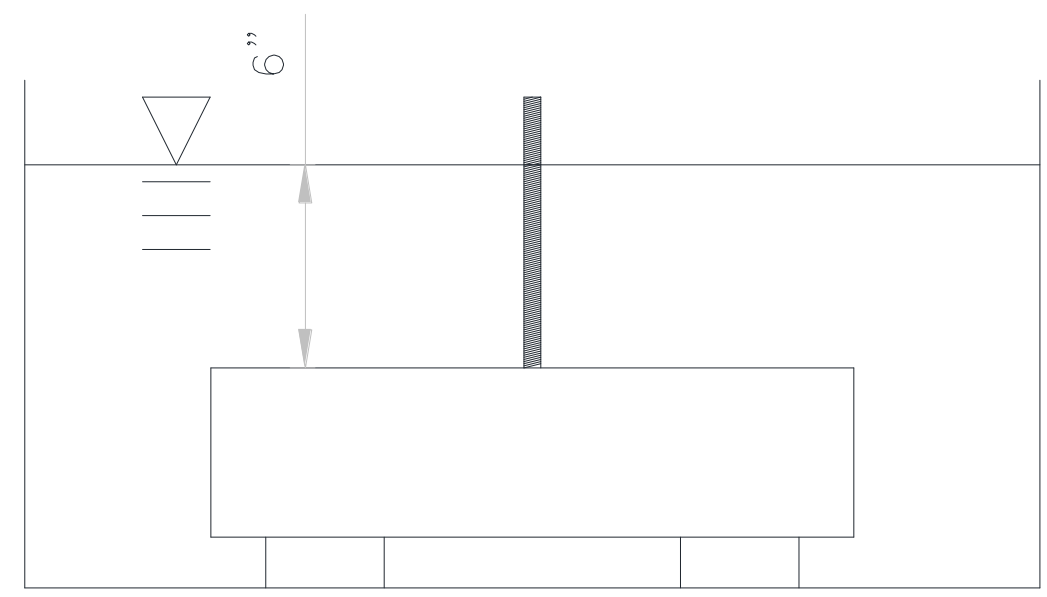

\section{Figure 4.3 - Submerged Specimen}

Some tests utilized a combination of dry cleaning and wet installation. During these tests the specimens were drilled and cleaned dry. The hole was then covered and the specimen was submerged. Once submerged, the hole was uncovered, allowed to fill with water and the epoxy was injected.

\subsubsection{Cleaning Methods}

Method 1 Dry Cleaning -Dry cleaning uses a combination of compressed air and brushing with a nylon brush. The compressed air was blown into the hole for a minimum of four seconds, the hole was then brushed clean a minimum of four times, and the compressed air was repeated. The combination of air and brushing is needed to remove all dust and debris from the hole ensuring a proper bond. 
Method 2 Wet Cleaning Brush- Underwater cleaning utilized the nylon brush to remove drilling material from the hole.

\subsection{Test Setup}

All testing was done using a MTS 322 test frame connected to computer through a Flextest control unit. The tests were displacement controlled and ran until failure. Each test specimen was anchored to the test machine using four 7/8" thread rods (Figure 4.4).

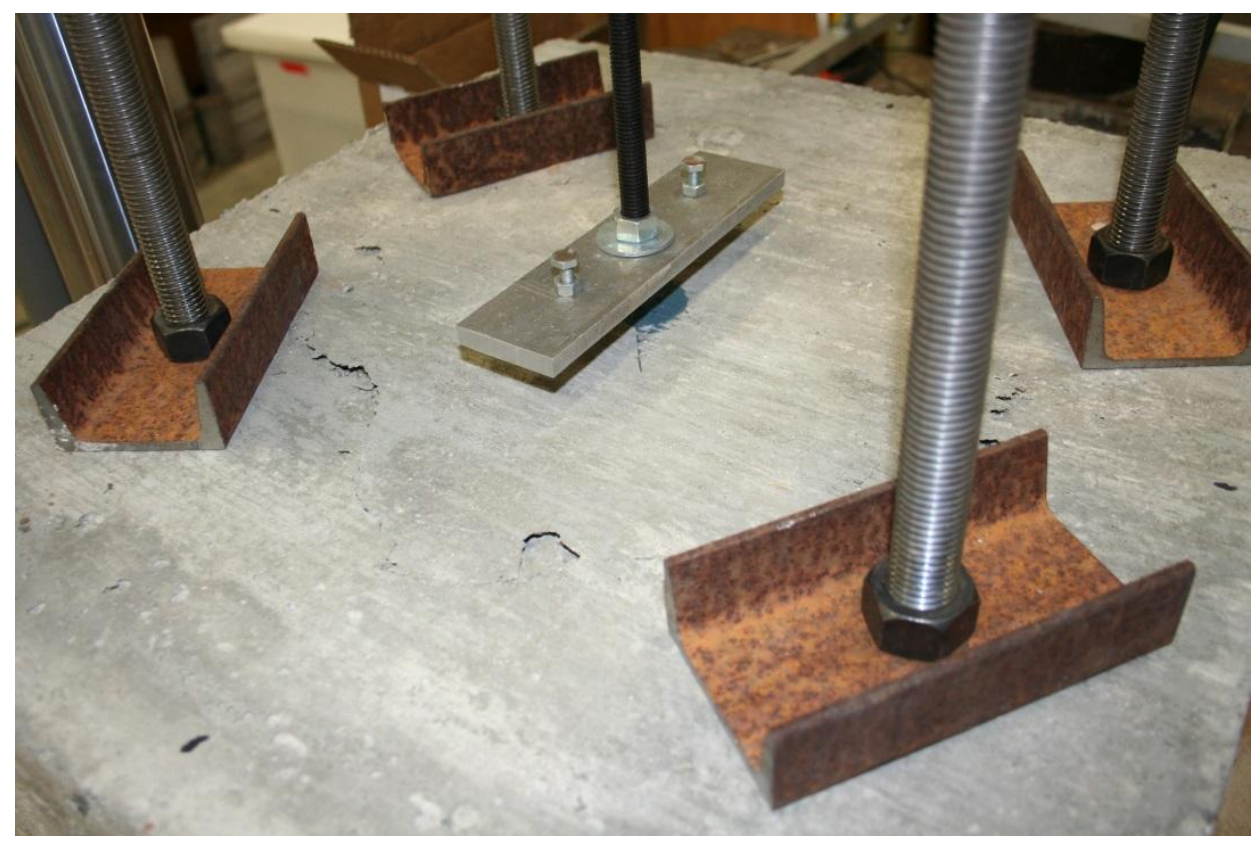

\section{Figure 4.4 - Specimen Hold Down Configuration}

The rods were inserted through precast holes in the test specimen and anchored to the existing T-slots. In accordance with ASTM E 488-03 all supports were at least one times the embedment depth from the center of the anchor. The displacement was measured using two Linear Variable Differential Transformers (LVDTs) which were anchored to 
the specimen. The LVDTs contacted a plate that was secured to the anchor rod as close to the surface of the concrete as possible (Figure 4.5). Each one was equal distance from the center of the anchor and the average measured displacement between the two was the final value used. A device was placed between the anchor and the hydraulic test ram that could rotate on two axes to limit any bending moment applied during testing as discussed in section 3.1.1 (Figure 4.6).

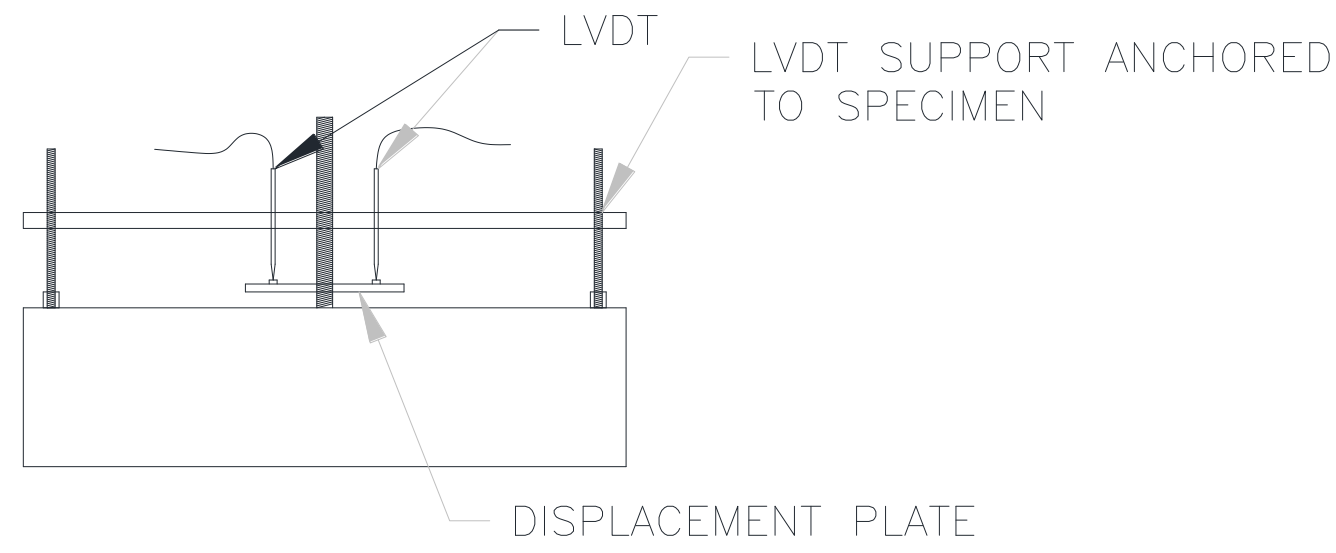

Figure 4.5 - LVDT Assembly Elevation 


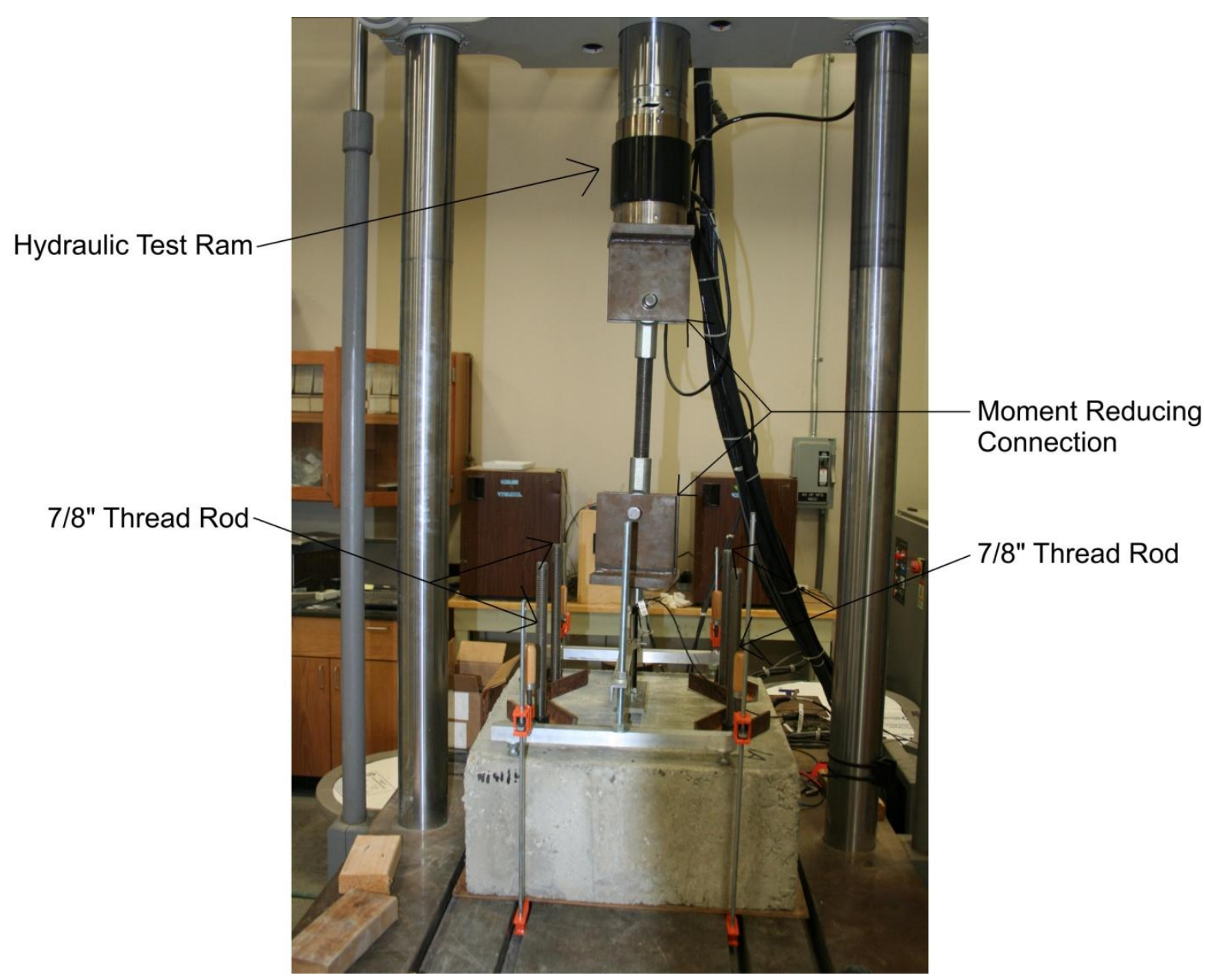

Figure 4.6 - Test Table Specimen Setup

\subsection{Loading and Failure Criteria}

Each anchor was loaded uniaxially at a rate of 0.05 inches per minute, resulting in failure within one to three minutes of loading (ASTM E 488, 2003). Failure was defined as one failure modes discussed in Chapter 2.2. All tests were continued well past failure to be sure all the data needed was obtained and to observe the characteristics of each failure mode. 


\subsection{Final Round Test Matrix}

\begin{tabular}{|c|c|c|c|c|c|}
\cline { 2 - 6 } \multicolumn{1}{c|}{} & \multicolumn{3}{c|}{ Epoxy A (\# of Tests Run) } & \multicolumn{2}{c|}{ Epoxy B (\# of Tests Run } \\
\hline $\begin{array}{c}\text { Embed. } \\
\text { Depth } \\
\text { (bar dia.) }\end{array}$ & $\begin{array}{c}\text { Dry } \\
\text { Cleaning } \\
+ \\
\text { Install }\end{array}$ & $\begin{array}{c}\text { Wet } \\
\text { Cleaning } \\
+ \\
\text { Install }\end{array}$ & $\begin{array}{c}\text { Dry } \\
\text { Cleaning } \\
+ \\
\text { Wet } \\
\text { Installation }\end{array}$ & $\begin{array}{c}\text { Dry } \\
\text { Cleaning } \\
+ \\
\text { Install }\end{array}$ & $\begin{array}{c}\text { Wet } \\
\text { Cleaning } \\
+ \\
\text { Install }\end{array}$ \\
\hline 2 & 2 & 2 & - & - & - \\
\hline 4 & 2 & 2 & 2 & 2 & - \\
\hline 9 & 4 & 4 & 2 & - & - \\
\hline
\end{tabular}

Table 4.3 - Final Round Test Matrix

The final round of tests conducted can be seen in Table 4.3. This round of tests was designed to compare the dry cleaning and installation procedure to the two submerged procedures. The second submerged procedure was designed to eliminate the cleaning procedure as a variable and compare only the presence of water when the epoxy is injected to the dry installations. 


\section{Chapter 5 Results and Analysis}

The results analyzed in this chapter will be broken into two main sections. Section 5.1 will focus on the pullout strengths measured during testing, while section 5.2 will focus on the failure modes of the anchors and how those modes relate to the load vs. displacement data obtained.

\subsection{Pullout Strengths}

\subsubsection{Predicted Pullout Strengths}

Based on the current models that are incorporated into ACI 318 Appendix D the concrete breakout strength of post-installed concrete anchors can be predicted by the following equation which gives a pullout capacity in kips (Fuchs et al., 1995).

$$
\bar{N}_{b}=35 \sqrt{f^{\prime}} h_{e f}^{1.5}
$$


This equation was originally designed for post installed mechanical anchors, however research has shown that shown that it also applies to the concrete breakout capacity of epoxy anchors (Eligehausen et al., 2006). The results from this equation are compared to anchor tests that exhibited a Type I failure in Figure 5.1 and Table 5.1. The similar values between the two shows that the results obtained in this research with the developed test setup are valid when compared to empirical data.

\subsubsection{Epoxy A Pullout Strength Results}

Figure 5.1 shows the overall trend for anchors that were brushed clean underwater and installed underwater with Epoxy A in comparison to those that were cleaned and installed dry. As expected, as embedment depth decreases so does the pullout strength. Overall, the anchors cleaned underwater had lower strengths than the anchors cleaned dry, and this strength loss was greater at deeper embedment depths. This indicates the strength loss due to underwater installation may be amplified at deeper embedments.

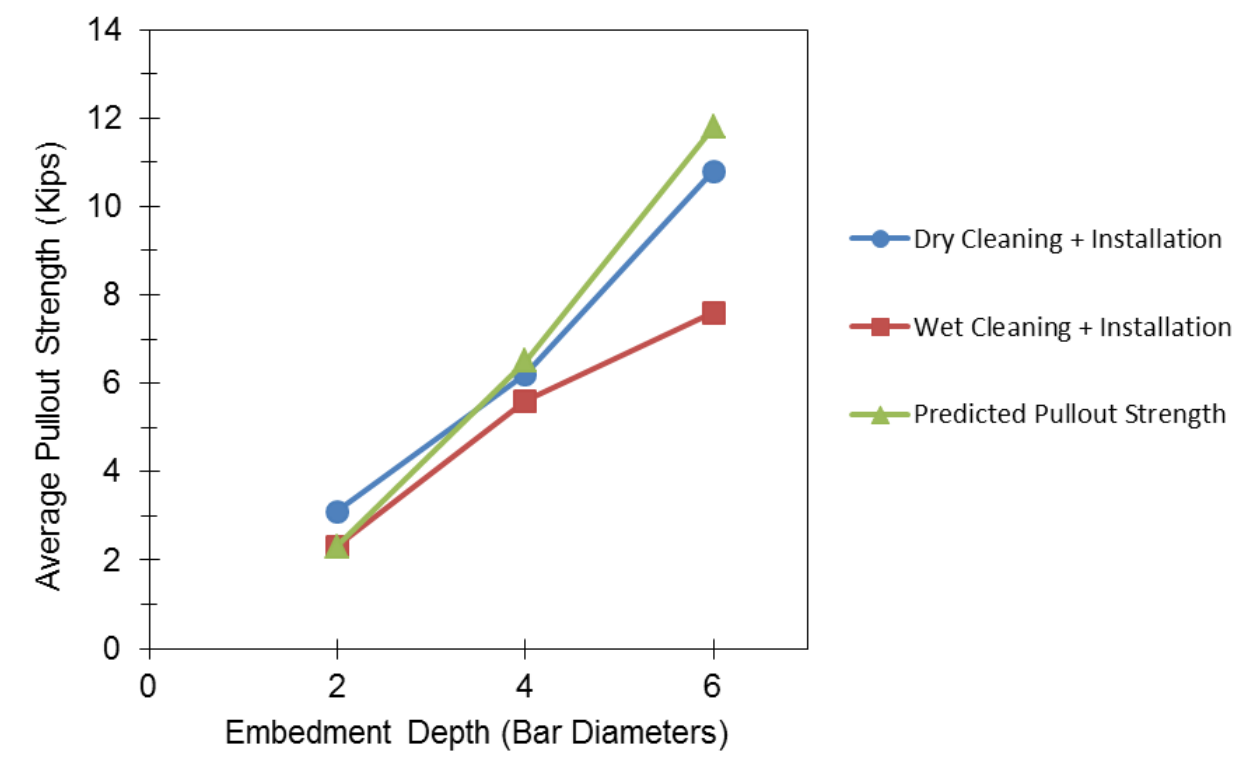

Figure 5.1 - Epoxy A Average Pullout Strengths 
The data for all anchors tests with a wet installation and cleaning were lower than the anchors cleaned dry except one test. One four bar diameter embedment test that was cleaned wet did have a pullout strength equal to the anchors installed dry as seen in Table 5.1. This test suggests that it is possible to have no strength loss when the anchor is cleaned and installed underwater but it is difficult to be consistent with all anchor installations.

Table 5.1 Epoxy A Pullout Strengths (Kips)

\begin{tabular}{|c|c|c|c|c|c|c|}
\hline & \multicolumn{2}{|c|}{2 Bar Diameters } & \multicolumn{2}{|c|}{4 Bar Diameters } & \multicolumn{2}{|c|}{6 Bar Diameters } \\
\hline & $\begin{array}{c}\text { Dry } \\
\text { Cleaning } \\
+ \\
\text { Install }\end{array}$ & $\begin{array}{c}\text { Wet } \\
\text { Cleaning } \\
+ \\
\text { Install }\end{array}$ & $\begin{array}{c}\text { Dry } \\
\text { Cleaning } \\
+ \\
\text { Install }\end{array}$ & $\begin{array}{c}\text { Wet } \\
\text { Cleaning } \\
+ \\
\text { Install }\end{array}$ & $\begin{array}{c}\text { Dry } \\
\text { Cleaning } \\
+ \\
\text { Install }\end{array}$ & $\begin{array}{c}\text { Wet } \\
\text { Cleaning } \\
+ \\
\text { Install }\end{array}$ \\
\hline & 2.8 & 1.7 & 6.1 & 4.2 & 10.1 & 6.1 \\
\hline & 3.3 & 2.8 & 6.2 & 7.0 & 10.3 & 6.5 \\
\hline & - & - & - & - & 10.8 & 8.2 \\
\hline & - & - & - & - & 12.2 & 9.0 \\
\hline Average & 3.1 & 2.3 & 6.2 & 5.6 & 10.8 & 7.6 \\
\hline Predicted & 2.3 & - & 6.5 & - & 11.9 & - \\
\hline C.O.V. & - & - & - & - & $8.7 \%$ & $16.3 \%$ \\
\hline $\begin{array}{l}\text { Failure } \\
\text { Mode* }\end{array}$ & Type I & Type I/II & Type I & Type I/II & Type I & Type II \\
\hline
\end{tabular}

*Failure Modes are defined in Section 2.2

The data for 6 bar diameter embedments shows that tests that were cleaned and installed underwater had a much higher variation in pullout strength compared to those 
that were cleaned and installed dry. This variation shows that there is an inconsistency in the cleaning process or interference with the bond by the presence of water. This can also be confirmed when looking at the range for shallower embedments. The tests for dry anchors had a smaller variation while the anchors with wet cleanings had a much larger spread.

\subsubsection{Epoxy A and B Pullout Strength Comparison}

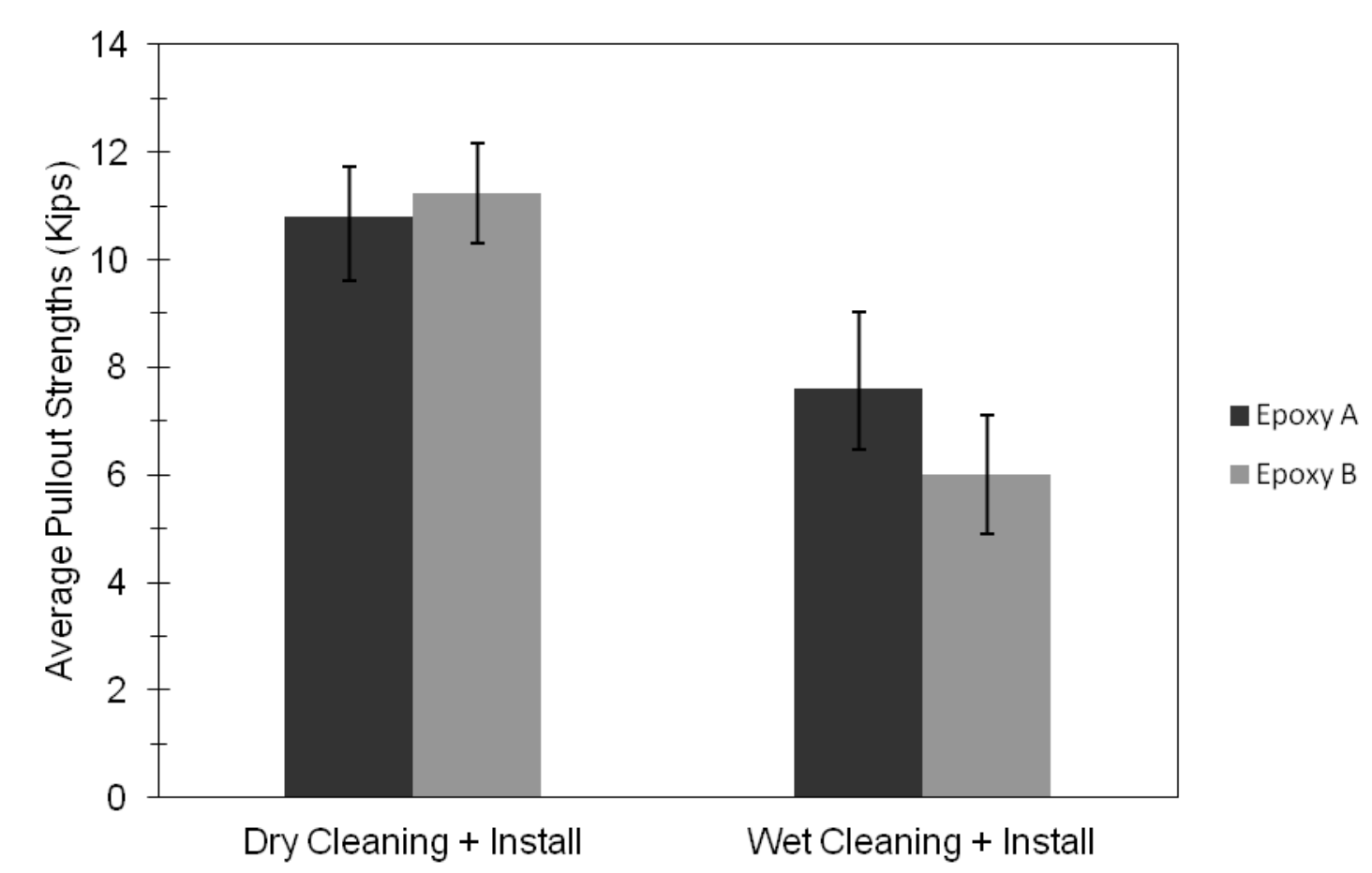

Figure 5.2 - 6 Bar Diameter Embedment Epoxy A and B Average Pullout Strength

As shown in Figure 5.2, both epoxies A and B had similar strengths when cleaned and installed dry. Each epoxy also showed a significant loss in strength when cleaned underwater. Although epoxy B had a larger strength loss the variation was within the 
range of epoxy A. This data leads to the conclusion that different brands with similarly rated epoxy types exhibit the same problems when cleaned wet and installed underwater.

\subsubsection{Dry Cleaning with Wet and Dry Installations}

The pullout strengths presented to this point do not give a clear answer to the question of what is causing the strength loss between dry and wet installations. This strength loss could either be due to the difficulty cleaning the hole underwater or the presence of water when the anchor is installed. Figure 5.3 shows that specimens that were drilled and cleaned dry, then placed underwater prior to injecting the epoxy and inserting the rod showed no loss in strength. This leads to the conclusion that water does not affect the ability of the epoxy to bond to the concrete, but creates difficulty when cleaning the drilled hole.

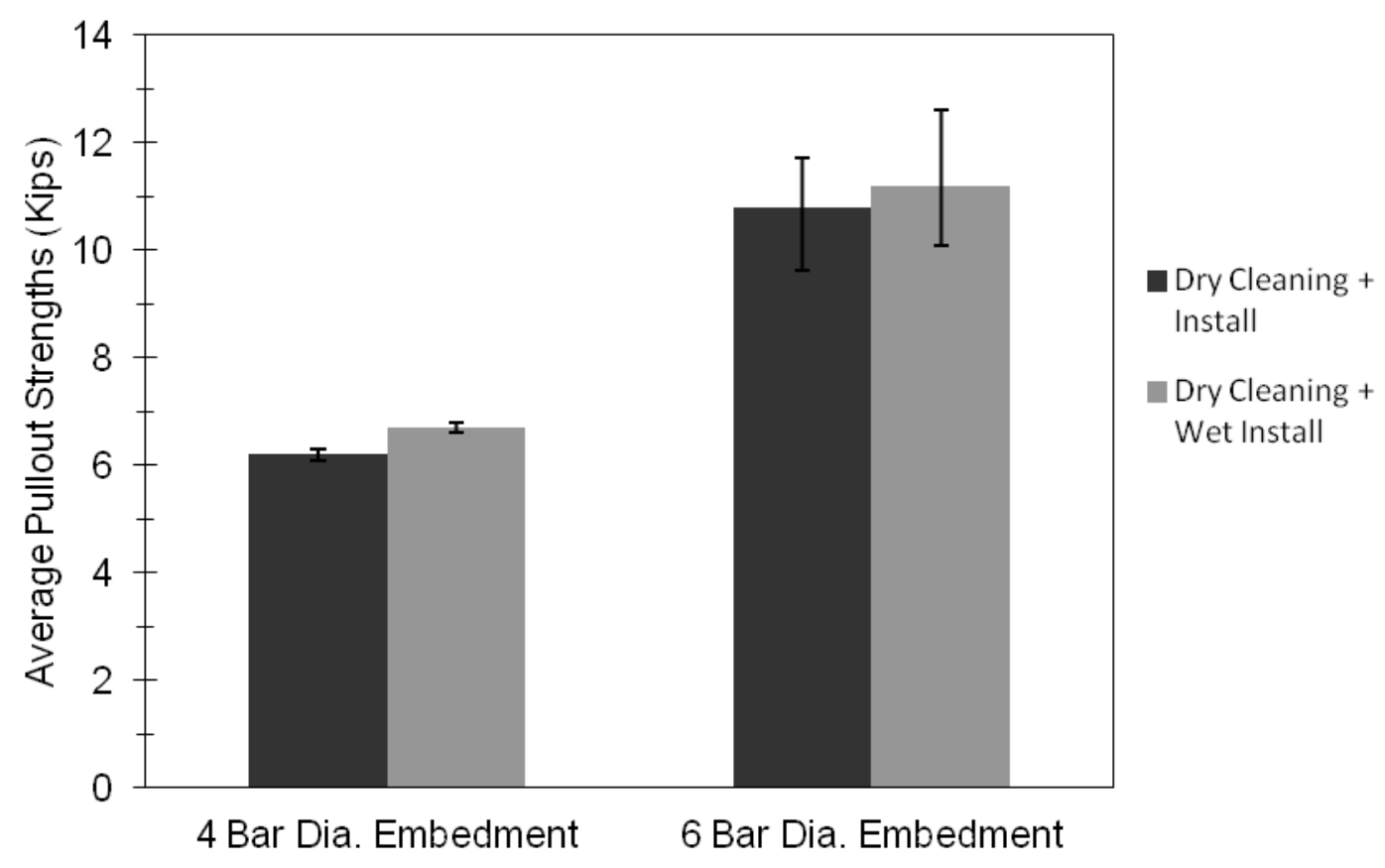

Figure 5.3 - Epoxy A Dry Cleaning and Mixed Installation Pullout Strengths 


\subsection{Failure Modes}

Throughout all the tests there were three distinct failure modes that occurred. The majority of failures were either Type I or Type II. The Type II failures varied between a complete bond failure and mixed concrete breakout cone and bond failure. However, all the bond failures occurred between the epoxy and the concrete. The third failure mode observed was a result of the block failing. These failure modes were closely related to the conditions under which the anchor was cleaned and the pullout strengths observed.

\subsubsection{Dry Cleaning Failure Modes}

Anchors cleaned and installed dry at embedment's of two, four, and six bar diameters, with Epoxy A, resulted in a Type I failure as seen in Figure 5.4. The anchors using epoxy A that were cleaned dry and installed underwater also showed a Type I failure. These installations were done at embedment depths of six and four bar diameters.

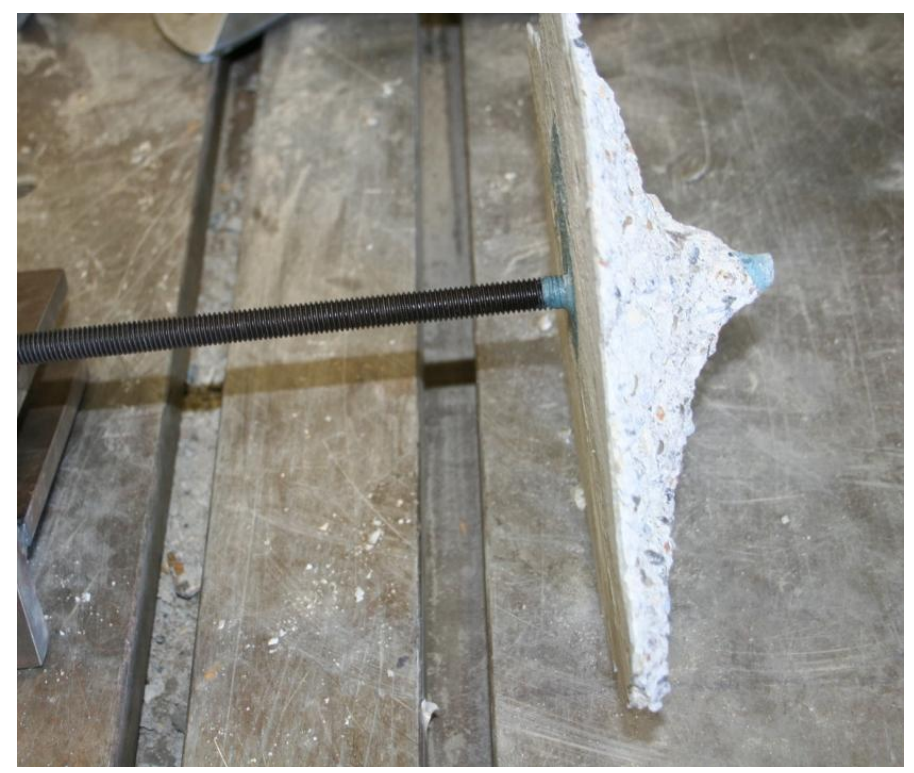

Figure 5.4 - Epoxy A Dry Cleaning Typical Failure 
Anchors using Epoxy B that underwent dry installations also showed no bond loss with a full concrete break out cone failure. Some Epoxy B tests did fail partially due to pullout cone and block failure. This was due to the fact this test was being done on the reverse side of a block that had already been tested. However, the epoxy did show a good bond to the concrete along the length of the anchor even though the member failed at the same time. Because this bond was intact, the test was considered valid.

\subsubsection{Underwater Cleaning Failure Modes}

Anchors that were installed underwater exhibited a Type II failure, shown in Figure 5.5, with some having a complete loss of bond along the entire length of the anchor as seen in Figure 5.6.

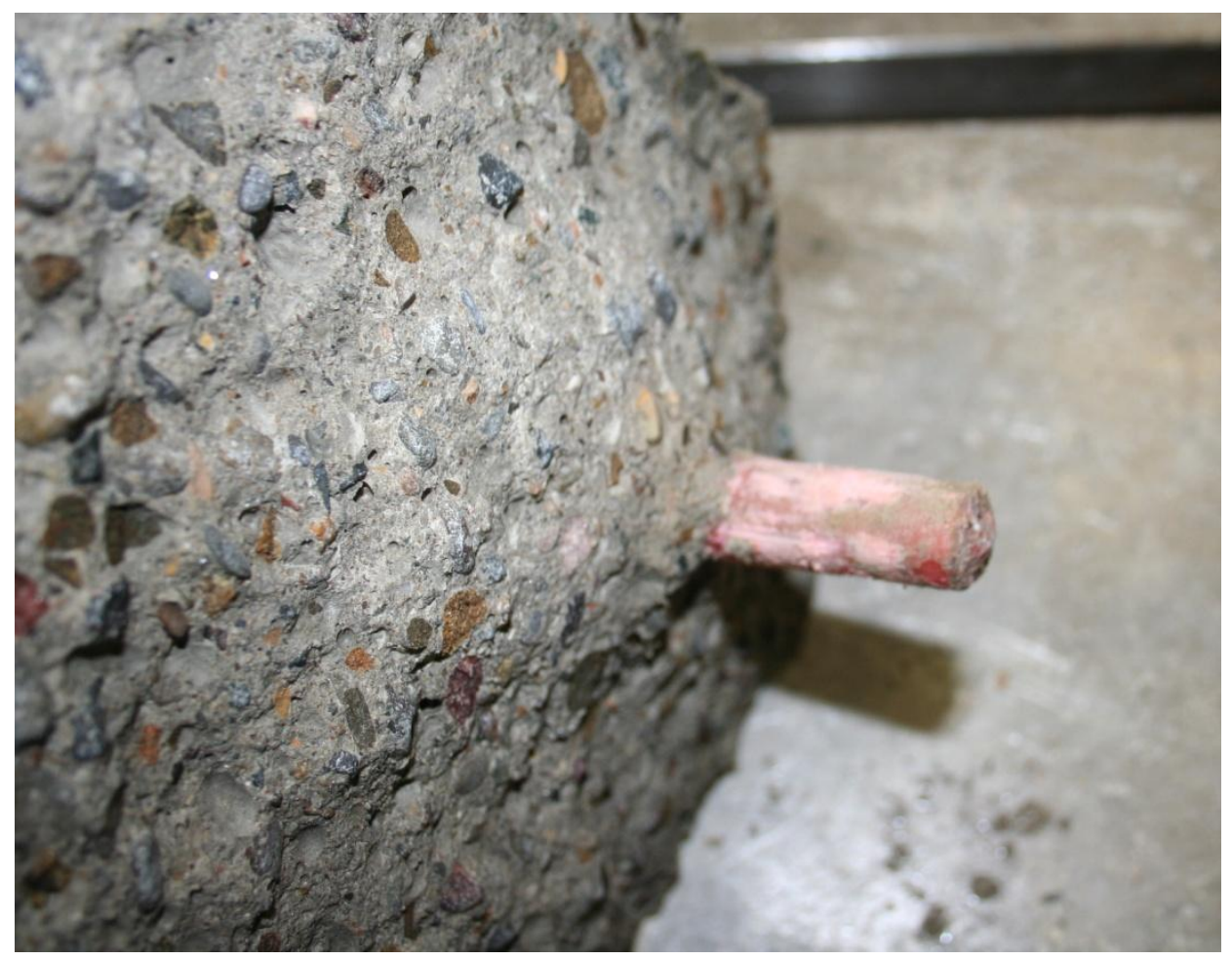

Figure 5.5 - Wet Cleaning Mixed Cone Bond Failure 


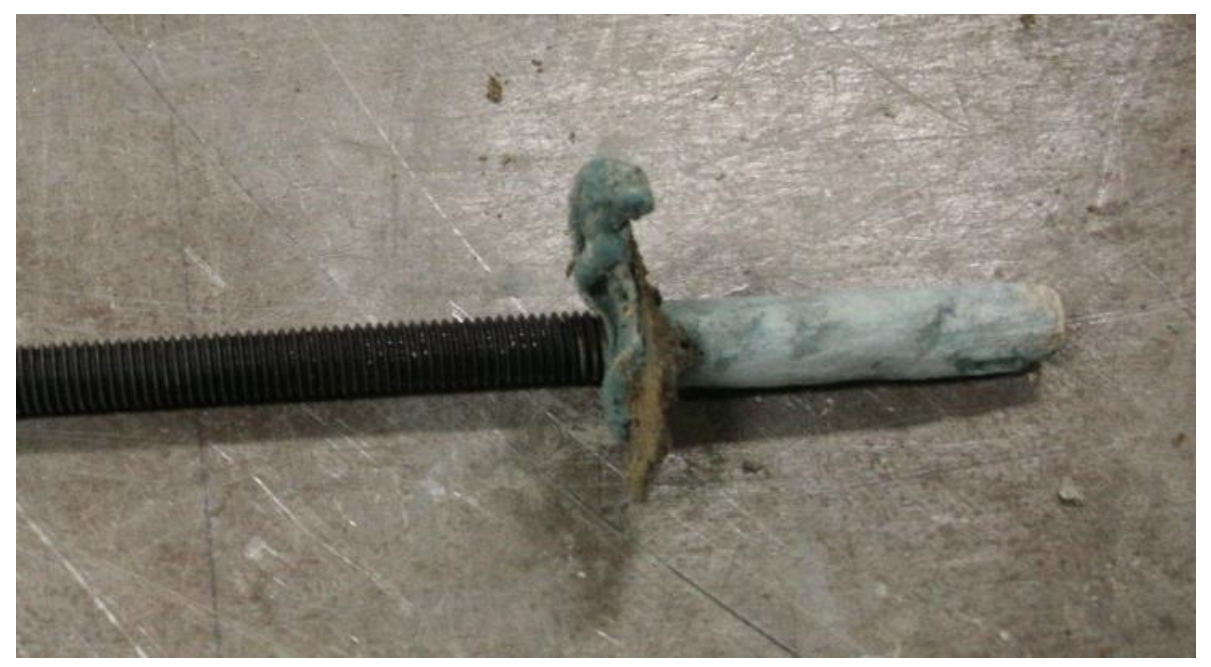

Figure 5.6 - Wet Cleaning Complete Bond Failure

While inspecting the anchor samples after failure there was clear evidence of drilling debris on the hardened epoxy. The debris was present on samples with a reduced capacity from both epoxies A and B, and across all embedments of anchors that were cleaned underwater. The presence of this debris is what reduced the bond capacity of the anchor resulting in lower pullout strengths. This leads to the conclusion that brushing alone is not an effective cleaning method when cleaning takes place underwater.

\subsubsection{Load vs. Displacement Behavior}

The observed failure modes can be related to the load vs. displacement behavior recorded during the pullout test. Figure 5.8 compares a complete concrete breakout cone failure, a mixed concrete cone bond failure and a full bond loss failure for a 6 bar diameter embedment. 


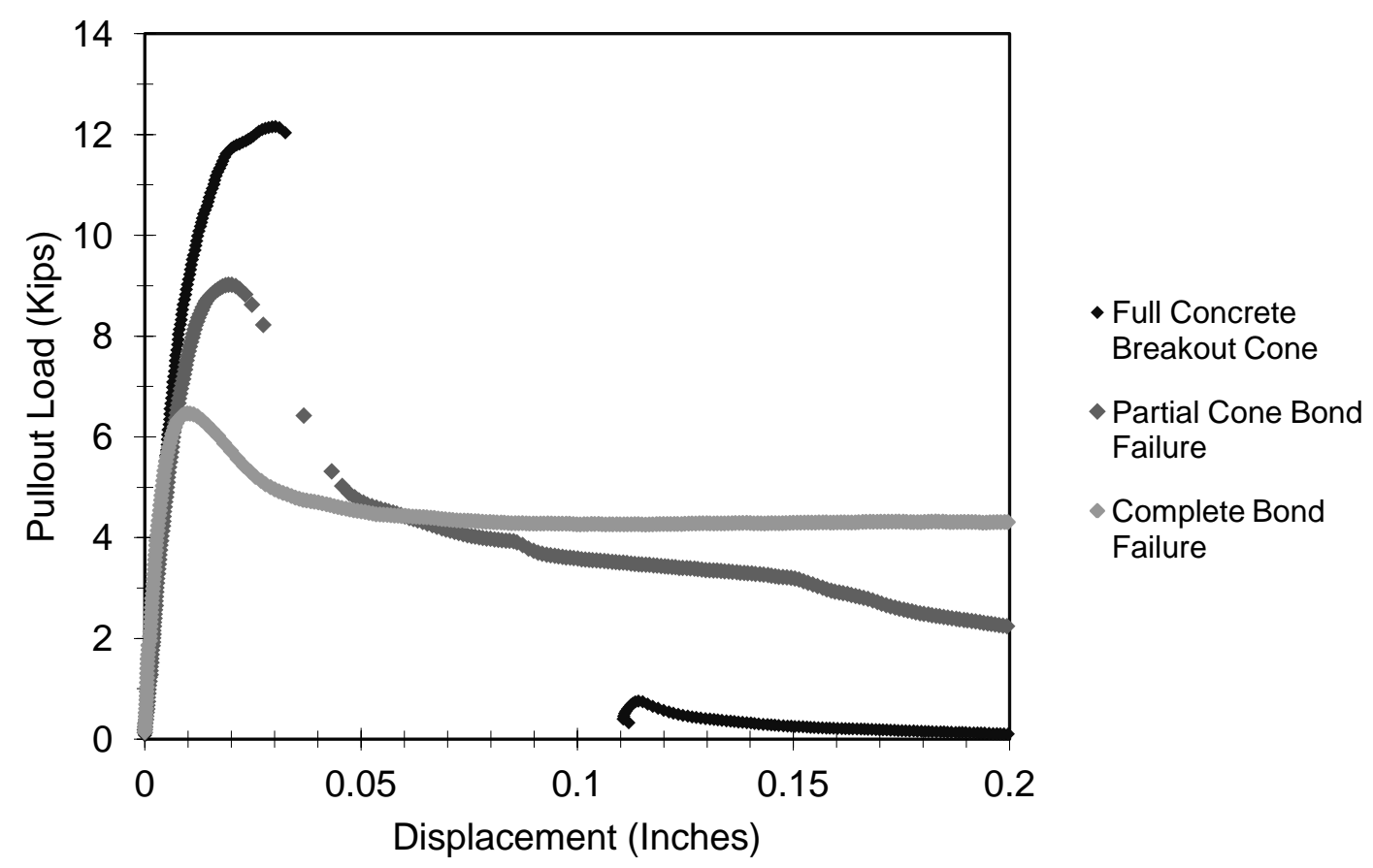

Figure 5.7 - 6 Bar Dia. Embedment Failure Comparison

Anchors that experienced a Type I failure had the highest pullout strengths, because they were able to utilize the full capacity of the concrete. These failures resulted in a steep load capacity drop off once the concrete failed, with no load capacity after failure, as seen in Figure 5.7. As mentioned previously these failure modes were seen with anchors that were cleaned dry. Anchors that failed with a mixed concrete breakout cone bond failure showed a sudden drop in load capacity followed by a period of some load capacity that diminished as the displacement increased. Tests that showed a full bond failure had the lowest ultimate load capacities. These anchors showed a small drop off in load after the ultimate capacity was reached followed by a period of displacement at a constant load. The remaining capacity during this period of displacement was due to the friction forces that developed between the epoxy and the concrete. 
The amount of bond loss typically related to the reduction in pullout strength. Anchors with a full concrete breakout cone had the highest ultimate capacities while anchors with no bond loss had the lowest. Anchors that failed with a mix of the two had ultimate capacities in between. 


\section{Chapter 6 Conclusions and Future Research}

\subsection{Conclusions}

Comparing dry cleaning and wet cleaning anchor installations shows that epoxy anchors can retain full pullout load capacity when installed underwater. However, an effective underwater cleaning method needs to be established. The strength loss that occurred during some underwater tests is not due to the presence of water when the epoxy is injected into the anchor hole or when the anchor is inserted. It is a result of the difficulty cleaning the anchor hole after it is drilled underwater. The ineffective cleaning processes results in excess drilling material being left on the wall of the hole reducing the bond capacity between the epoxy and concrete surface. This material does not affect the bond between the steel and epoxy. The diminished bond capacity results in either a mixed cone bond failure or a complete bond failure along the length of the anchor. As a result the anchor system does not utilize the full concrete breakout cone capacity and the system 
has a lower pullout strength. A more effective cleaning method could result in little to no loss of strength.

\subsection{Future Research Recommendations}

While these results provided a much needed confirmation that it is only the underwater cleaning affecting the pullout strength not the water interfering with the bond, there are several additional projects that could be done based off this research. First and foremost, additional tests are needed using a wide range of cleaning methods to develop an effective procedure. Once a cleaning method is established it could be tested in a variety of water conditions. These tests could vary the amount of sediment in the water, the flow of water, and test salt water. High sediment content in the water could deposit debris in the hole after cleaning reducing the capacity. In addition to varying the type of water it would be beneficial to see the effects long term submersion has on the anchor. Long term exposure to salt water or changes in water temperature could degrade the epoxy over time. 


\section{References}

ASTM International. (2003). Standard Test Methods for Strength of Anchors in Concrete and Masonry Elements. E 488 , pp. 65-72.

ASTM International (2007). Standard Test Methods for Testing Bond Performance of Bonded Anchors. E 1512, pp. 717-721.

Cook, R. A. (1994). Adhesive Bonded Anchors: Bond Properties and Effects of InService and Installation Conditions. Structrues and Materials Research Report, pp. 164.

Cook, R. A., \& Konz, R. C. (2001). Factors Influencing Bond Strength of Adhesive Anchors. ACI Structural Journal, 98-S8, pp. 76-85.

Cook, R. A., Kunz, J., Fuchs, W., \& Konz, R. C. (1998, January- February). Behavior and Design of Single Adhesive Anchors under Tensile Load in Uncracked Concrete. ACI Structural Journal, pp. 9-26.

Eligehausen, R., Appl, J. J., Lehr, B., Meszaros, J., \& Fuchs, W. (2004). Tragverhalten und Bemessung von Befestigungen mit Verbunddübelnunter Zugbeanspruchung, Part 1: Einzeldübel mit großem Achs-und Randabstand. Beton und Stahlbetonbau, pp. 561-571.

Eligehausen, R., Cook, R. A., \& Appl, J. (2006). Behavior and Design of Adhesive Bonded Anchors. ACI Structural Journal, pp. 103-183. 
Eligehausen, R., Mallee, R., \& Silva, J. F. (2006). Anchorange in Concrete Construction. Darmstadt, Germany: Ernst \& Sohn.

Fuchs, W., Eligehausen, R., \& Breen, J. E. (1995). Concrete Capacity Design (CCD) Approach for Fastening to Concrete. ACI Structural Journal, pp. 73-94.

Mattis, L., \& Wollmershauser, R. (2007) Adhesive Anchors. St. Charles Missouri: Concrete Anchor Manufactuers Association.

ICBO Evaluation Service (2001). Acceptance Criteria for Adhesive Anchors in Concrete and Masonry Elements. International Conference of Building Officials.

Unterweger, R., \& Bergmeister, K. (1998). Investigations of Concrete Boreholes for Bonded Anchors. 2nd Int. PhD Symposium in Civil Engineering, pp. 1-7. 


\section{Appendix A Mix Design}

Appendix $\mathrm{A}$ is a record of the mix design broken down by material quantities and provides a sieve analysis for the aggregates used. 


\title{
CALPORTLAND \\ CONSTRUCTION
}

\section{CONCRETE MIX DESIGN NUMBER: $\underline{540 G N 3010}$}

April 12, 2011

JEFFREY BLANCHETTE

CAL POLY

SAN LUIS OBISPO, CALIFORNIA

USE:

ANCHOR TESTS

DESCRIPTION:

\author{
5.74 sks $/ \mathrm{yd}^{3-}$ Total Cementitious \\ 5" Slump \\ $\mathrm{W} / \mathrm{CM}=0.56$ \\ $\mathrm{gal} / \mathrm{sack}=6.27$
}

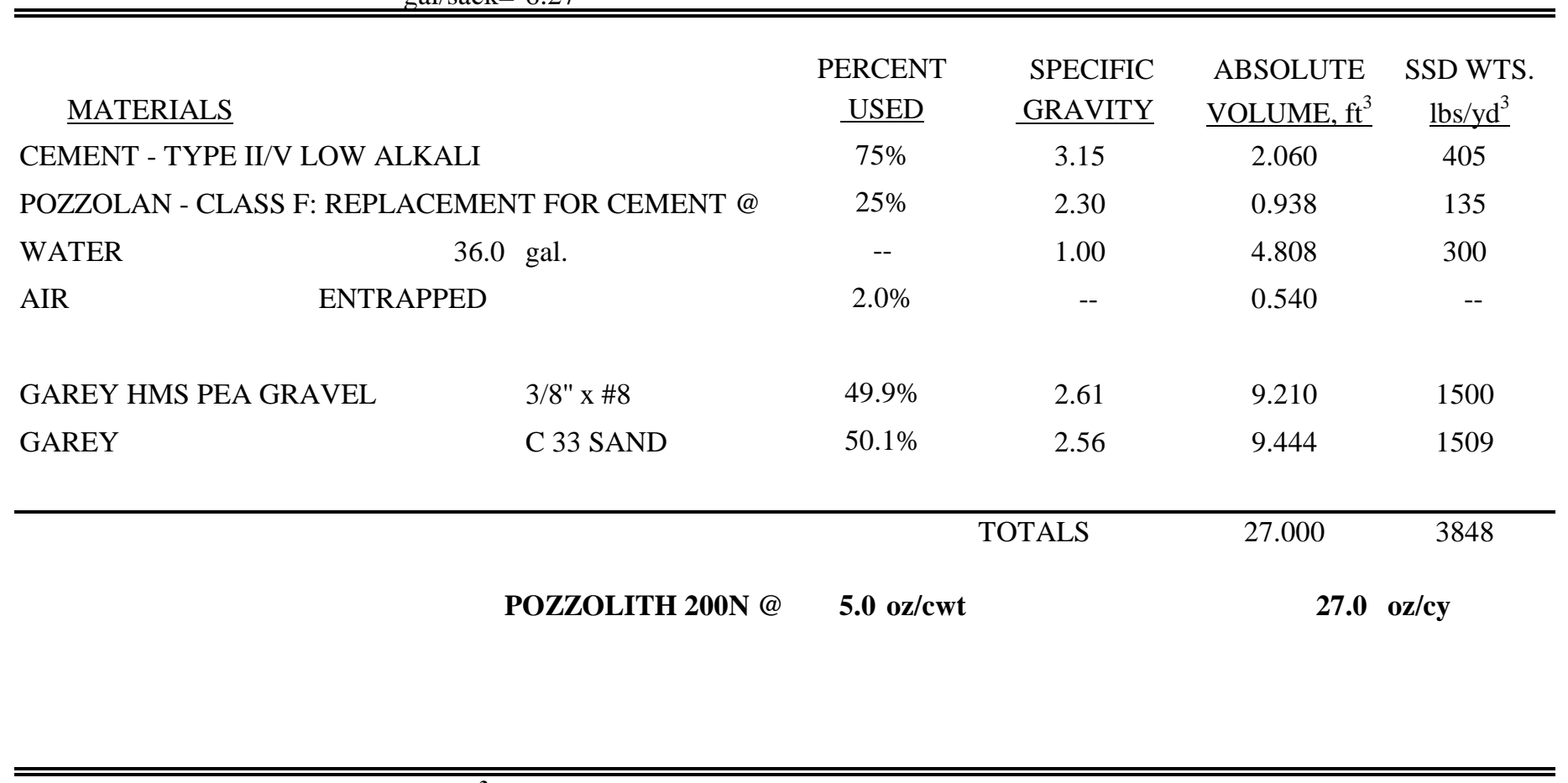

\section{PLASTIC DENSITY $\left(\mathrm{lbs} / \mathrm{ft}^{3}\right)=142.5$}

THE WEIGHTS ARE IN POUNDS FOR ONE CUBIC YARD OF FRESH CONCRETE. THE WEIGHTS OF WATER AND AGGREGATE ARE FOR MATERIALS IN SATURATED, SURFACE-DRY CONDITION AND MUST BE ADJUSTED FOR MOISTURE WHEN BATCHED.

Mixes intended for pump placement should be reviewed by the pumping contractor prior to use to ensure compatibility with equipment.

AGGREGATE SOURCE: CALPORTLAND CONSTRUCTION - GAREY, CA - SMARA \#91-42-0014 
CALPORTLAND

CONSTRUCTION

SIEVE ANALYSIS

for

MIX NUMBER 540GN3010

PERCENT PASSING

\begin{tabular}{|c|c|c|c|c|}
\hline \multicolumn{2}{|c|}{ AGGREGATE SOURCE } & $\begin{array}{l}\text { GAREY HMS } \\
\text { PEA GRAVEL }\end{array}$ & GAREY & $\begin{array}{l}\text { COMBINED } \\
\text { GRADATION }\end{array}$ \\
\hline \multicolumn{2}{|c|}{ SIEVE SIZE } & $3 / 8 " x \# 8$ & C 33 SAND & \\
\hline SI & US & $50 \%$ & $50 \%$ & \\
\hline $37.50 \mathrm{~mm}$ & $1-1 / 2 "$ & & & 100 \\
\hline $25.00 \mathrm{~mm}$ & $1 "$ & & & 100 \\
\hline $19.00 \mathrm{~mm}$ & 3/4" & & & 100 \\
\hline $12.50 \mathrm{~mm}$ & $1 / 2^{\prime \prime}$ & 100 & & 100 \\
\hline $9.50 \mathrm{~mm}$ & 3/8" & 94 & 100 & 97 \\
\hline $4.75 \mathrm{~mm}$ & $\# 4$ & 19 & 100 & 60 \\
\hline $2.36 \mathrm{~mm}$ & \#8 & 1 & 88 & 45 \\
\hline $1.18 \mathrm{~mm}$ & \#16 & 0 & 71 & 36 \\
\hline $600 \mathrm{um}$ & \#30 & & 47 & 24 \\
\hline 300 um & \#50 & & 20 & 10 \\
\hline 150 um & \#100 & & 6 & 3 \\
\hline 75 um & \#200 & & 2 & 1 \\
\hline S.E. & & & 88 & \\
\hline C.V. & & 83 & & \\
\hline
\end{tabular}




\section{Appendix B Individual Test Summary}

Appendix B consists of individual test summaries giving the parameters, load vs.

displacement curve, photos, and notes for each pullout test that was conducted during the final phase of testing. 


\begin{tabular}{|c|c|c|c|c|c|}
\hline Test & Emb. Depth (Bar Dia.) & Drilled & Cleaned & Epoxy Injected & Epoxy \\
\hline 1A & 6 & Dry & Dry & Dry & A \\
\hline
\end{tabular}

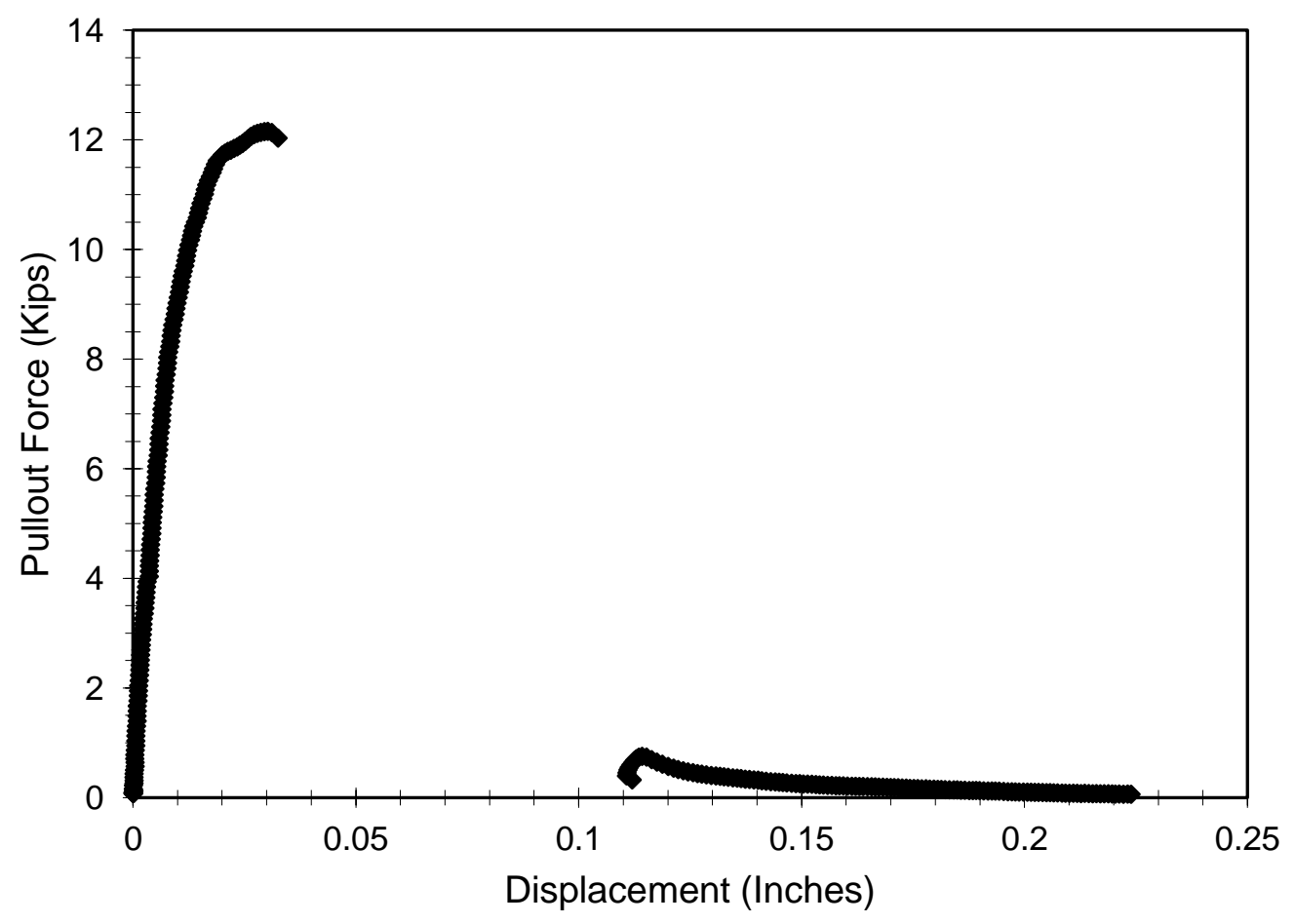

\section{Failure Pictures:}
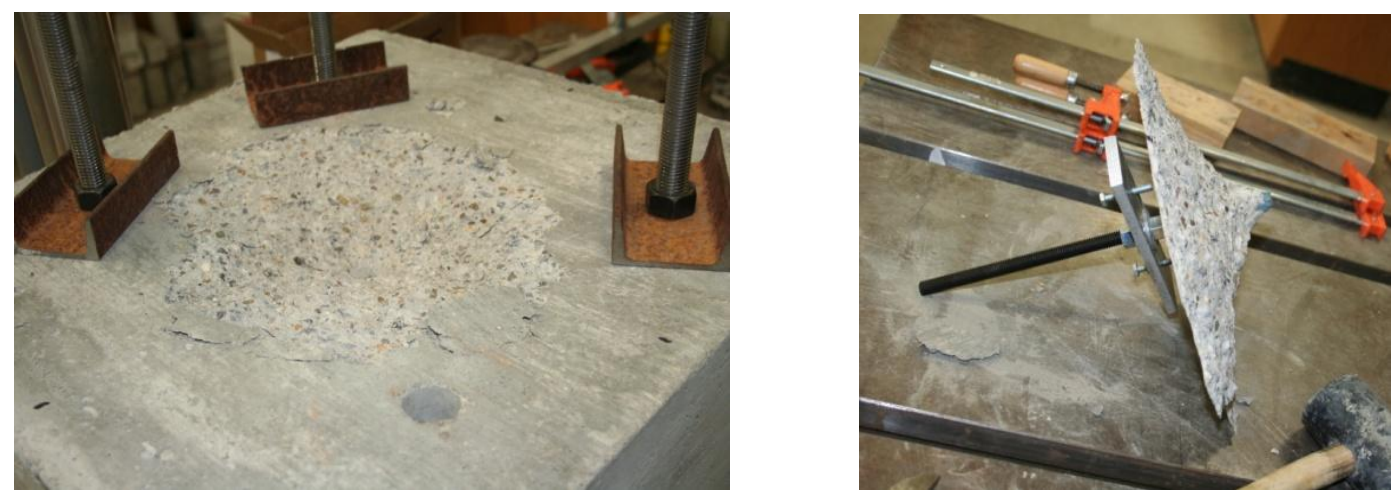

Notes: Type I failure 


\begin{tabular}{|c|c|c|c|c|c|}
\hline Test & Emb. Depth (Bar Dia.) & Drilled & Cleaned & Epoxy Injected & Epoxy \\
\hline $2 \mathrm{~A}$ & 6 & Dry & Dry & Dry & A \\
\hline
\end{tabular}

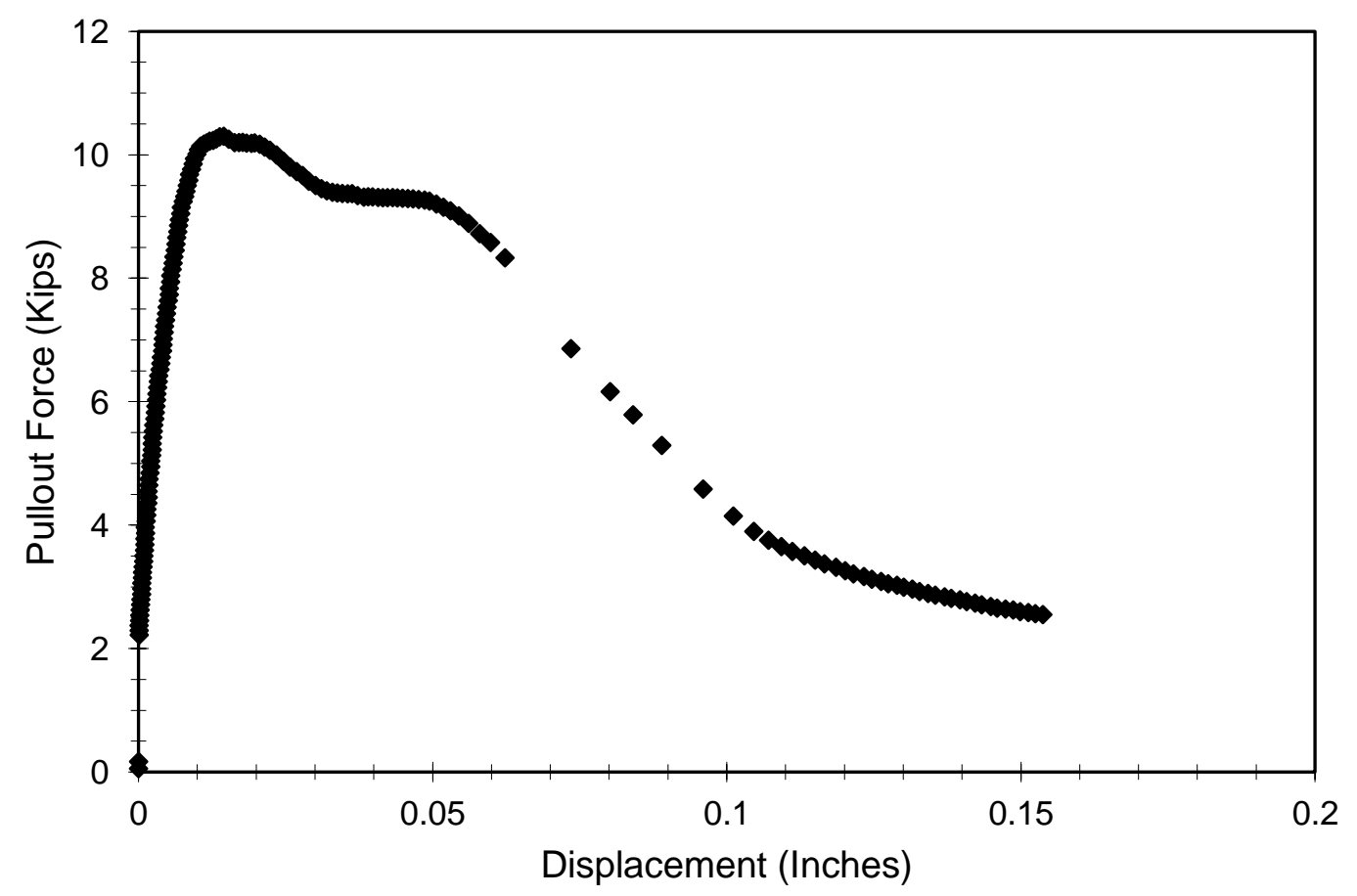

\section{Failure Pictures:}
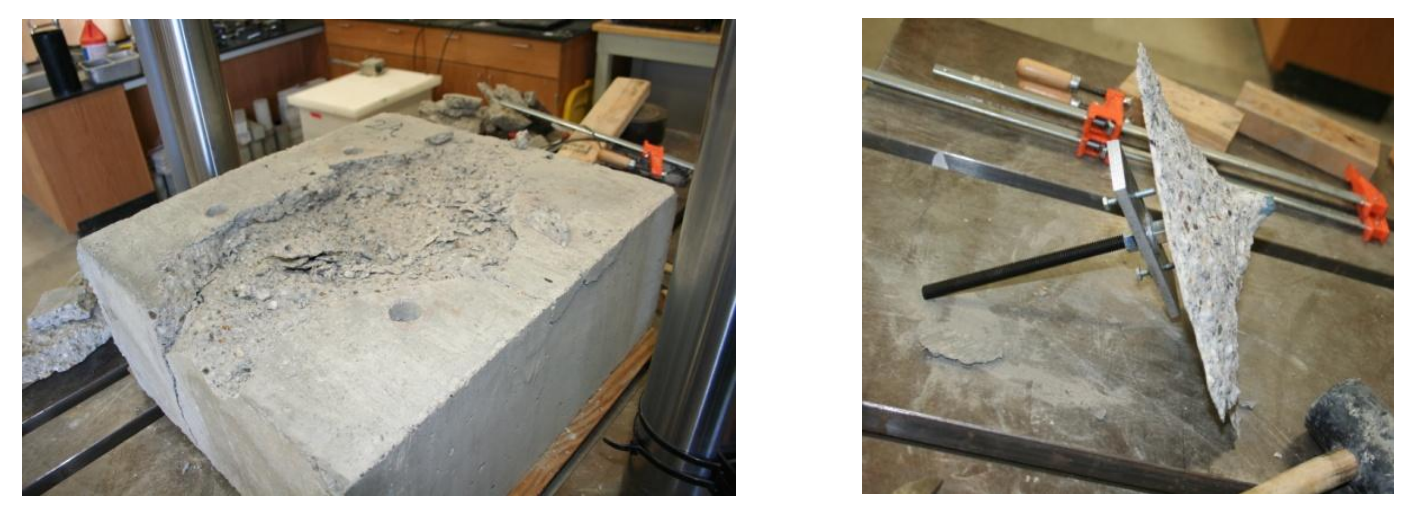

Notes: Type I failure, some concrete failure on edges of block lead to extra slope in curve 


\begin{tabular}{|c|c|c|c|c|c|}
\hline Test & Emb. Depth (Bar Dia.) & Drilled & Cleaned & Epoxy Injected & Epoxy \\
\hline $3 \mathrm{~A}$ & 6 & Wet & Wet & Wet & A \\
\hline
\end{tabular}

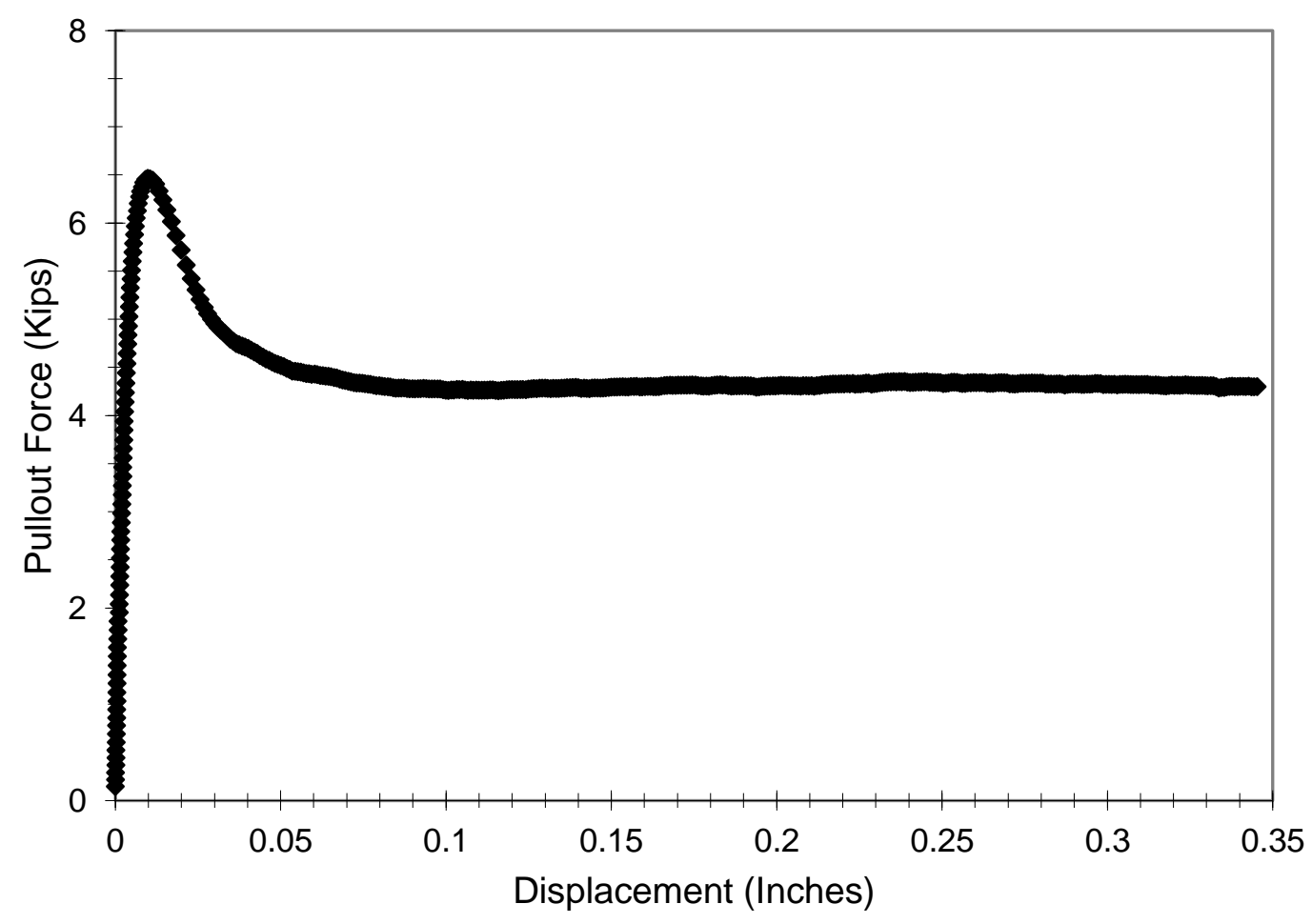

\section{Failure Pictures:}
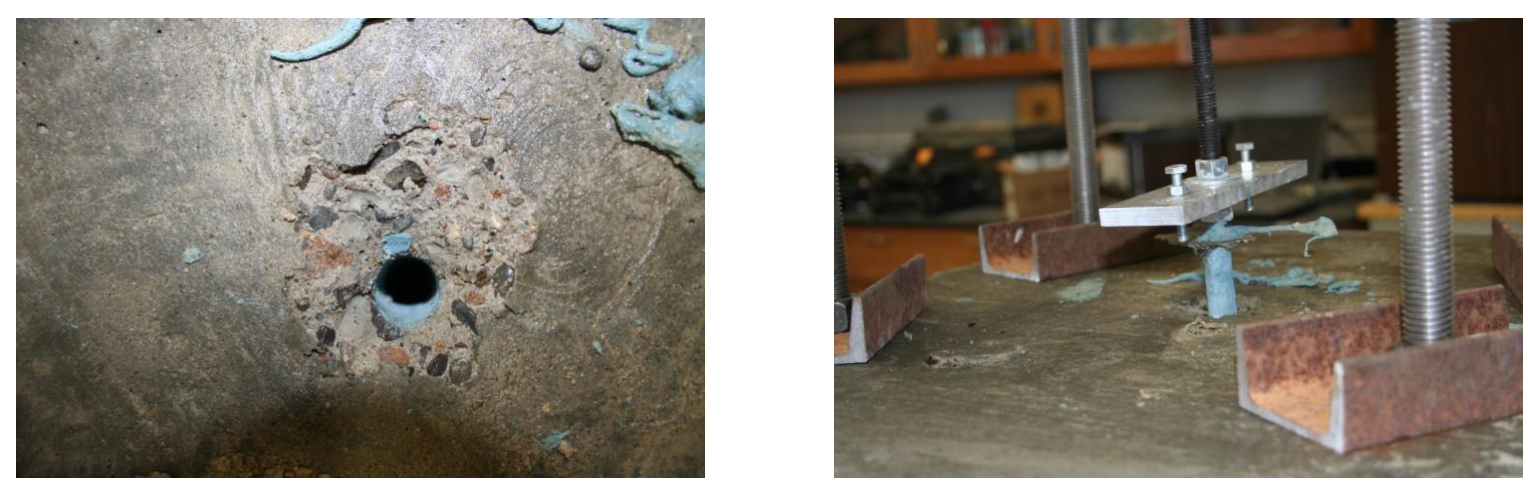

Notes: Type II failure, complete bond failure along the length of the anchor 


\begin{tabular}{|c|c|c|c|c|c|}
\hline Test & Emb. Depth (Bar Dia.) & Drilled & Cleaned & Epoxy Injected & Epoxy \\
\hline $4 \mathrm{~A}$ & 6 & Wet & Wet & Wet & A \\
\hline
\end{tabular}

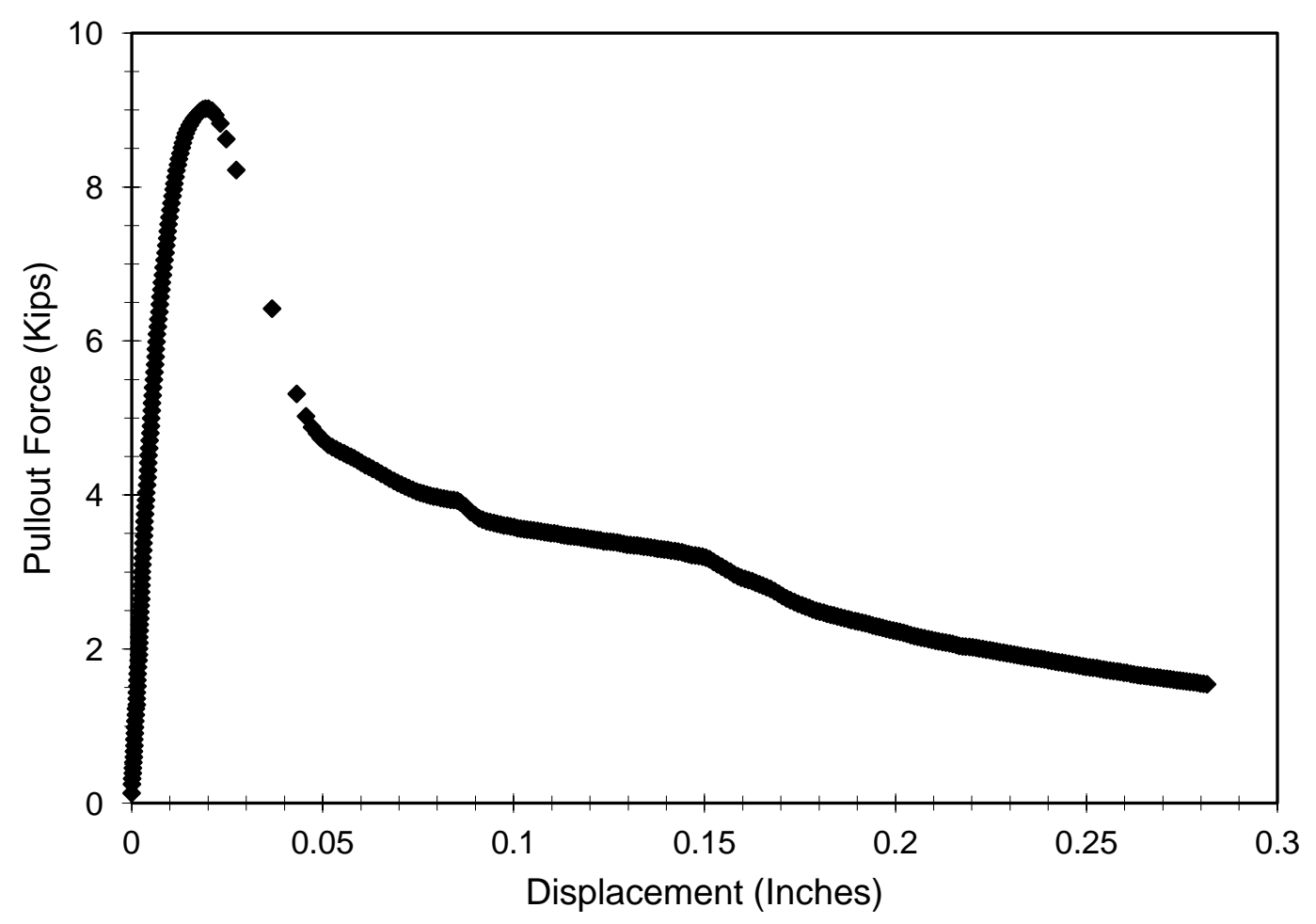

\section{Failure Pictures:}
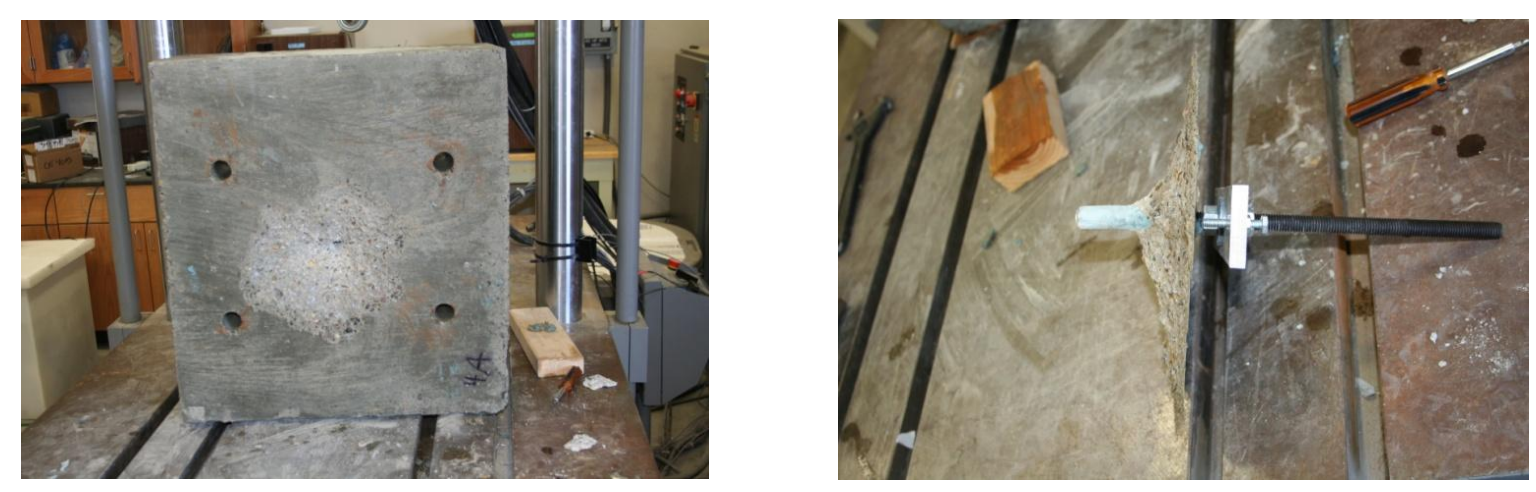

Notes: Type II failure, partial bond/cone failure 


\begin{tabular}{|c|c|c|c|c|c|}
\hline Test & Emb. Depth (Bar Dia.) & Drilled & Cleaned & Epoxy Injected & Epoxy \\
\hline $5 \mathrm{~A}$ & 6 & Dry & Dry & Dry & A \\
\hline
\end{tabular}

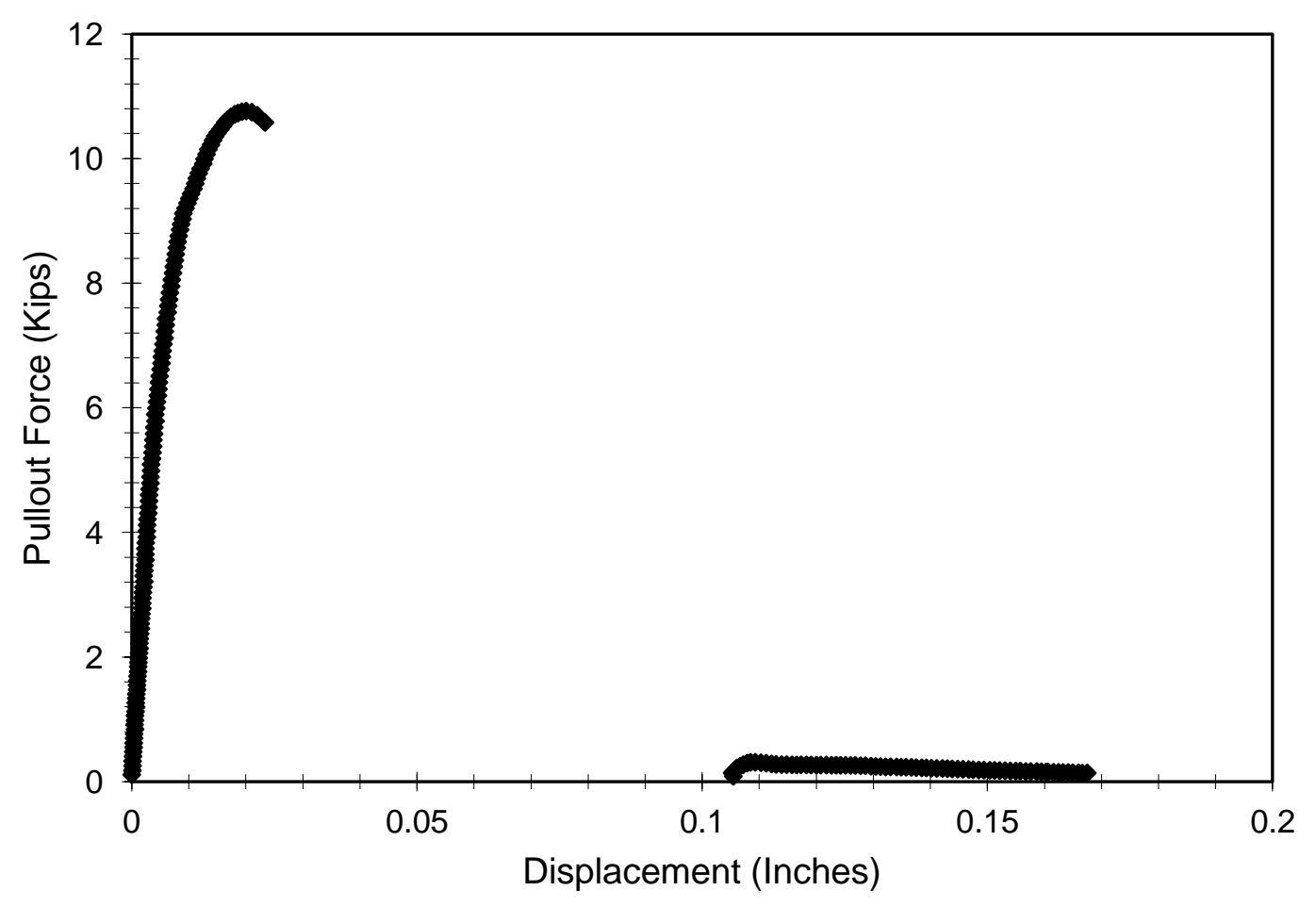

\section{Failure Pictures:}
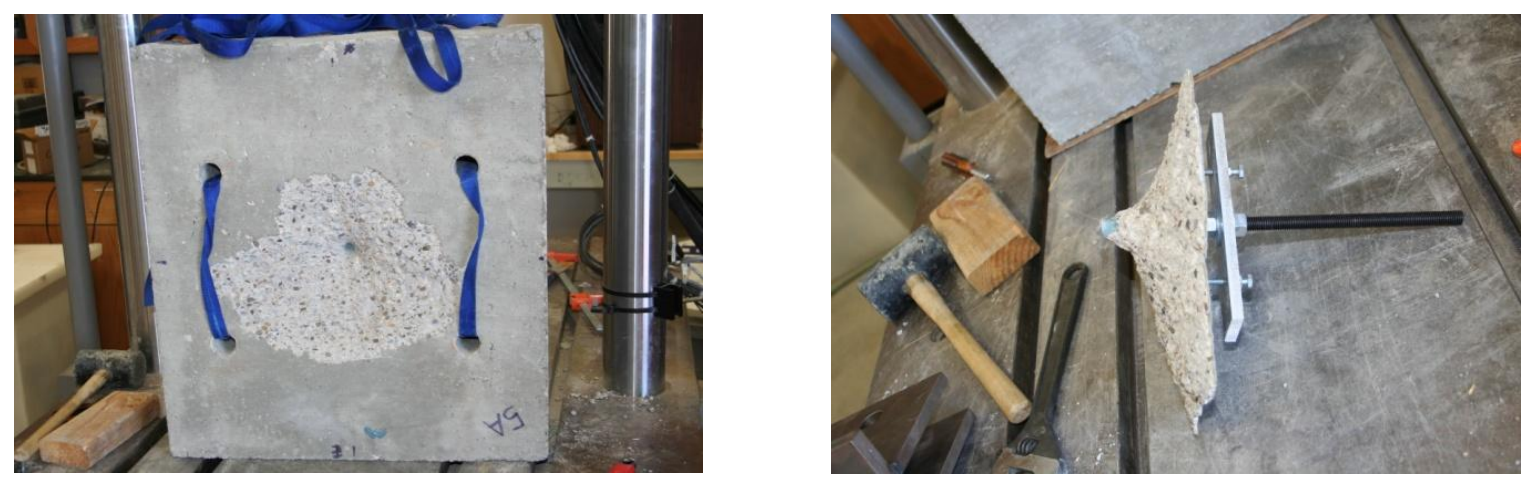

Notes: Type I failure 


\begin{tabular}{|c|c|c|c|c|c|}
\hline Test & Emb. Depth (Bar Dia.) & Drilled & Cleaned & Epoxy Injected & Epoxy \\
\hline 6A & 6 & Dry & Dry & Dry & A \\
\hline
\end{tabular}

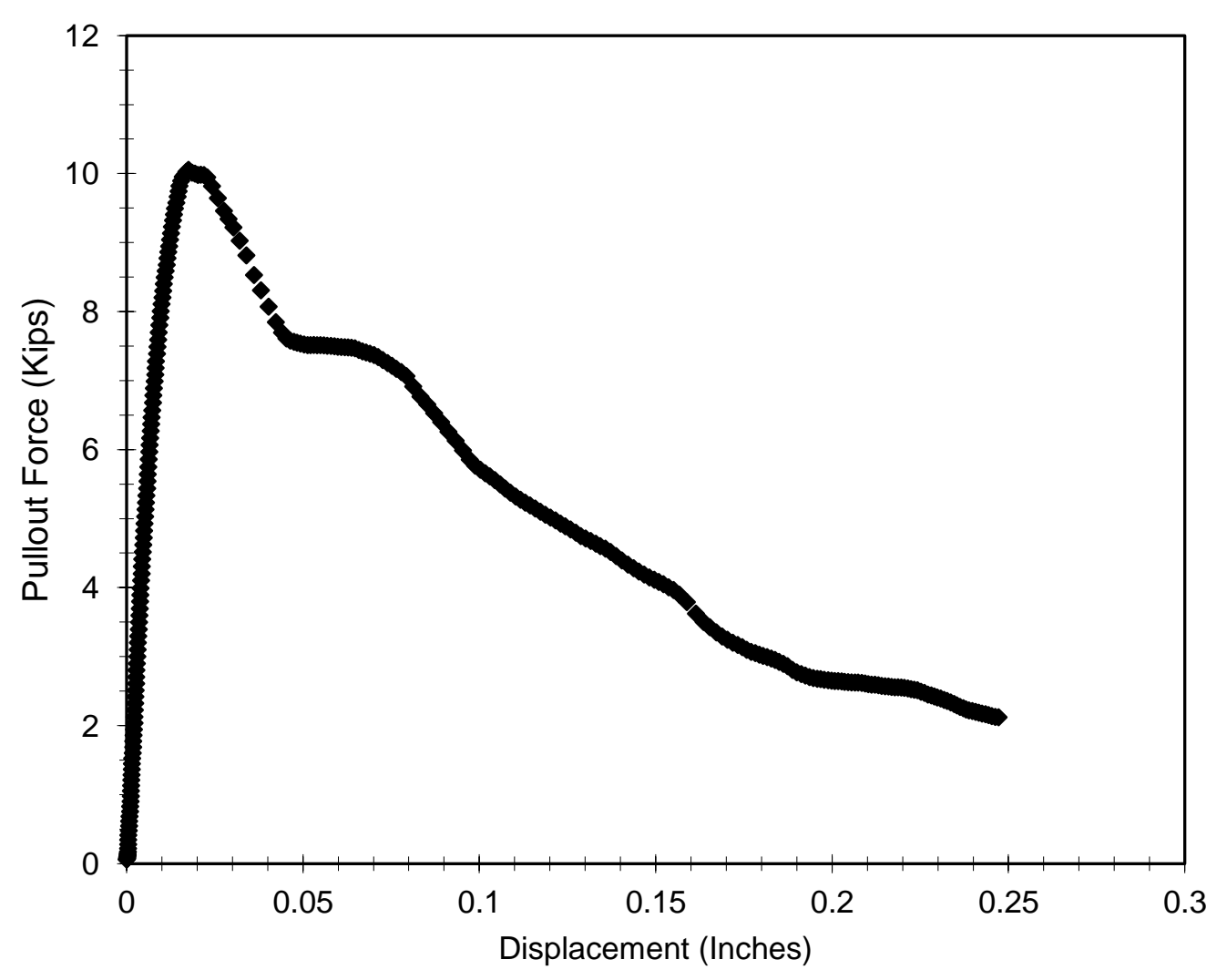

\section{Failure Pictures:}
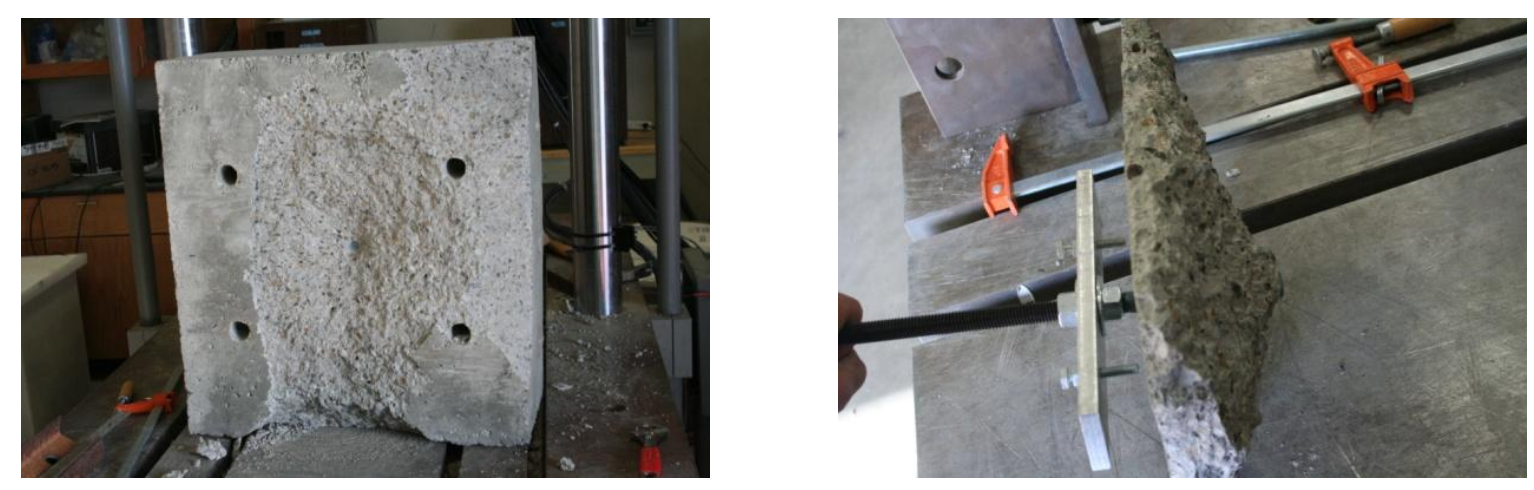

Notes: Type I failure, some damage to edges of block resulted in extra curve slope 


\begin{tabular}{|c|c|c|c|c|c|}
\hline Test & Emb. Depth (Bar Dia.) & Drilled & Cleaned & Epoxy Injected & Epoxy \\
\hline $7 \mathrm{~A}$ & 6 & Wet & Wet & Wet & A \\
\hline
\end{tabular}

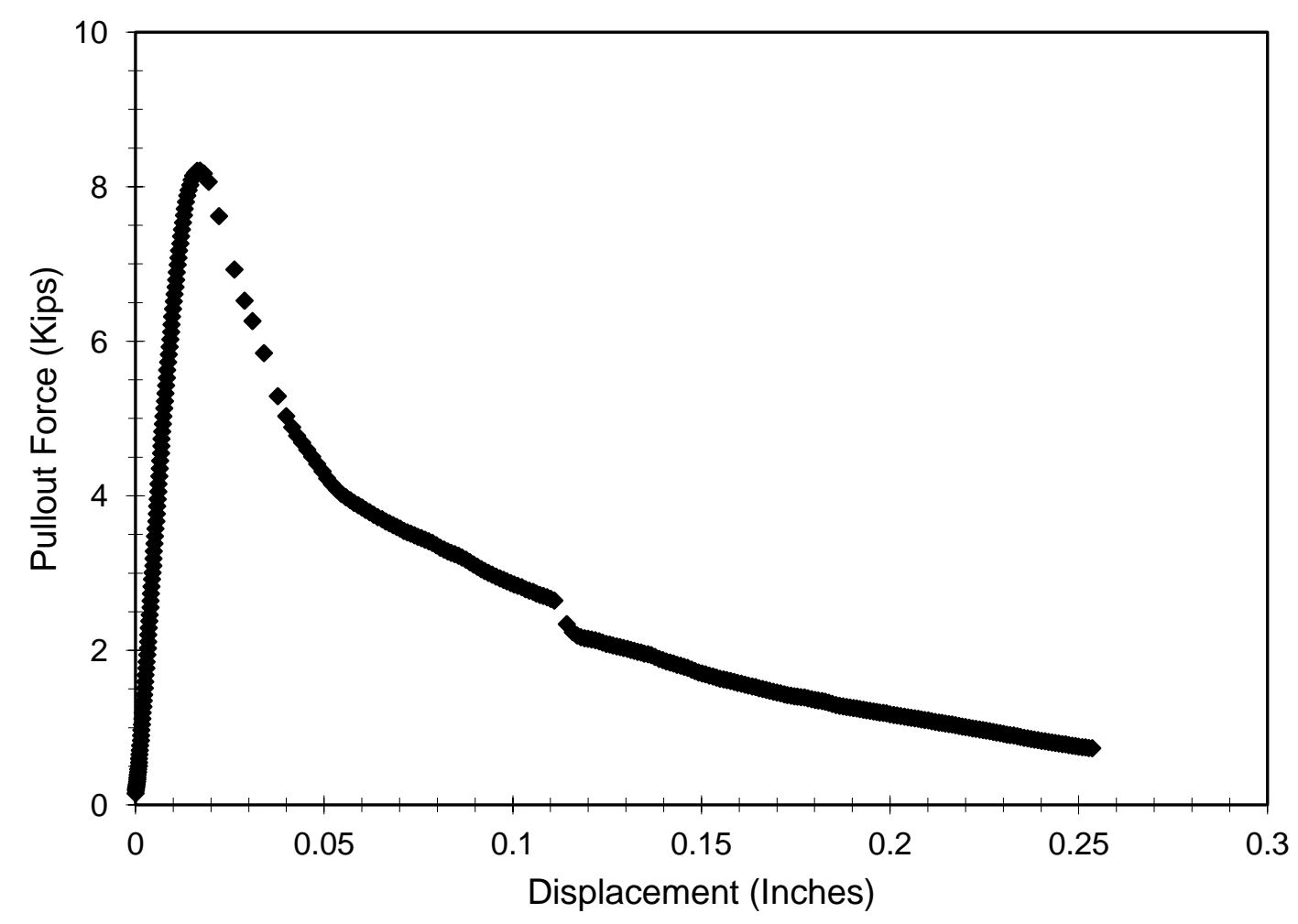

\section{Failure Pictures:}
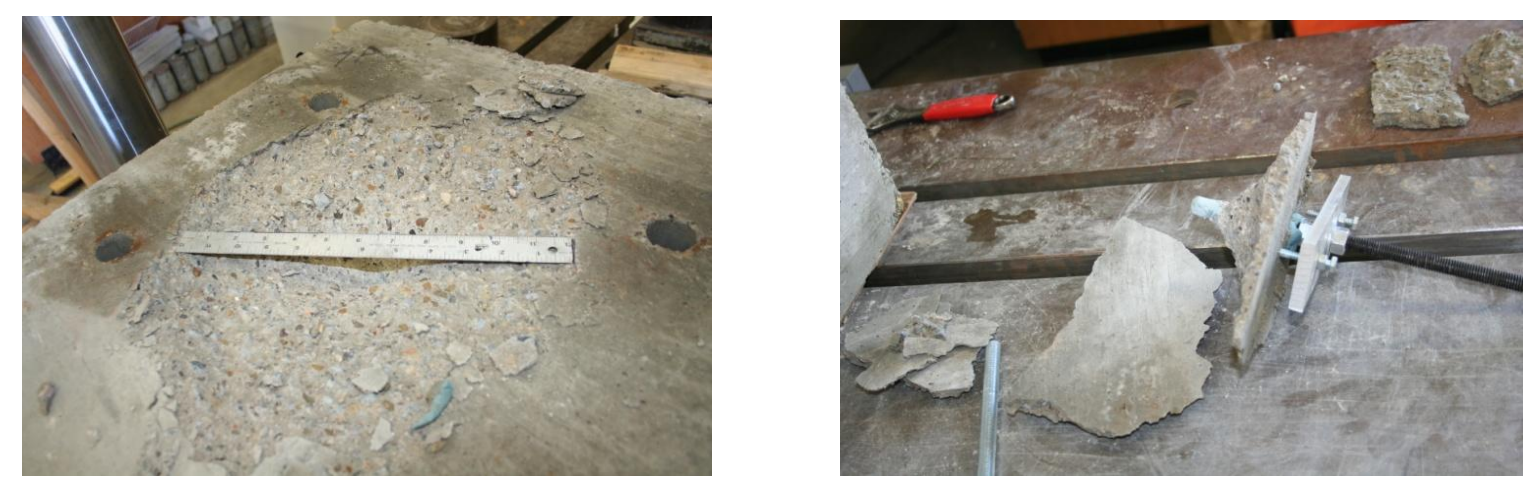

Notes: Type II failure 


\begin{tabular}{|c|c|c|c|c|c|}
\hline Test & Emb. Depth (Bar Dia.) & Drilled & Cleaned & Epoxy Injected & Epoxy \\
\hline $8 \mathrm{~A}$ & 6 & Wet & Wet & Wet & A \\
\hline
\end{tabular}

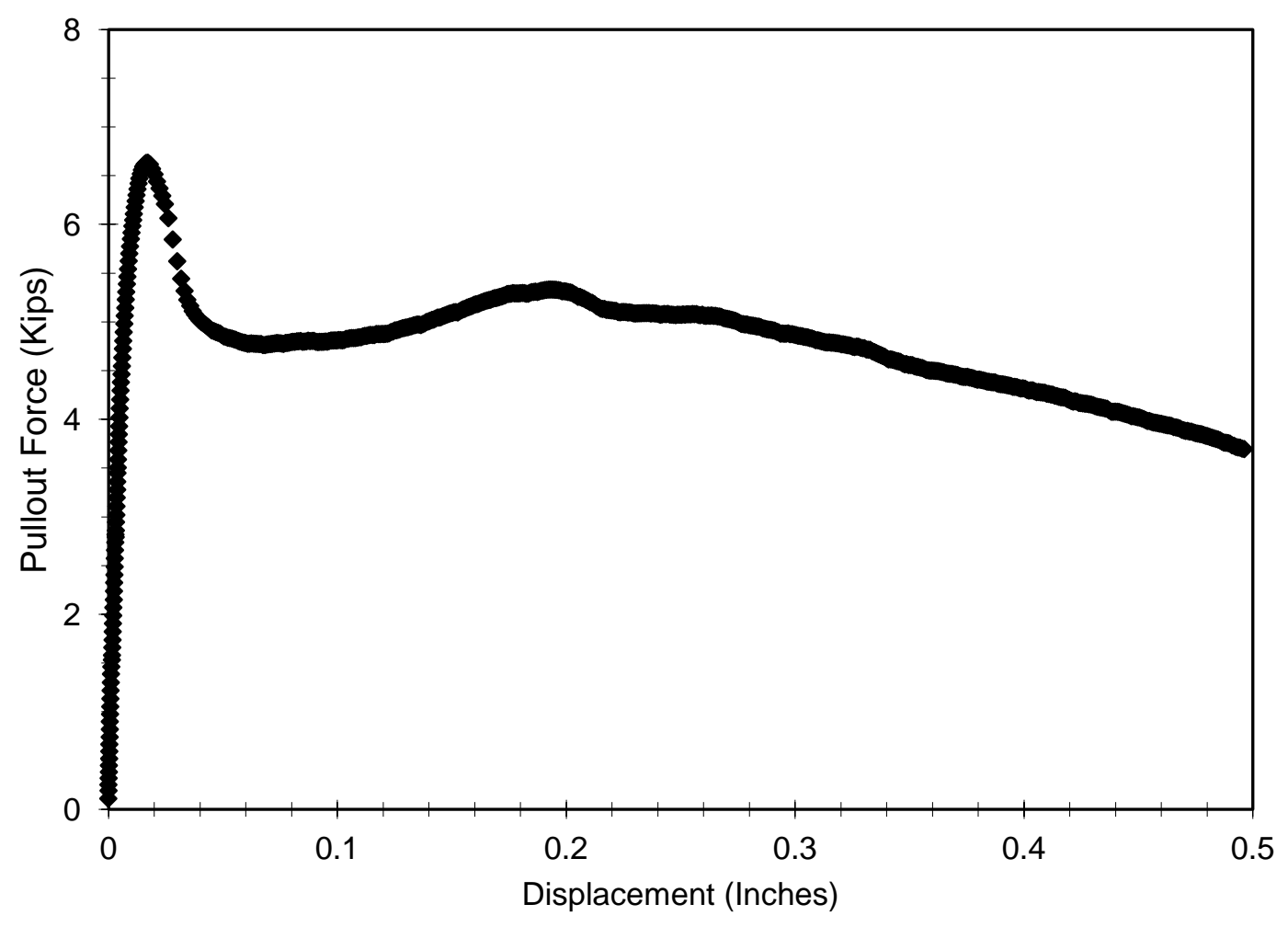

\section{Failure Pictures:}
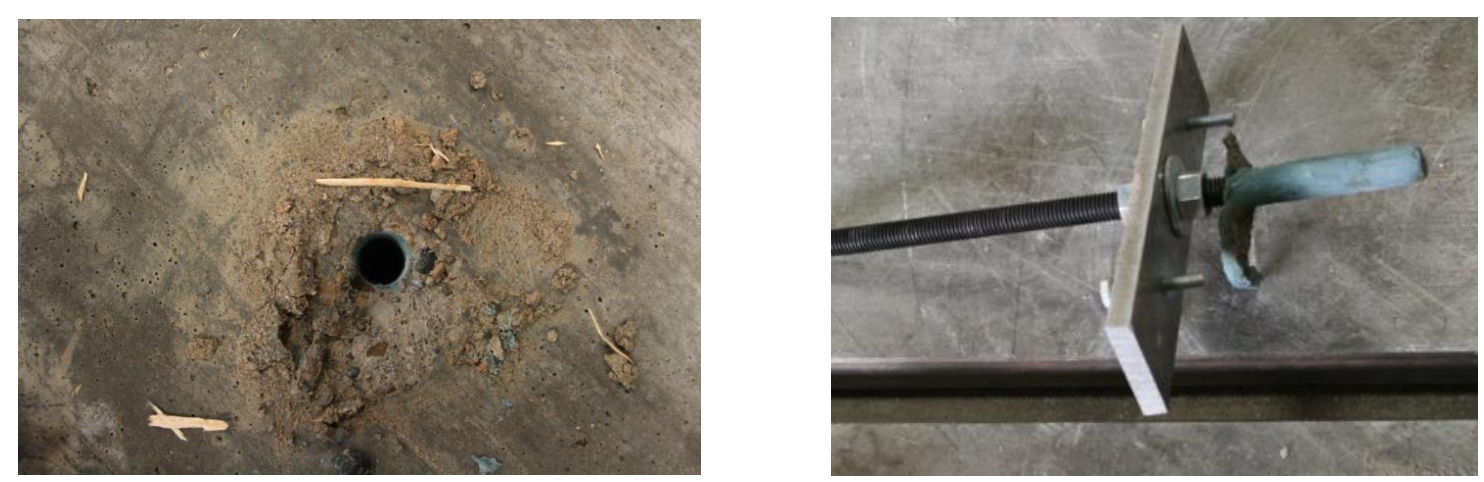

Notes: Type II complete bond failure 


\begin{tabular}{|c|c|c|c|c|c|}
\hline Test & Emb. Depth (Bar Dia.) & Drilled & Cleaned & Epoxy Injected & Epoxy \\
\hline $9 \mathrm{~A}$ & 4 & Dry & Dry & Dry & A \\
\hline
\end{tabular}

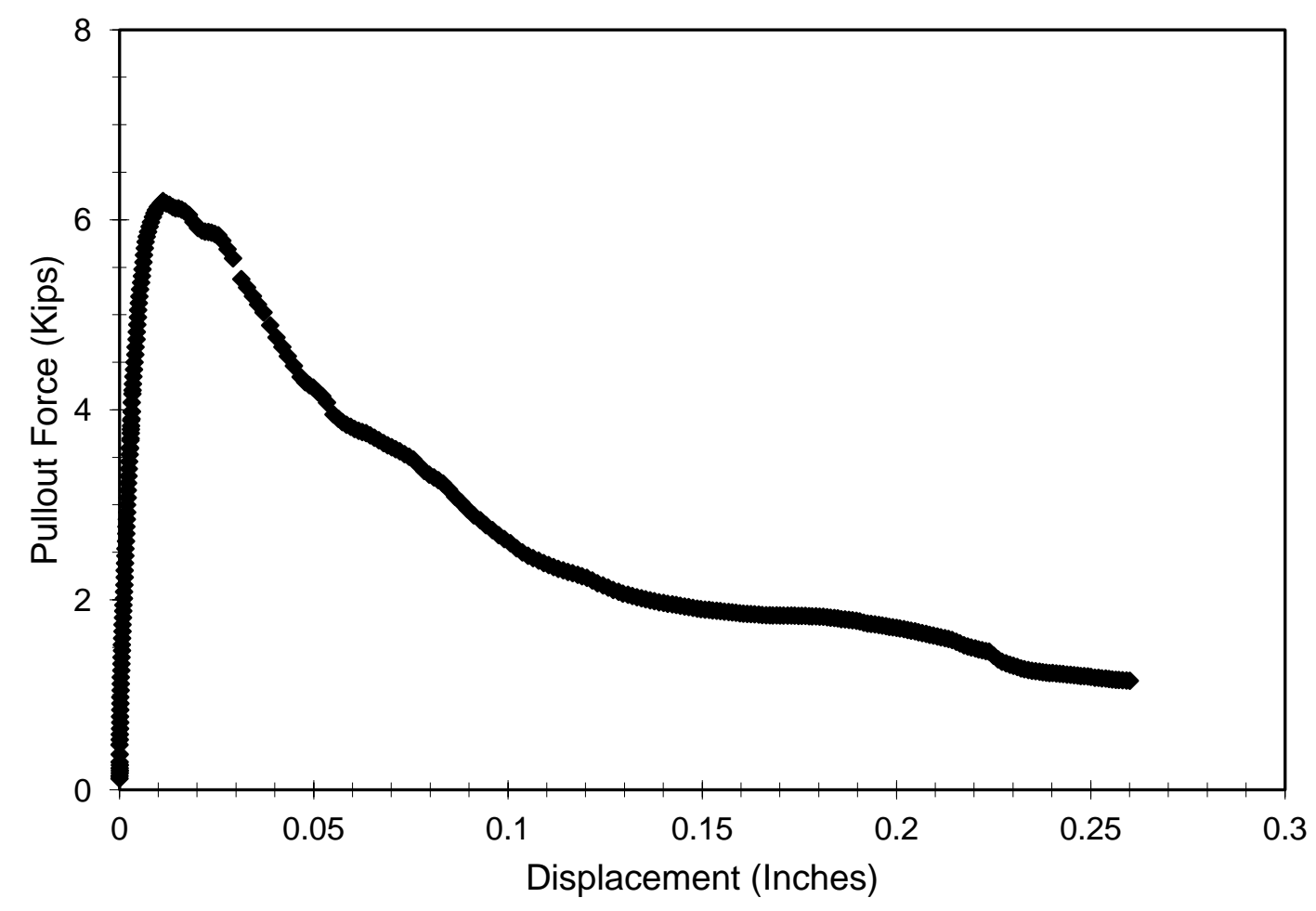

\section{Failure Pictures:}

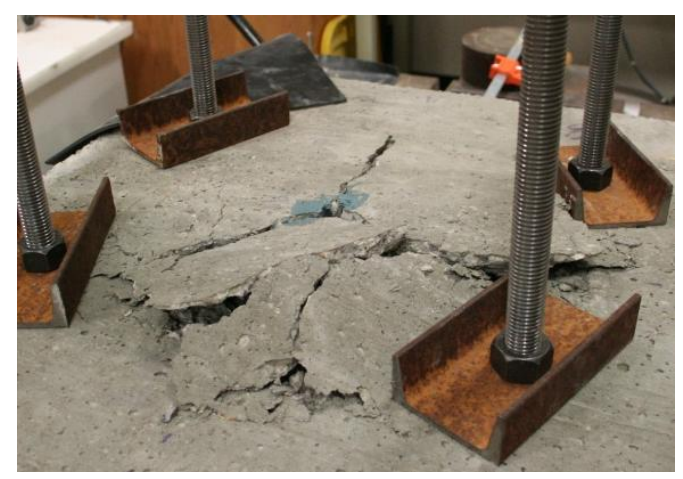

Notes: Type I failure 


\begin{tabular}{|c|c|c|c|c|c|}
\hline Test & Emb. Depth (Bar Dia.) & Drilled & Cleaned & Epoxy Injected & Epoxy \\
\hline $10 \mathrm{~A}$ & 4 & Dry & Dry & Dry & A \\
\hline
\end{tabular}

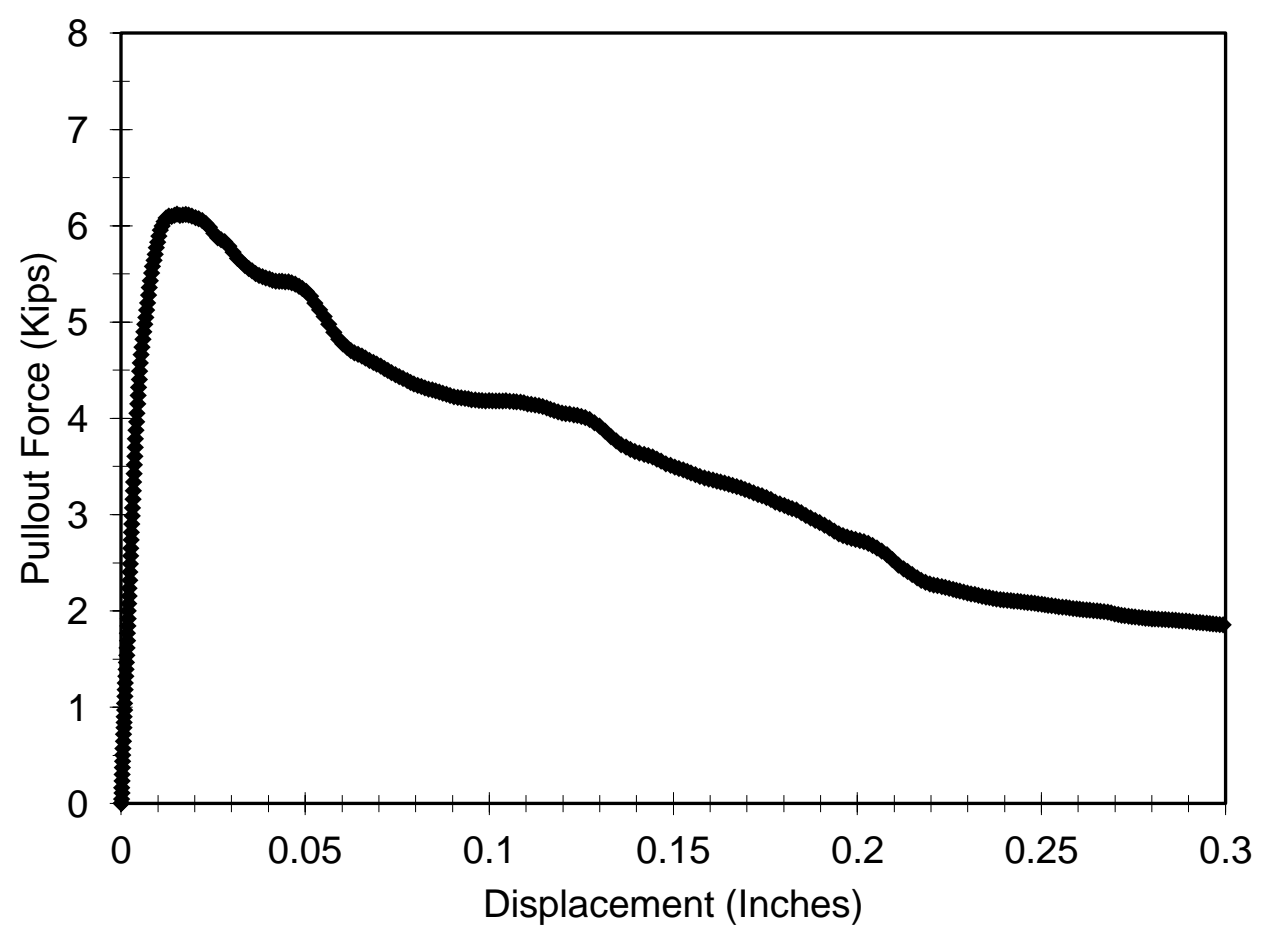

\section{Failure Pictures:}
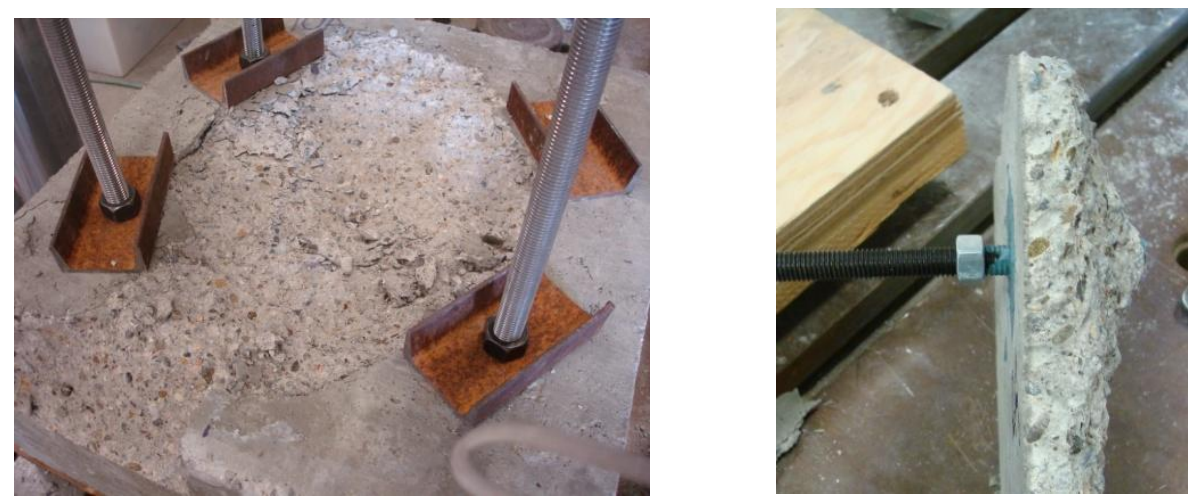

Notes: Type I failure, cone failure extended to the edge of the block 


\begin{tabular}{|c|c|c|c|c|c|}
\hline Test & Emb. Depth (Bar Dia.) & Drilled & Cleaned & Epoxy Injected & Epoxy \\
\hline $11 \mathrm{~A}$ & 4 & Wet & Wet & Wet & A \\
\hline
\end{tabular}

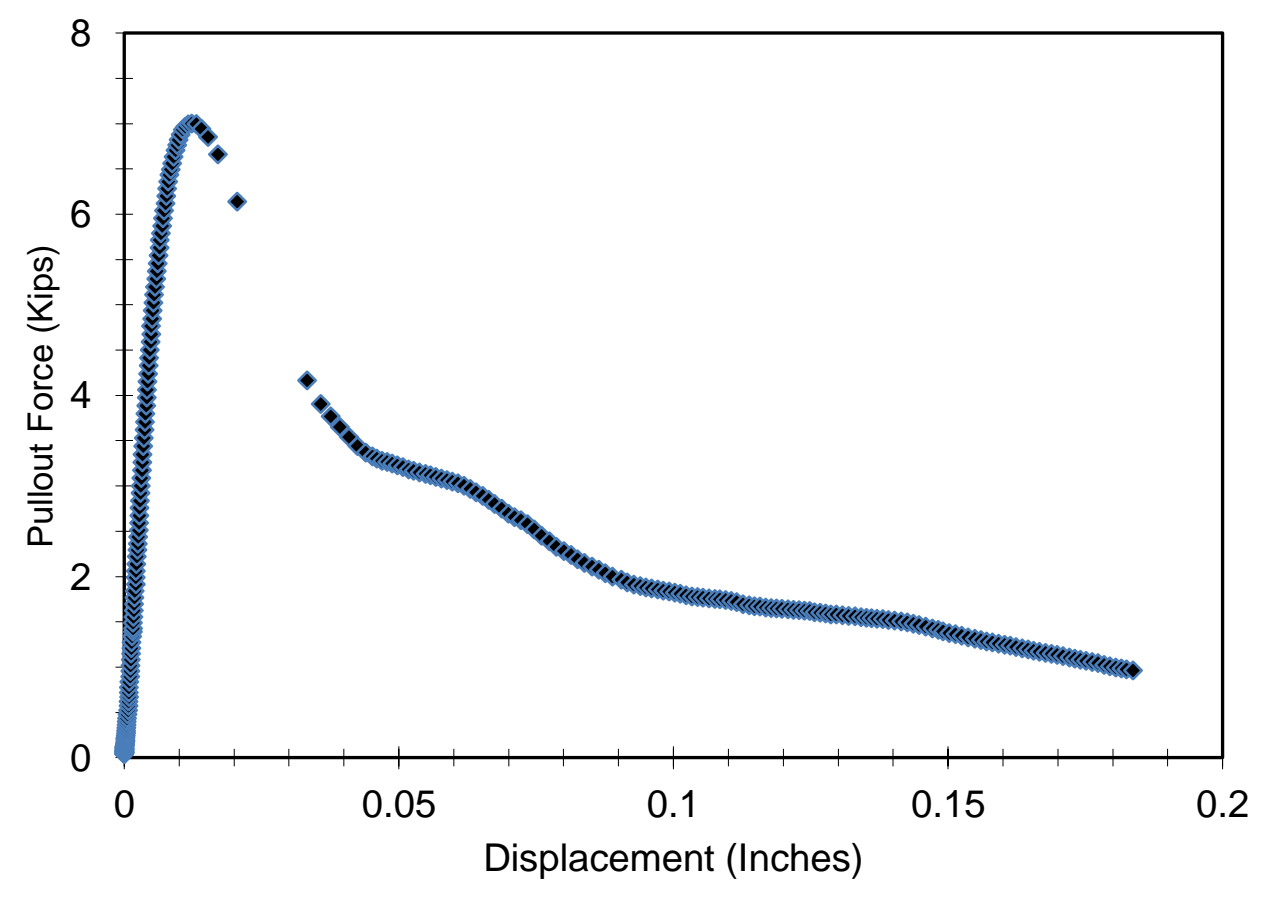

\section{Failure Pictures:}
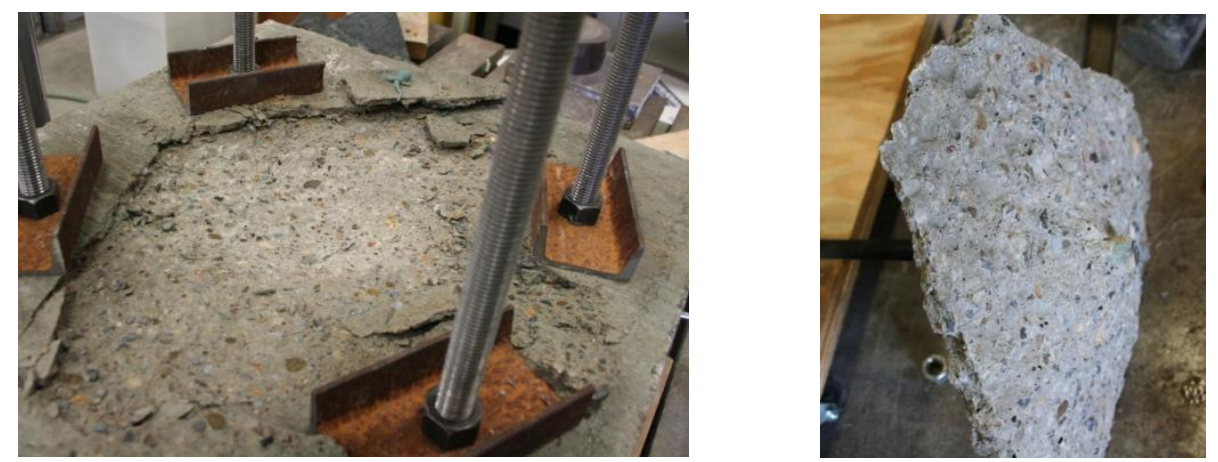

Notes: Type I failure 


\begin{tabular}{|c|c|c|c|c|c|}
\hline Test & Emb. Depth (Bar Dia.) & Drilled & Cleaned & Epoxy Injected & Epoxy \\
\hline $12 \mathrm{~A}$ & 4 & Wet & Wet & Wet & A \\
\hline
\end{tabular}

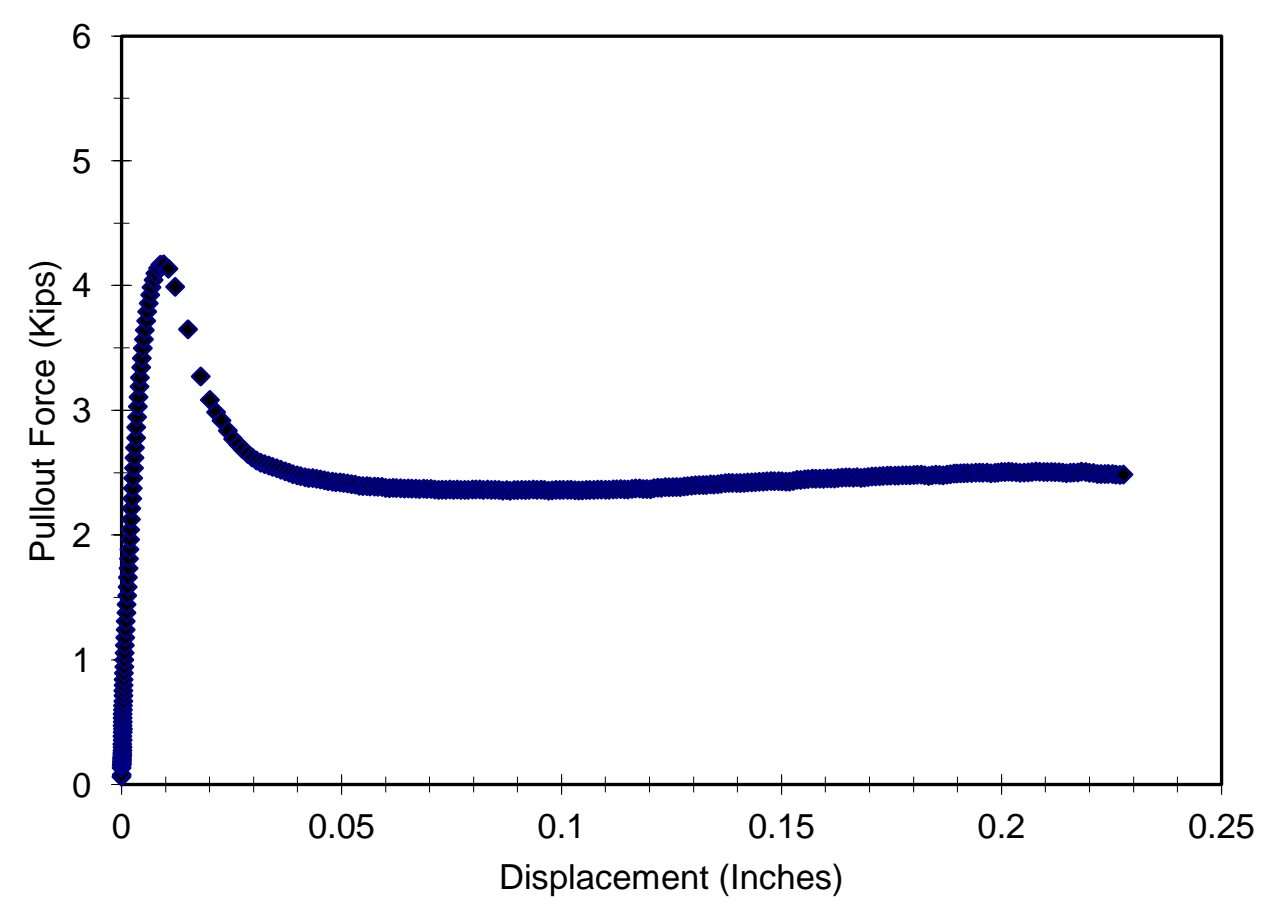

\section{Failure Pictures:}

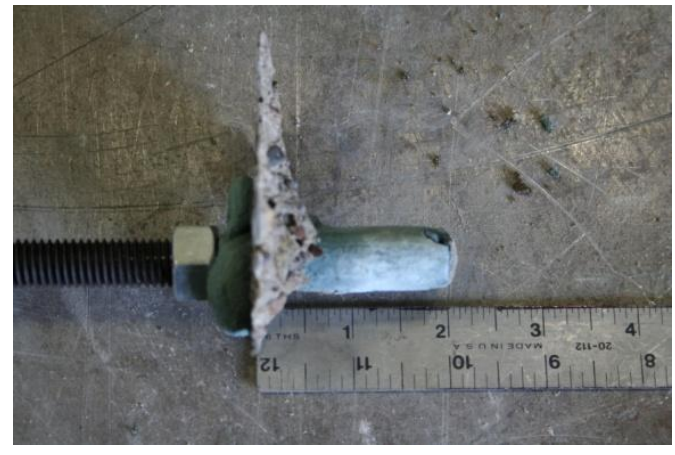

Notes: Type II failure, complete bond failure 


\begin{tabular}{|c|c|c|c|c|c|}
\hline Test & Emb. Depth (Bar Dia.) & Drilled & Cleaned & Epoxy Injected & Epoxy \\
\hline $13 \mathrm{~A}$ & 2 & Dry & Dry & Dry & A \\
\hline
\end{tabular}

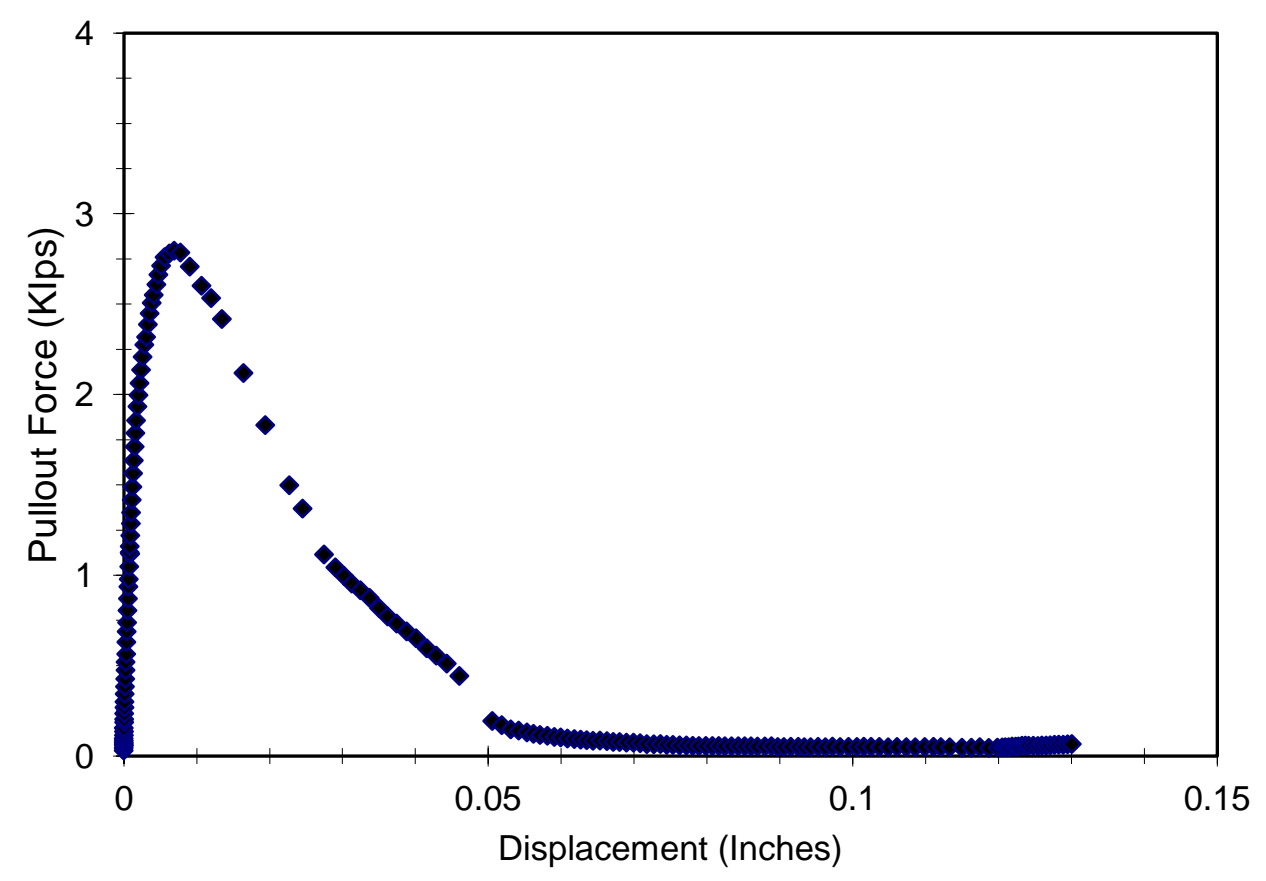

\section{Failure Pictures:}

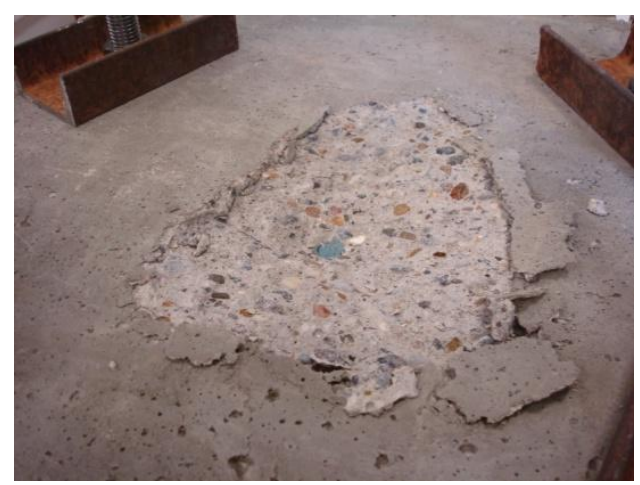

Notes: Type I failure 


\begin{tabular}{|c|c|c|c|c|c|}
\hline Test & Emb. Depth (Bar Dia.) & Drilled & Cleaned & Epoxy Injected & Epoxy \\
\hline $14 \mathrm{~A}$ & 2 & Dry & Dry & Dry & A \\
\hline
\end{tabular}

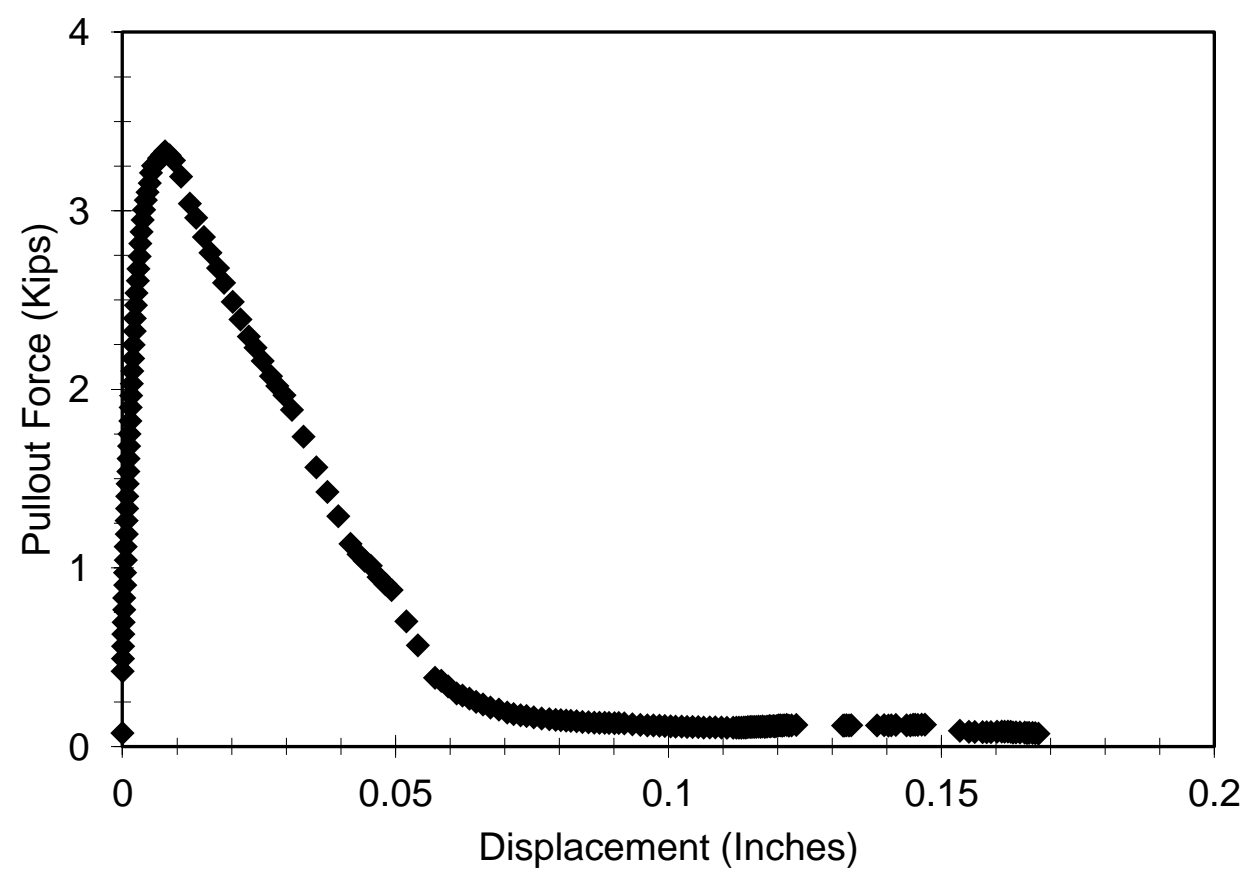

Failure Pictures:

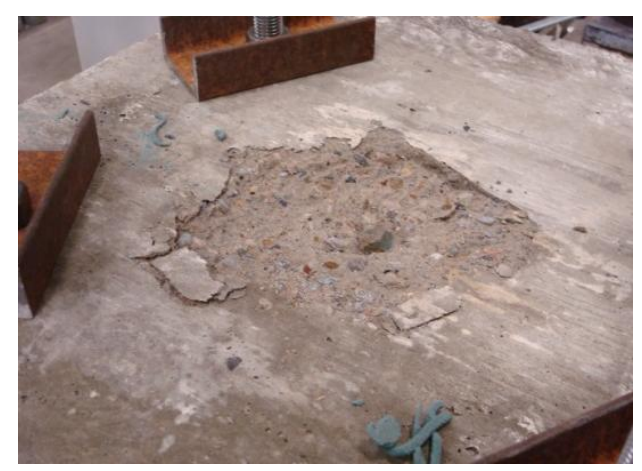

Notes: Type I failure 


\begin{tabular}{|c|c|c|c|c|c|}
\hline Test & Emb. Depth (Bar Dia.) & Drilled & Cleaned & Epoxy Injected & Epoxy \\
\hline $15 \mathrm{~A}$ & 2 & Wet & Wet & Wet & A \\
\hline
\end{tabular}

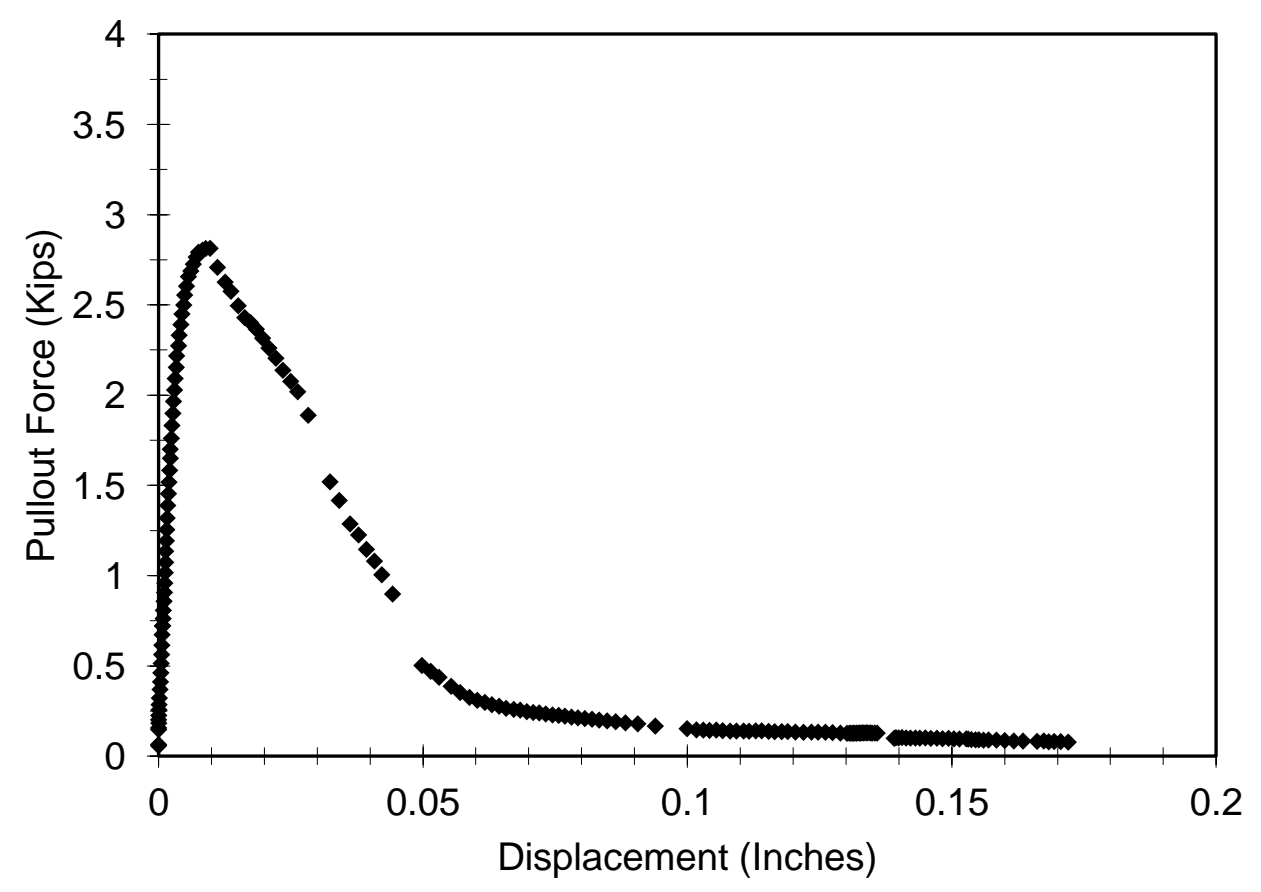

\section{Failure Pictures:}
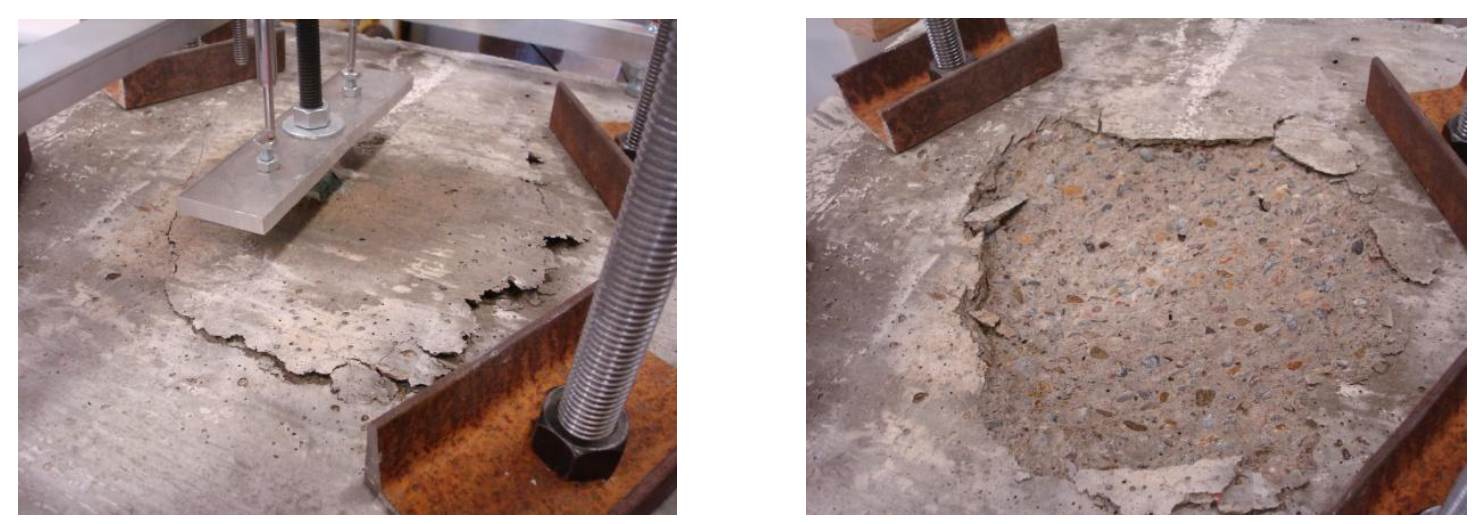

Notes: Type I failure 


\begin{tabular}{|c|c|c|c|c|c|}
\hline Test & Emb. Depth (Bar Dia.) & Drilled & Cleaned & Epoxy Injected & Epoxy \\
\hline $16 \mathrm{~A}$ & 2 & Wet & Wet & Wet & A \\
\hline
\end{tabular}

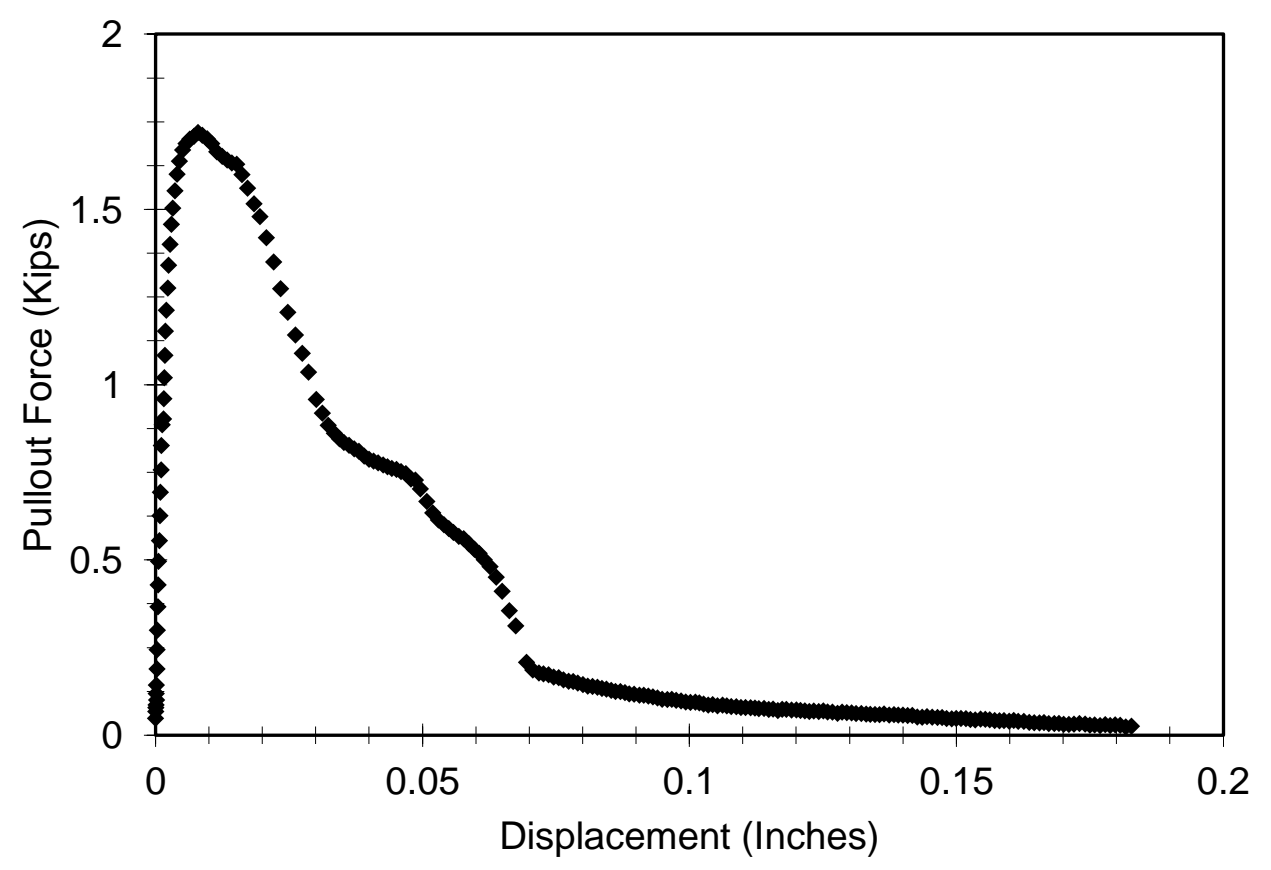

\section{Failure Pictures:}

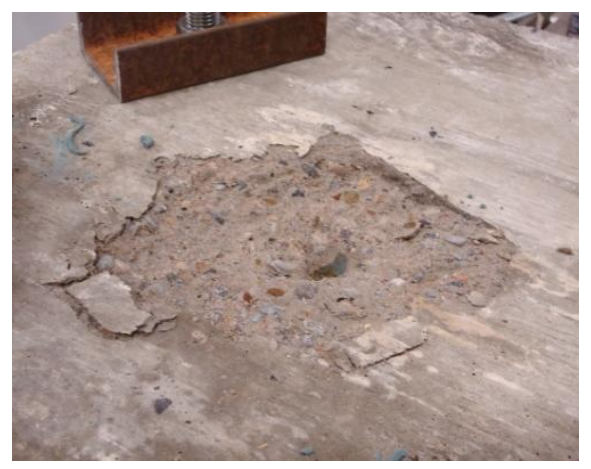

Notes: Type II failure, some limited bond failure with drilling residue on the bottom 


\begin{tabular}{|c|c|c|c|c|c|}
\hline Test & Emb. Depth (Bar Dia.) & Drilled & Cleaned & Epoxy Injected & Epoxy \\
\hline 1B & 6 & Dry & Dry & Wet & A \\
\hline
\end{tabular}

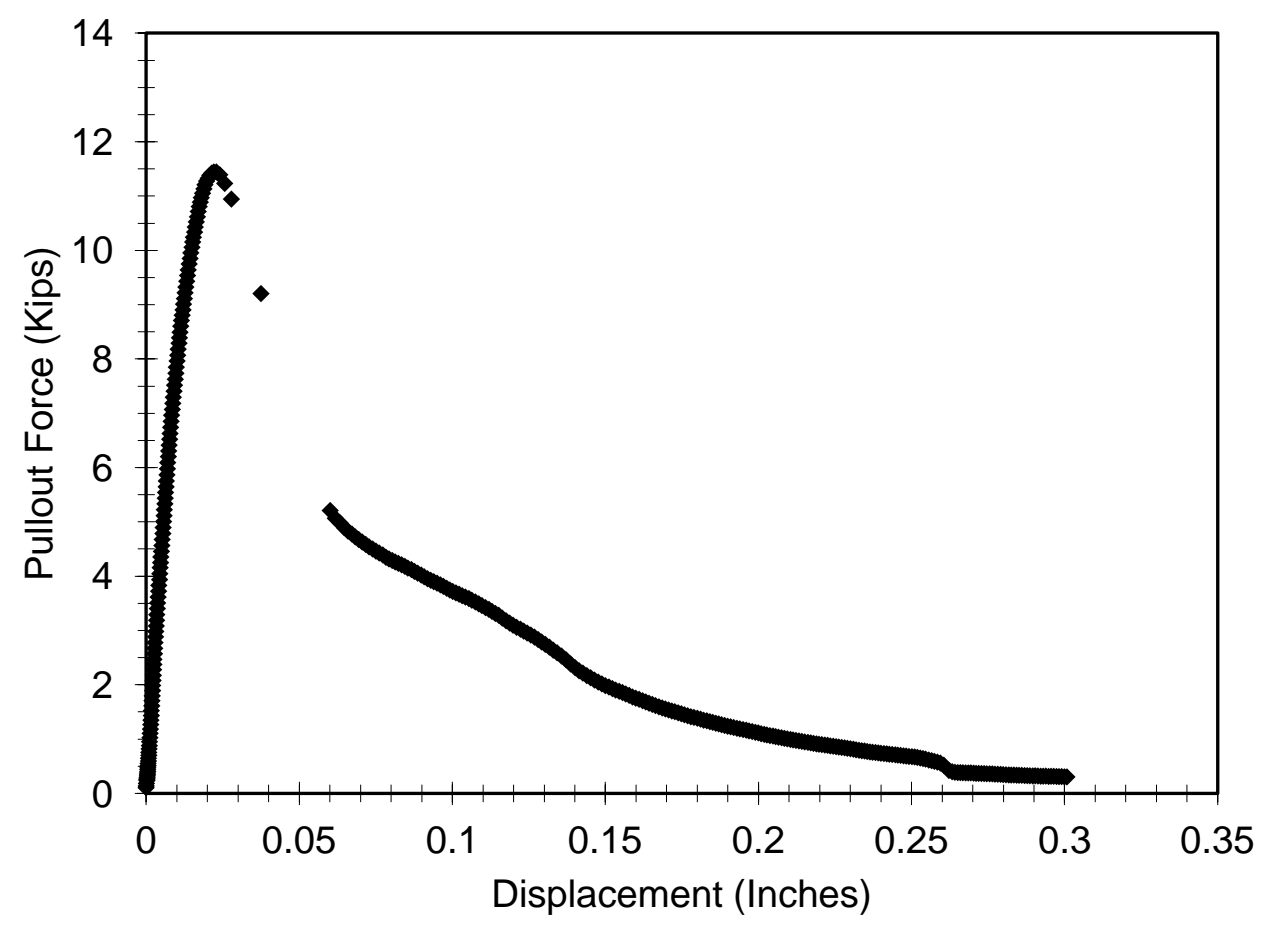

\section{Failure Pictures:}

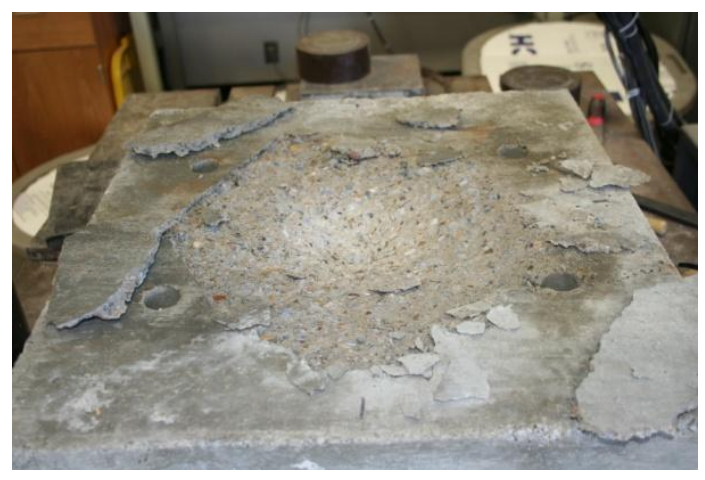

Notes: Type I failure 


\begin{tabular}{|c|c|c|c|c|c|}
\hline Test & Emb. Depth (Bar Dia.) & Drilled & Cleaned & Epoxy Injected & Epoxy \\
\hline 3B & 6 & Wet & Wet & Wet & B \\
\hline
\end{tabular}

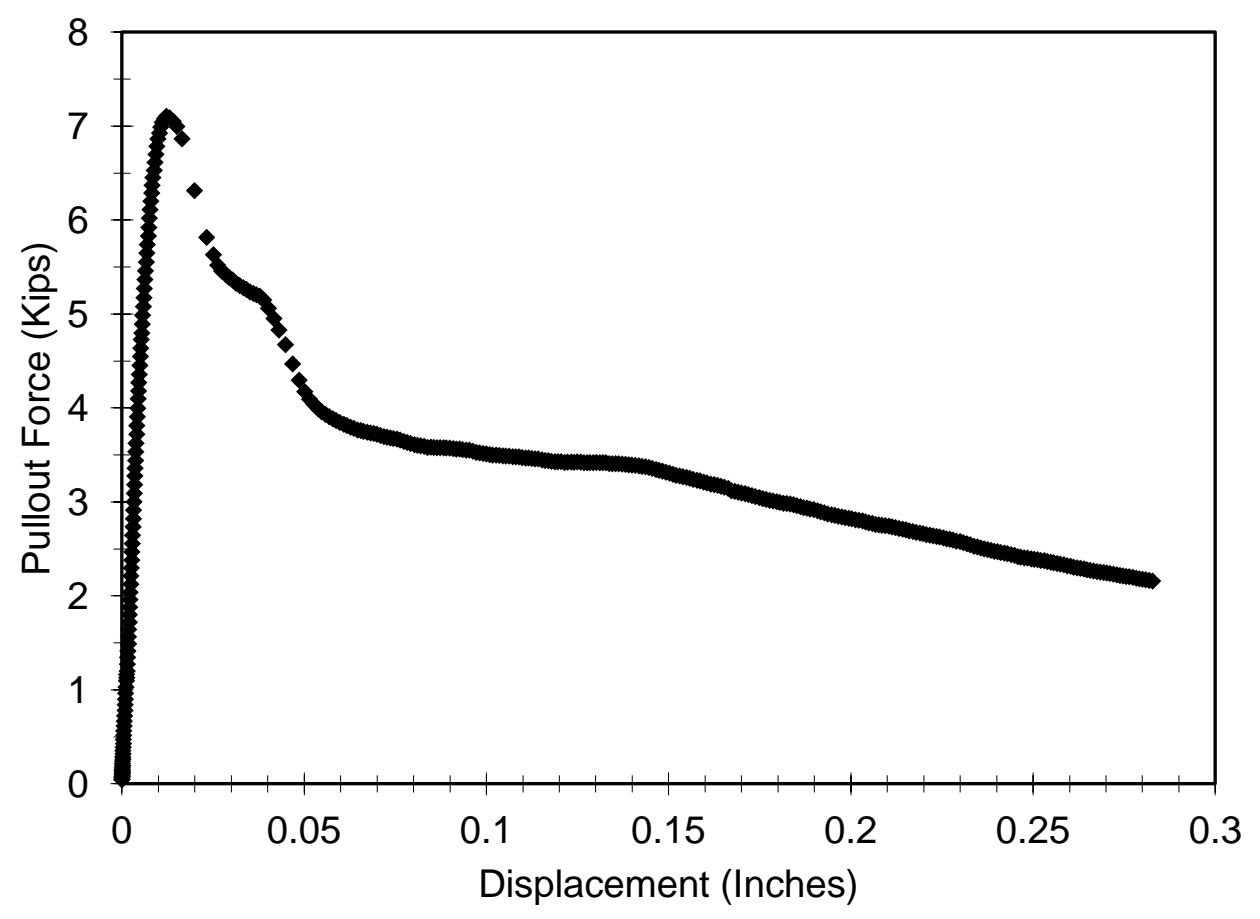

\section{Failure Pictures:}

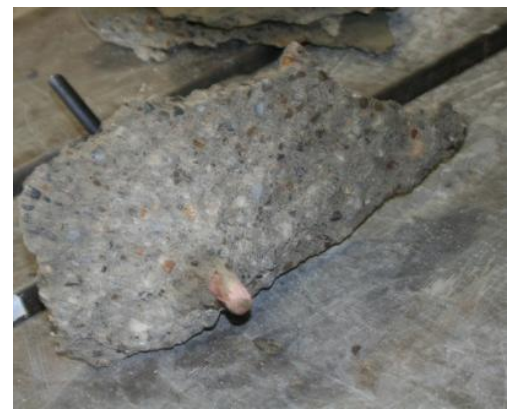

Notes: Type II failure 


\begin{tabular}{|c|c|c|c|c|c|}
\hline Test & Emb. Depth (Bar Dia.) & Drilled & Cleaned & Epoxy Injected & Epoxy \\
\hline 4B & 6 & Dry & Dry & Wet & A \\
\hline
\end{tabular}

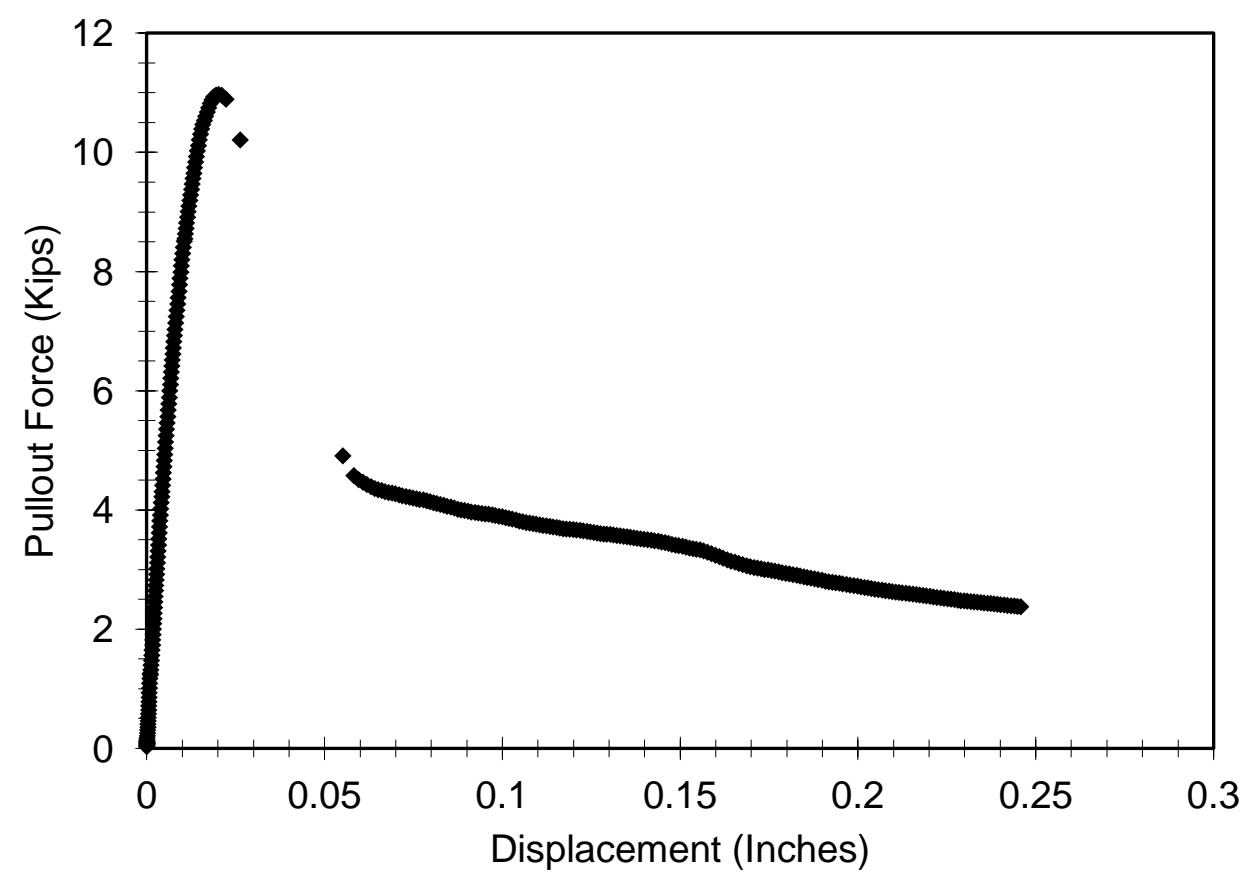

\section{Failure Pictures:}

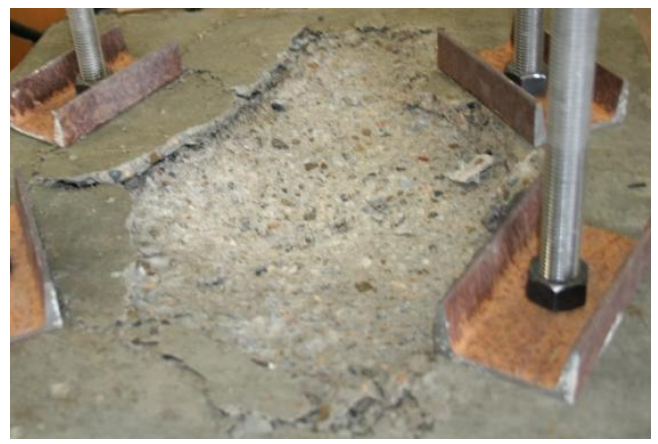

Notes: Type I failure 


\begin{tabular}{|c|c|c|c|c|c|}
\hline Test & Emb. Depth (Bar Dia.) & Drilled & Cleaned & Epoxy Injected & Epoxy \\
\hline 5B & 6 & Dry & Dry & Dry & B \\
\hline
\end{tabular}

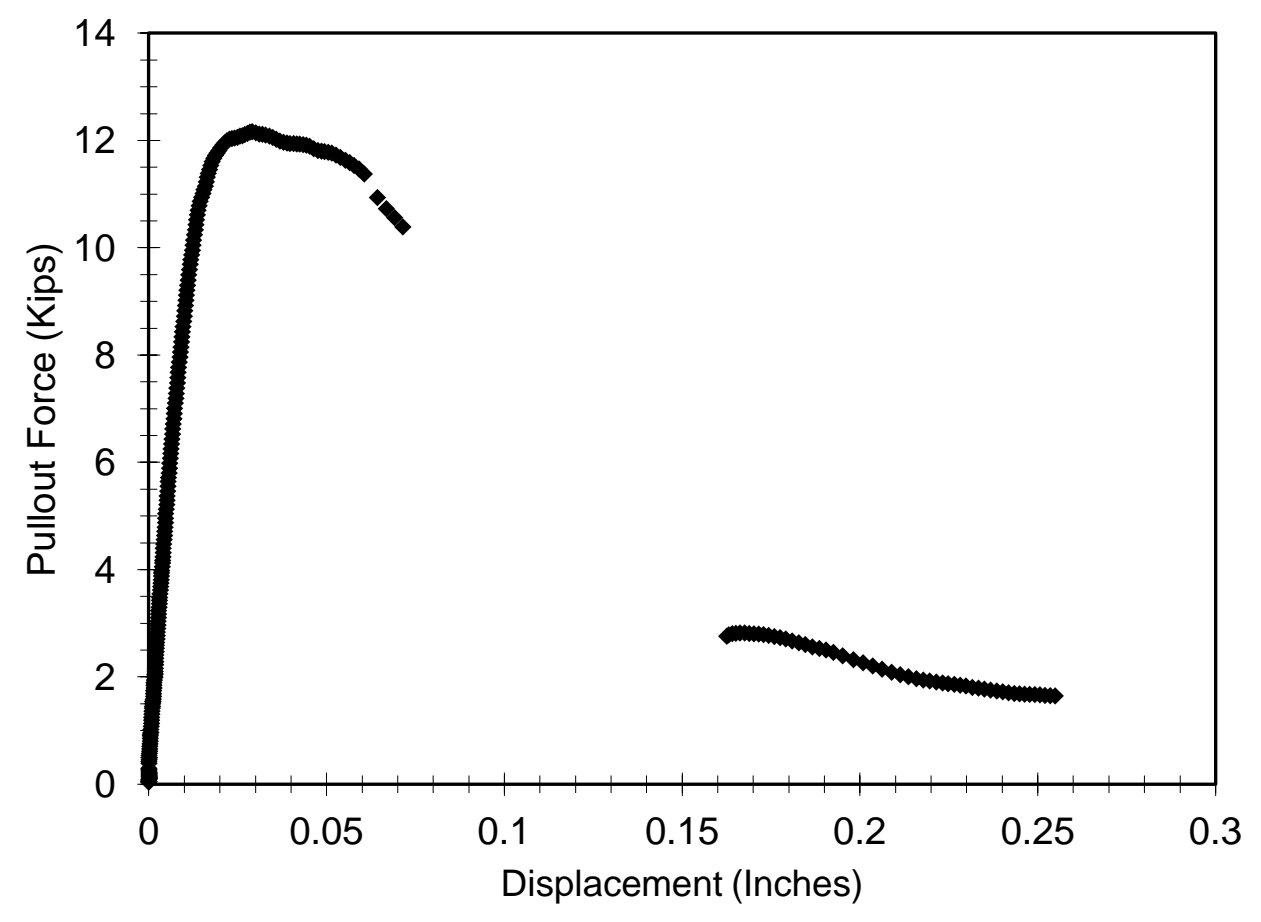

\section{Failure Pictures:}

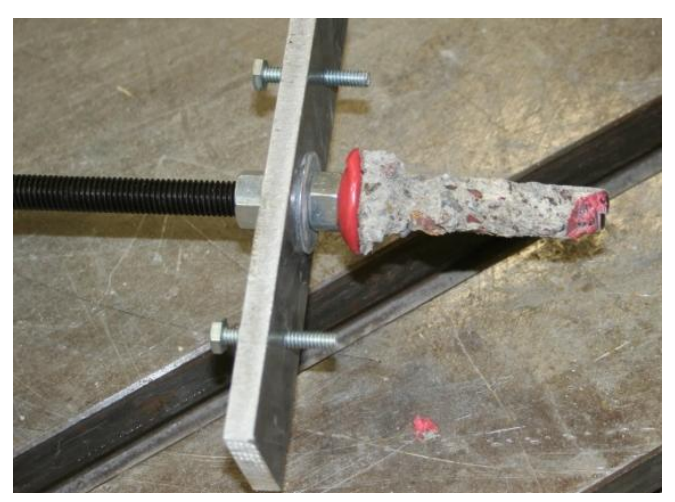

Notes: Type I failure, block failure due to reverse side damage, good bond 


\begin{tabular}{|c|c|c|c|c|c|}
\hline Test & Emb. Depth (Bar Dia.) & Drilled & Cleaned & Epoxy Injected & Epoxy \\
\hline 7B & 6 & Wet & Wet & Wet & B \\
\hline
\end{tabular}

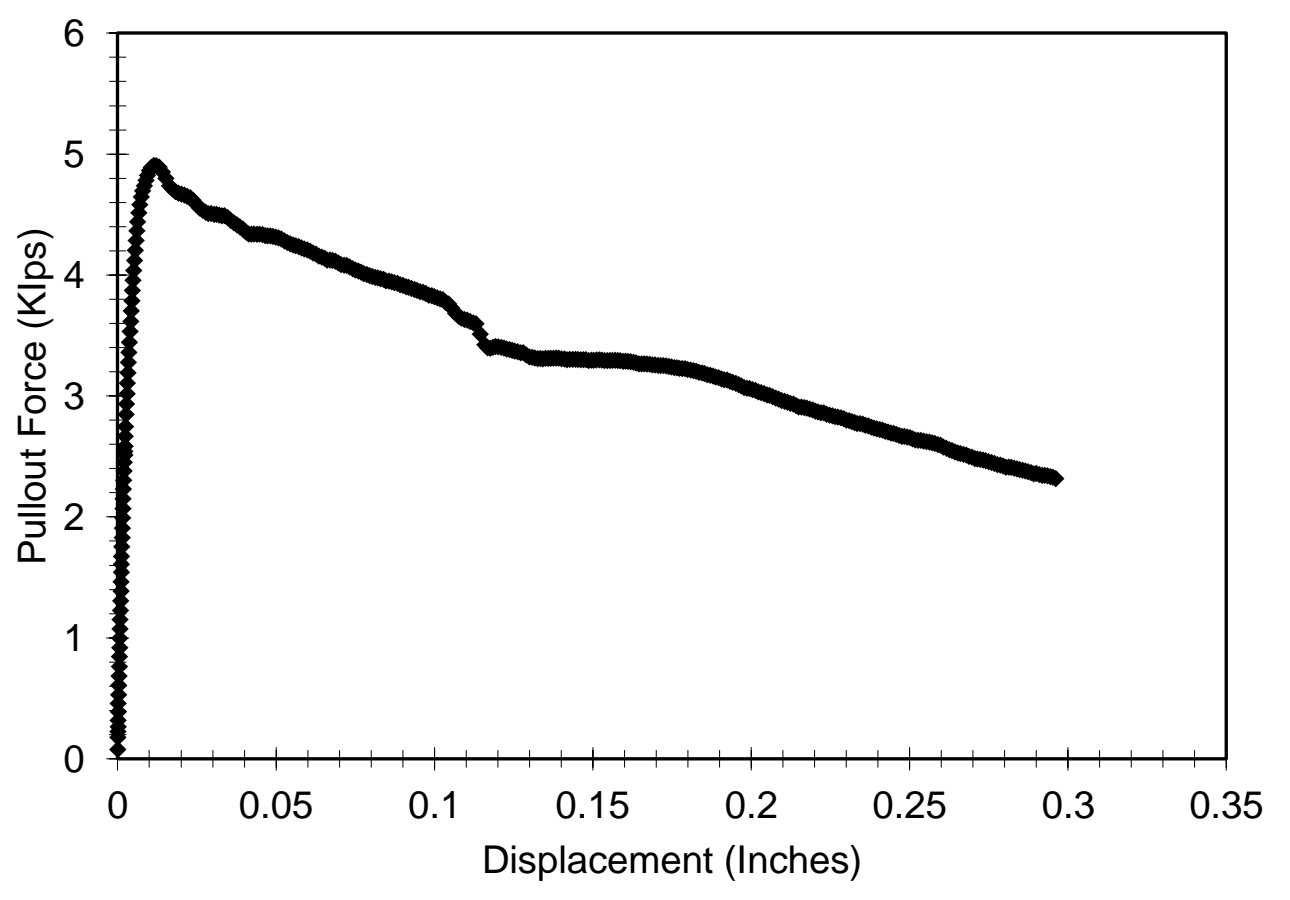

Failure Pictures:
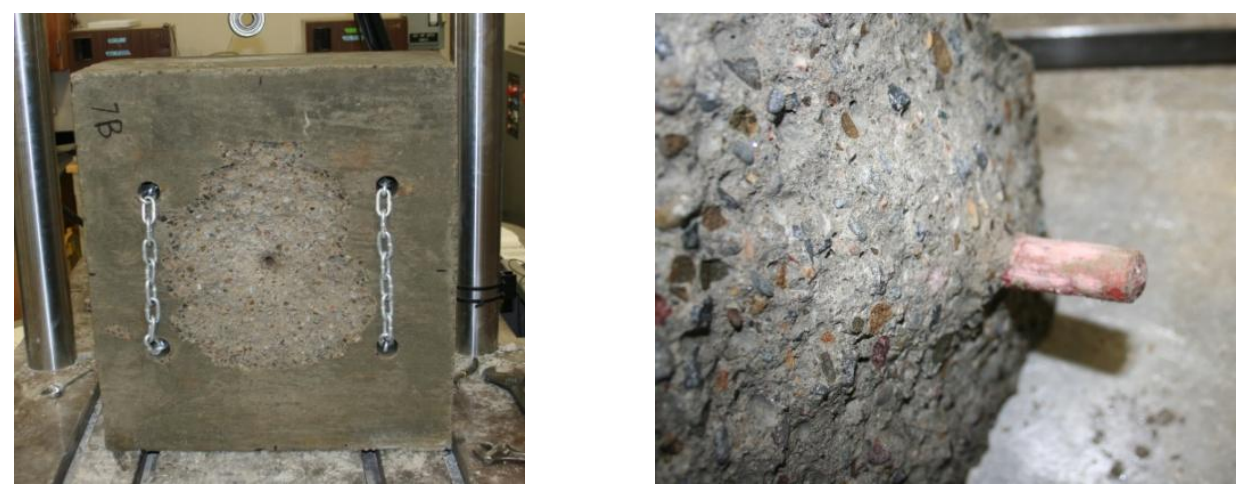

Notes: Mixed cone bond failure 


\begin{tabular}{|c|c|c|c|c|c|}
\hline Test & Emb. Depth (Bar Dia.) & Drilled & Cleaned & Epoxy Injected & Epoxy \\
\hline 8B & 6 & Dry & Dry & Dry & B \\
\hline
\end{tabular}

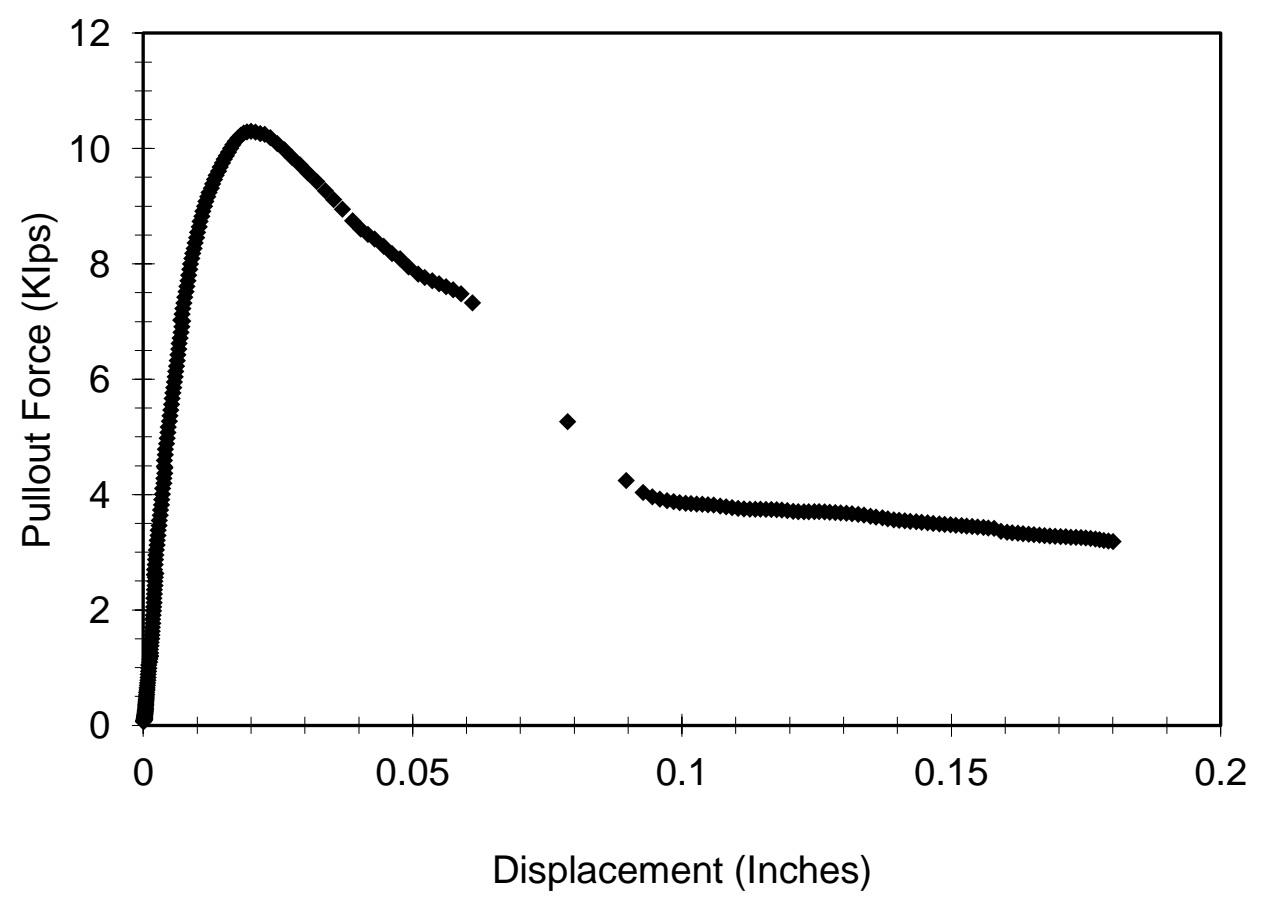

\section{Failure Pictures:}

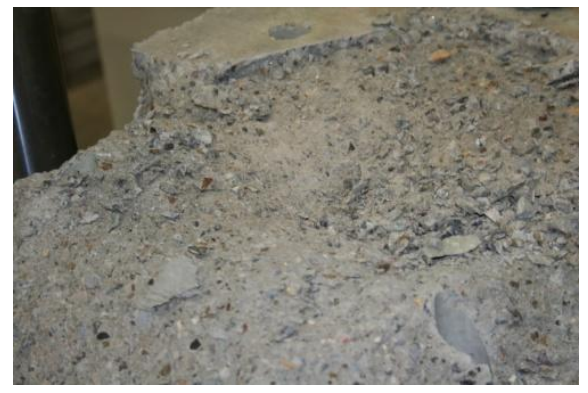

Notes: Type I, Block failure resulted in extended curve 


\begin{tabular}{|c|c|c|c|c|c|}
\hline Test & Emb. Depth (Bar Dia.) & Drilled & Cleaned & Epoxy Injected & Epoxy \\
\hline 11B & 9 & Dry & Dry & Wet & A \\
\hline
\end{tabular}

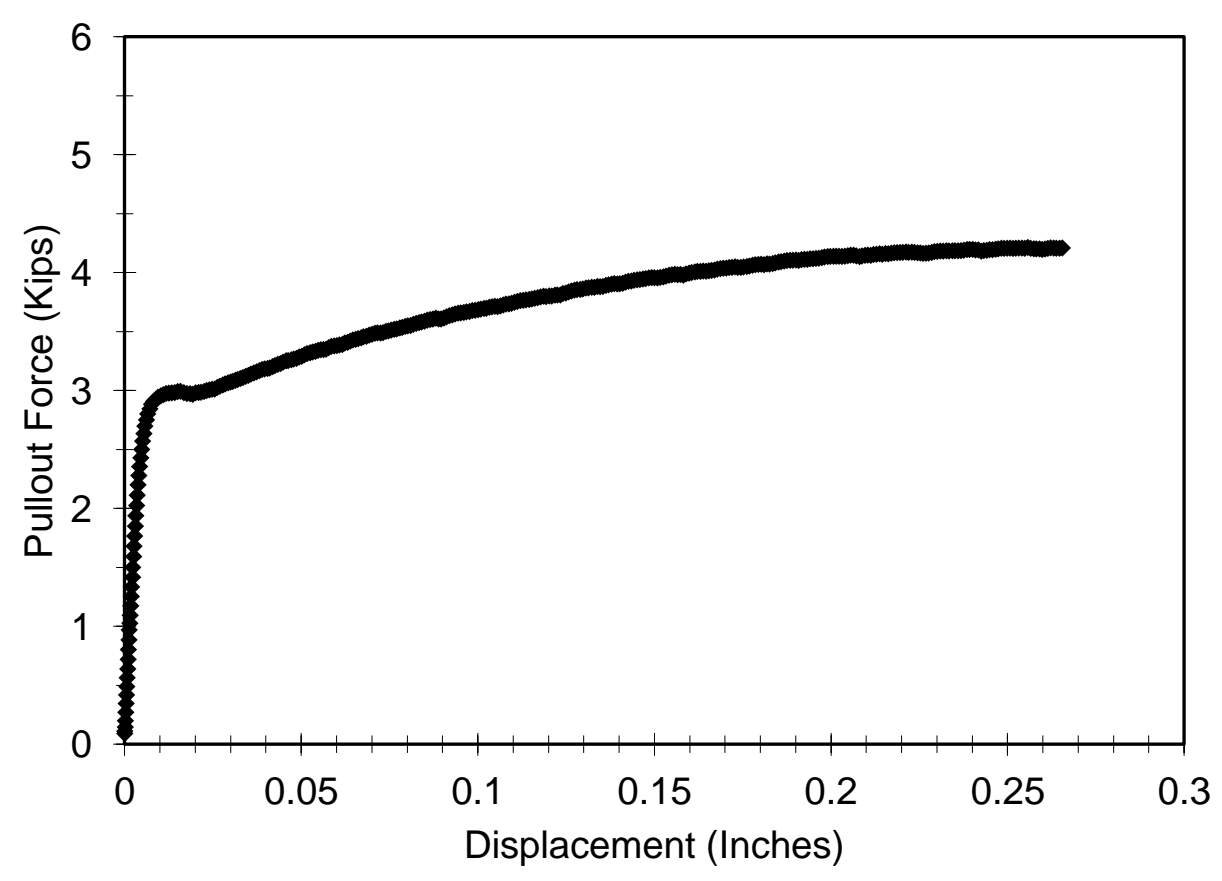

Failure Pictures:

Notes: Type II failure, bad installation hole drilled to incorrect depth resulted in bond a failure 


\begin{tabular}{|c|c|c|c|c|c|}
\hline Test & Emb. Depth (Bar Dia.) & Drilled & Cleaned & Epoxy Injected & Epoxy \\
\hline 13B & 4 & Dry & Dry & Wet & A \\
\hline
\end{tabular}

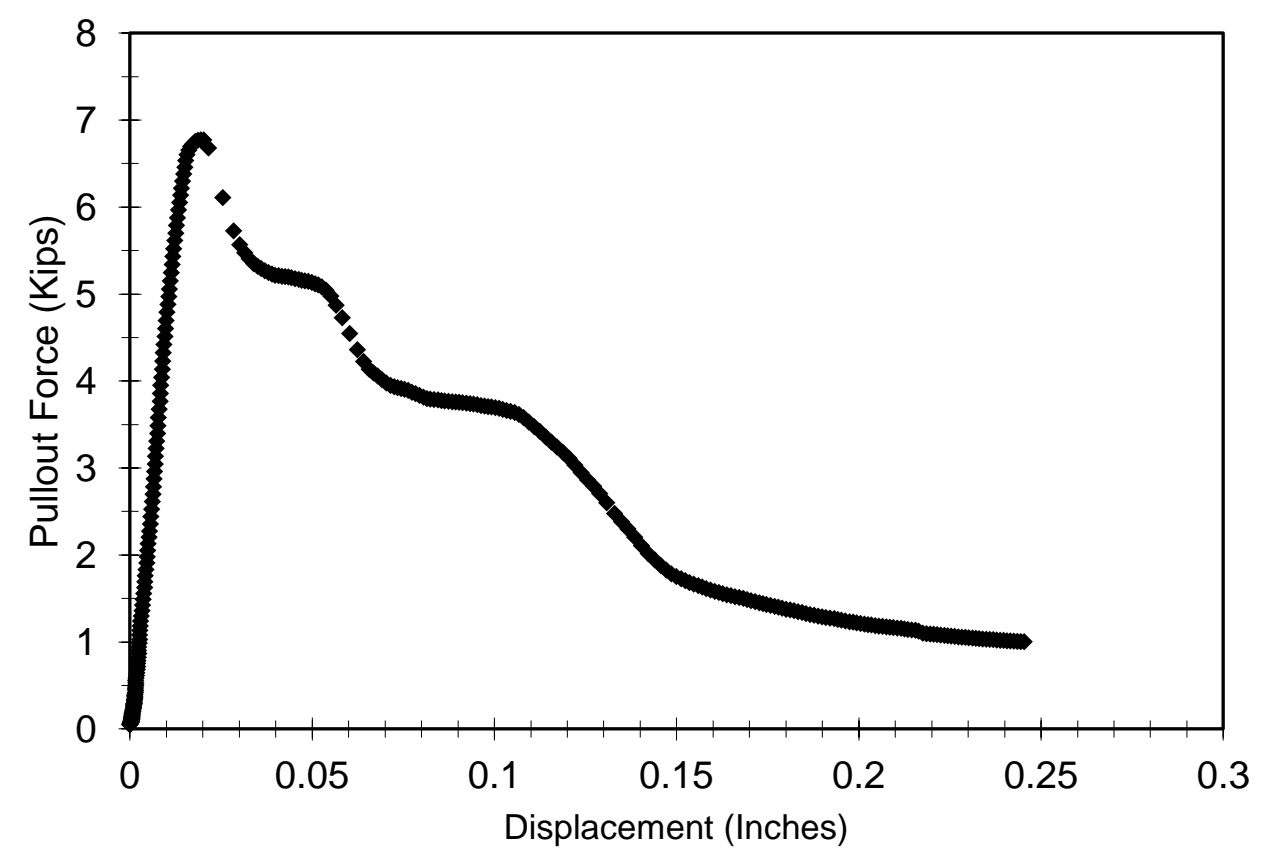

Failure Pictures:
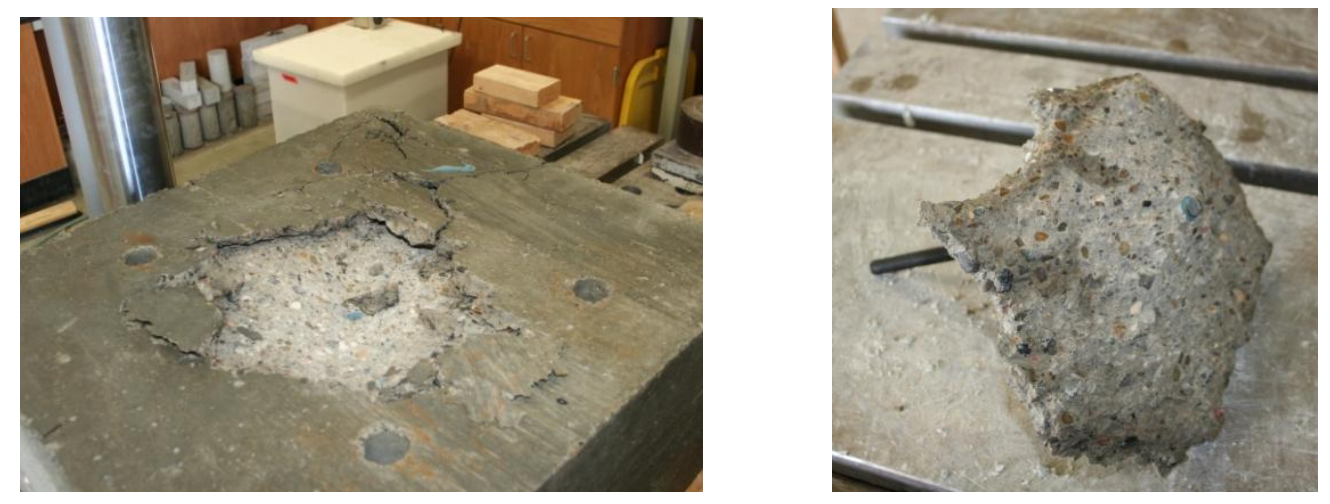

Notes: Type I failure 


\begin{tabular}{|c|c|c|c|c|c|}
\hline Test & Emb. Depth (Bar Dia.) & Drilled & Cleaned & Epoxy Injected & Epoxy \\
\hline 14B & 9 & Dry & Dry & Dry & A \\
\hline
\end{tabular}

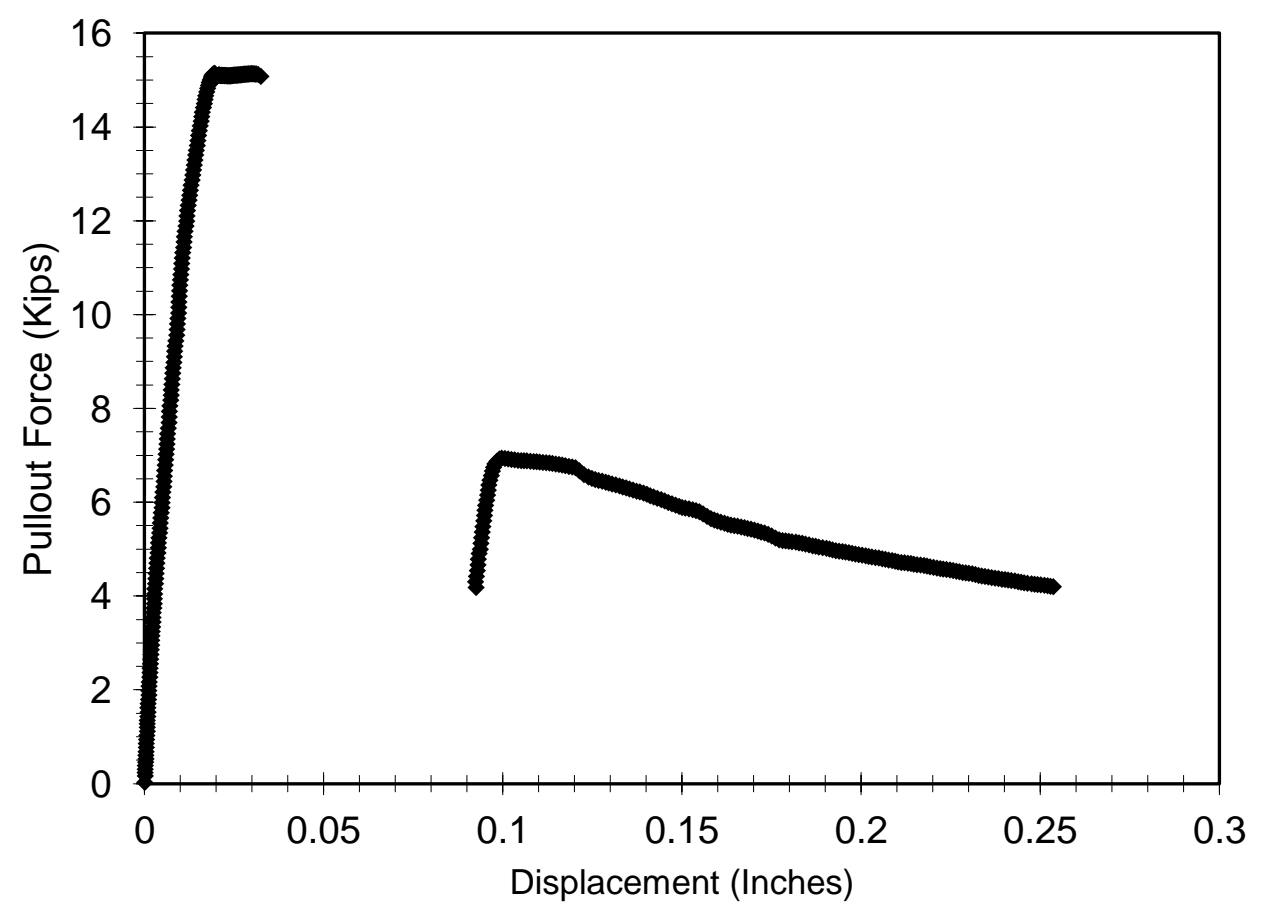

\section{Failure Pictures:}

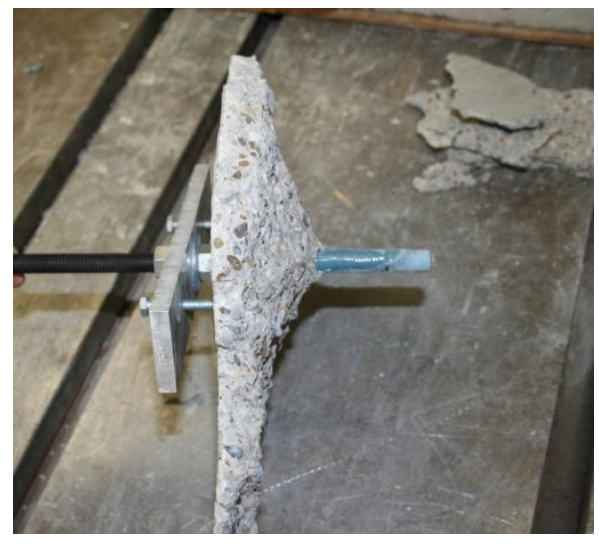

Notes: Air Bubble formed during installation cause a significantly reduced pullout strength 


\begin{tabular}{|c|c|c|c|c|c|}
\hline Test & Emb. Depth (Bar Dia.) & Drilled & Cleaned & Epoxy Injected & Epoxy \\
\hline 16B & 4 & Dry & Dry & Wet & A \\
\hline
\end{tabular}

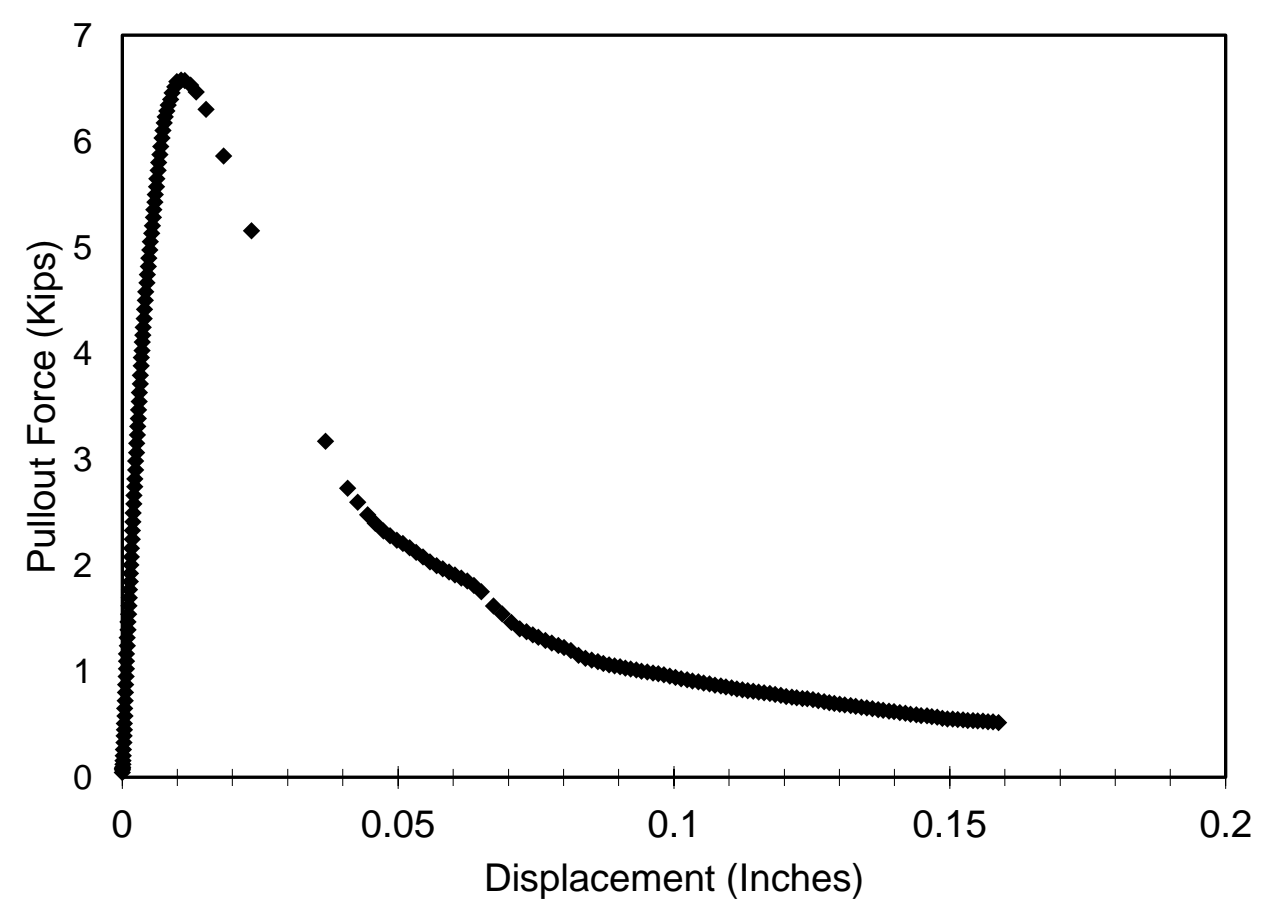

\section{Failure Pictures:}

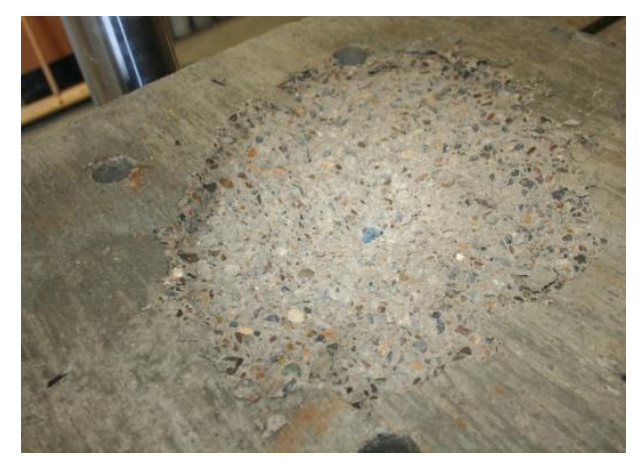

Notes: Type I failure 


\section{Appendix C Anchor Installation}

Appendix $\mathrm{C}$ is a guide with the typical installation instructions from a manufacturer. 
H USA / Canada | Change Location...

$>$ Home $>$ Products $>$ Anchor Systems $>$ Adhesives

\section{ADHESIVE ANCHORING INSTALLATION INSTRUCTIONS}

JUMP TO:

- 1. Hole Preparation

- 2. Cartridge Preparation

a $\underline{\text { 3. Filling the Hole: Vertical Anchorage }}$

- 3 . Filling the Hole: Horizontal and Overhead Anchorage

- 3. Filling the Hole: When Anchoring with Screens: For AT, ET-HP, and SET Adhesives (except SET1.7KT)

- 3 . Filling the Hole: VGC Vinylester Glass Capsule (Hammer Capsule)
1 NOTE: Always check expiration date on product label. Do not use expired product.

WARNING: When drilling and cleaning hole use eye and lung protection. When installing adhesive use eye and skin protection.

Notes:

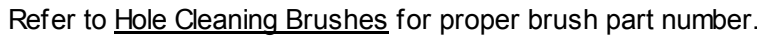

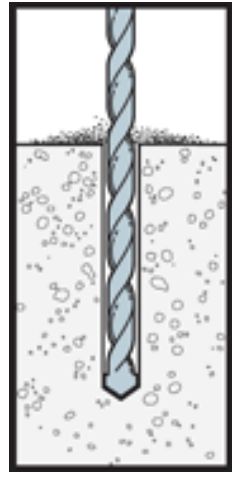

1. Drill Drill hole to specified diameter and depth.

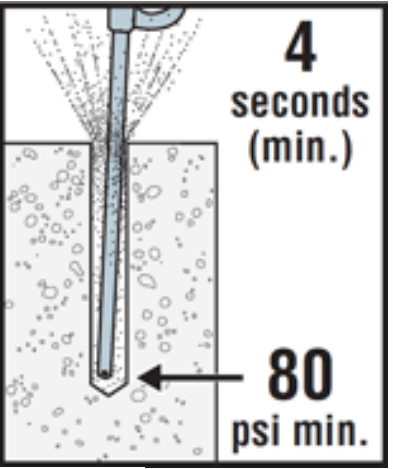

\section{Blow -}

Remove dust from hole with oil-free compressed air for a minimum of 4 seconds. Compressed air nozzle must reach the bottom of the hole.

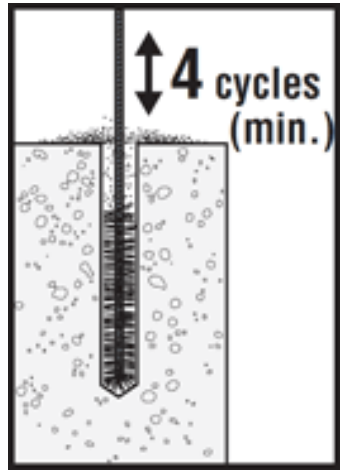

3. Brush -

Clean with a nylon brush for a minimum of 4 cycles. Brush should provide resistance to insertion. If no resistance is felt, the brush is worn and must be replaced.

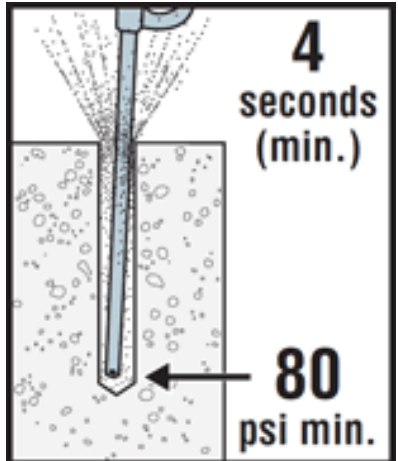

4. Blow -

Remove dust from hole with oil-free compressed air for a minimum of 4 seconds. Compressed air nozzle must reach the bottom of the hole. 
1. Check -

Check expiration

date on product

label. Do not use

expired product.

Product is usable

until end of printed

expiration month.

Note: For bulk dispensing, check pail or drum label for detailed mixing and preparation instructions. Open cartridge per package instructions.
2. Open -

\section{FILLING THE HOLE: Vertical Anchorage}

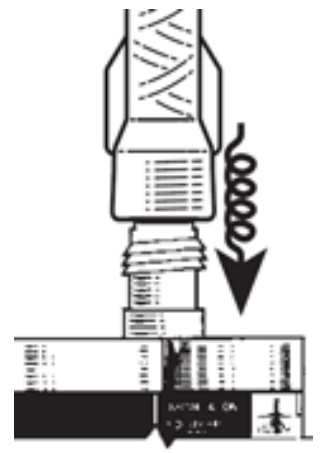

3. Attach - Attach proper Simpson StrongTie ${ }^{\circledR}$ nozzle to cartridge. Do not modify nozzle.

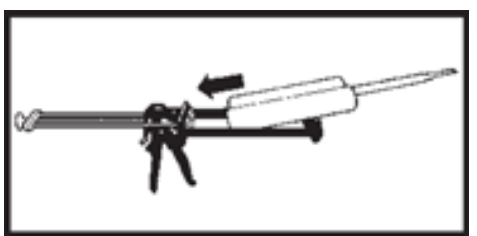

4. Insert - Insert cartridge into dispensing tool.

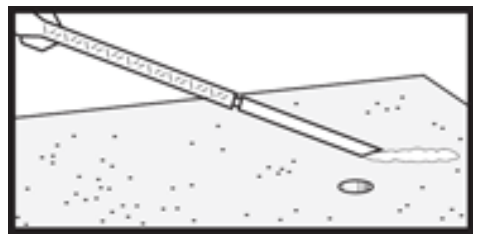

5. Dispense - Dispense adhesive to the side until properly mixed (uniform color).

Prepare the hole per instructions "hole Preparation".

Note: Nozzle extensions may be needed for deep holes.

Dry and Damp Holes:

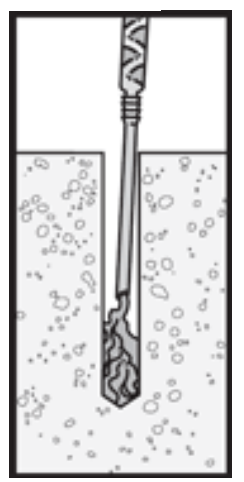

1. Fill -

Fill hole 1/2 -

2/3 full, starting from bottom of hole to prevent air pockets. Withdraw nozzle as hole fills up.

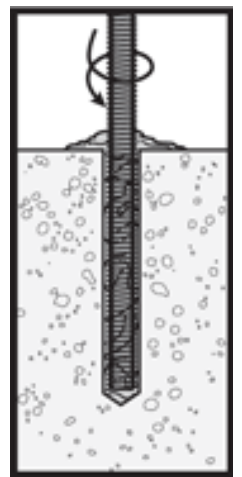

Threaded rod or rebar
2. Insert Insert clean, oil free anchor, turning slowly until the anchor contacts the bottom of the hole.

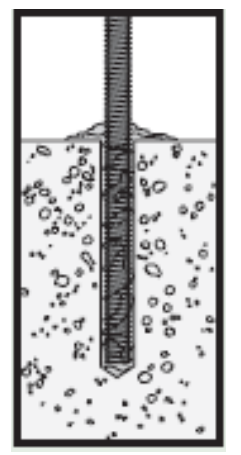

3. Do not disturb - Do not disturb anchor until fully cured. (See cure schedule for specific adhesive.)

\section{Water Filled Holes:}




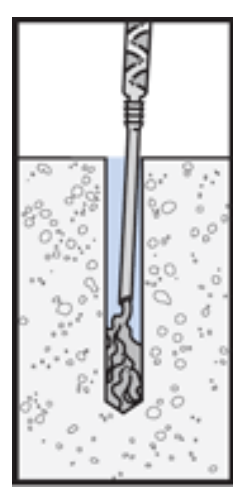

1. Fill -

Fill hole completely full, starting from bottom of hole to prevent water pockets. Withdraw nozzle as hole fills up.

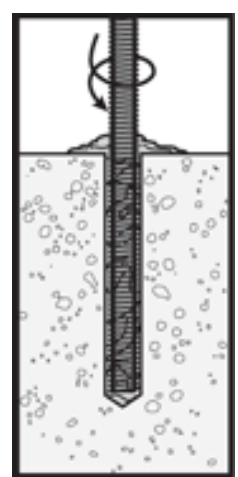

2. Insert Insert clean, oil-free anchor, turning slowly until the anchor contacts the bottom of the hole.

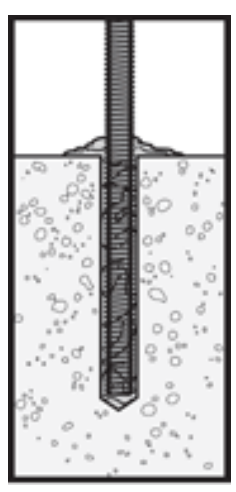

3. Do not disturb - Do not disturb anchor until fully cured. (See cure schedule for specific adhesive.)

Threaded rod or rebar

Prepare the hole per instructions "Hole Preparation".

Note: Nozzle extensions may be needed for deep holes.

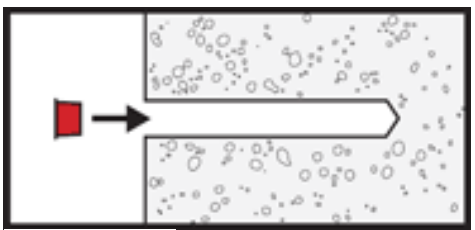

1. Install - Install Simpson Strong-Tie $®$ ARC adhesive retaining cap. Refer to Adhesive Retaning Caps for proper ARC size.

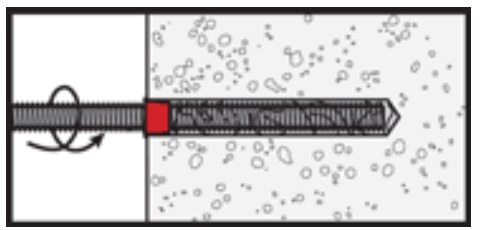

Threaded rod or rebar

3. Insert - Insert clean, oil-free anchor, turning slowly until the anchor contacts the bottom of the hole.

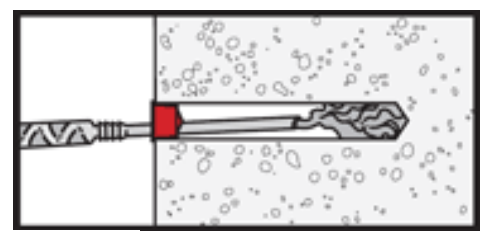

2. Fill - Fill hole 1/2 - 2/3

full, starting from bottom of hole to prevent air pockets. Withdraw nozzle as hole fills up.
Threaded rod or rebar

Prepare the hole per instructions "Hole Preparation".

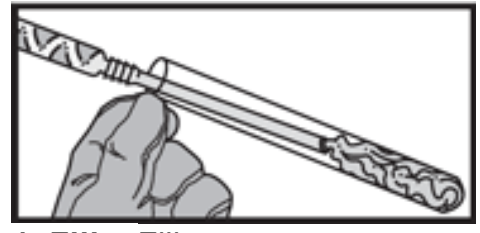

1. Fill - Fill screen completely. Fill from the bottom of the screen and withdraw the nozzle as the screen fills to prevent air pockets. (Opti-Mesh $\circledast$

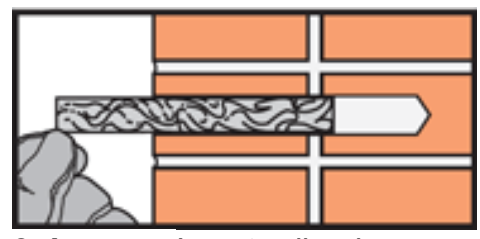

2. Insert - Insert adhesive filled screen into hole. 